Aus der Klinik für Hämatologie und Medizinische Onkologie (Prof. Dr. L. Trümper) der Medizinischen Fakultät der Universität Göttingen

\title{
IL10 und CpG induzieren über STAT3 und NF- $x$ B die Zellproliferation und die Genexpression des Glutaminolyseenzyms GOT2 in der Modellzelllinie P493-6
}

\author{
INAUGURAL-DISSERTATION \\ zur Erlangung des Doktorgrades \\ der Medizinischen Fakultät der \\ Georg-August-Universität zu Göttingen
}

\author{
vorgelegt von \\ Judith Kemper \\ aus \\ Höxter \\ Göttingen 2018
}


Dekan: $\quad$ Prof. Dr. rer. nat. H. K. Kroemer

Referent: $\quad$ Prof. Dr. rer. nat. D. Kube

Ko-Referent: $\quad$ Prof. Dr. rer. nat. J. Wienands

Datum der mündlichen Prüfung: 09.05.2019 
Hiermit erkläre ich, die Dissertation mit dem Titel „IL10 und CpG induzieren über STAT3 und NF- $x$ B die Zellproliferation und die Genexpression des Glutaminolyseenzyms GOT2 in der Modellzelllinie P493-6“ eigenständig angefertigt und keine anderen als die von mir angegebenen Quellen als Hilfsmittel verwendet zu haben.

Göttingen, den.

Unterschrift. 


\section{Inhaltsverzeichnis}

Inhaltsverzeichnis

Abbildungsverzeichnis

III

Tabellenverzeichnis

Abkürzungsverzeichnis $\mathrm{V}$

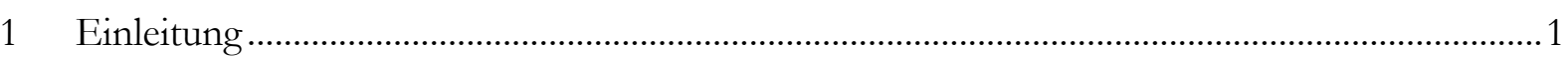

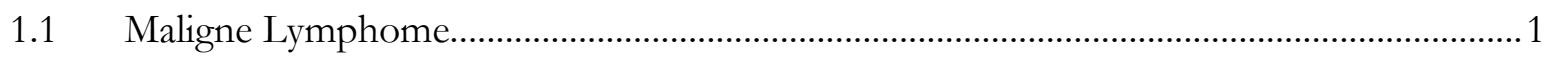

1.2 Diffuses großzelliges Non-Hodgkin-Lymphom ……...................................................

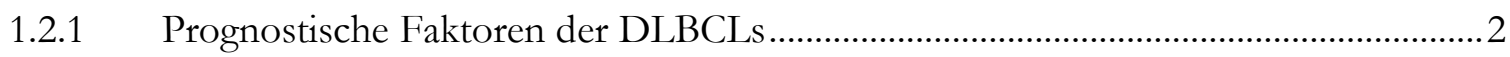

1.3 Tumorumgebung und Signalwege

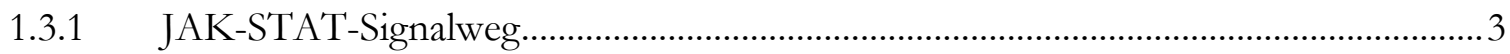

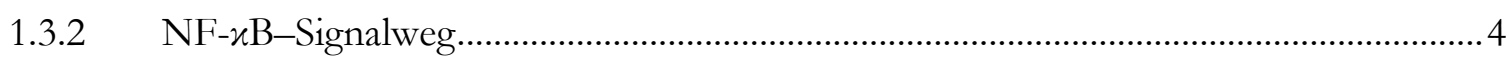

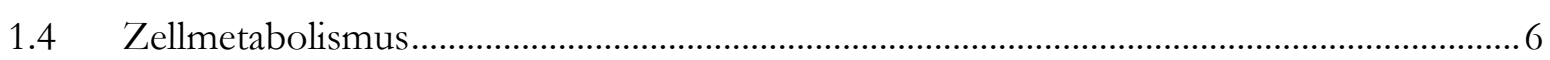

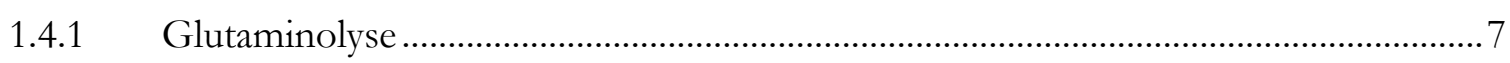

1.4.2 Die Redoxbalance der Zelle .............................................................................................

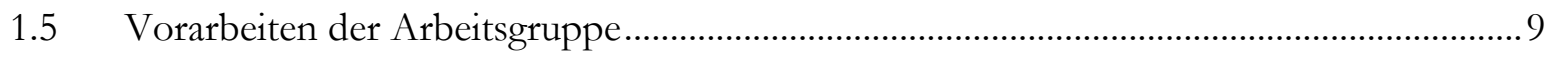

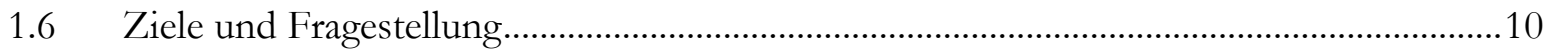

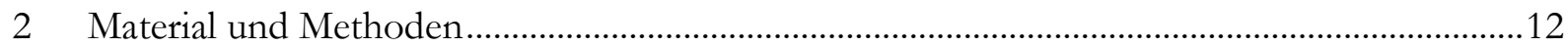

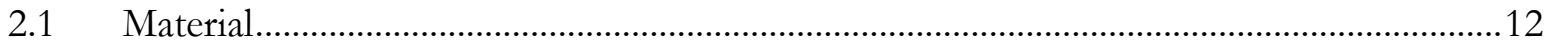

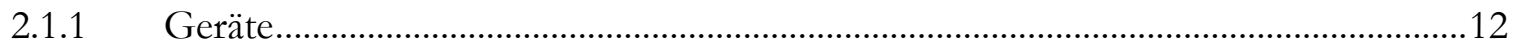

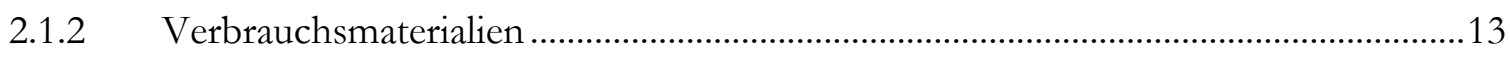

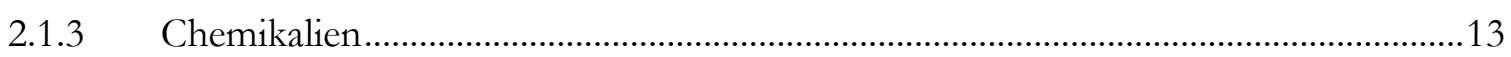

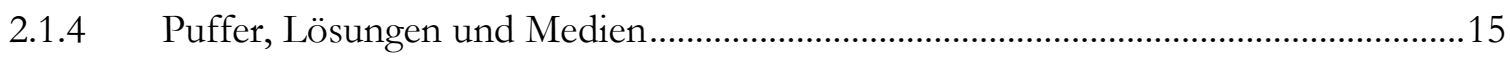

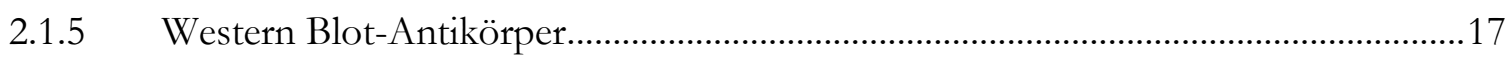

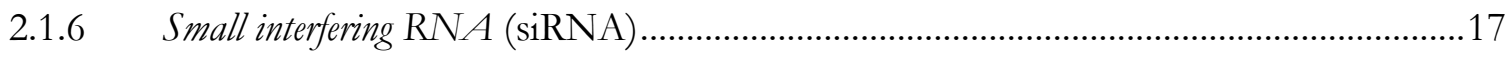

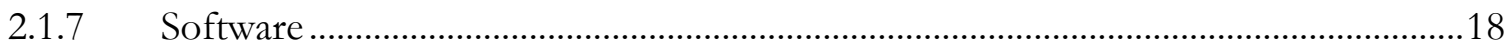

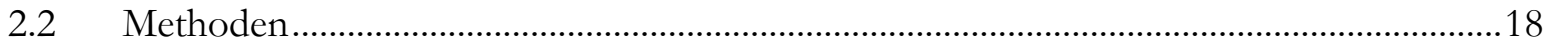

2.2.1 Kultivierung und Stimulation der P493-6-Zelllinie ...................................................18

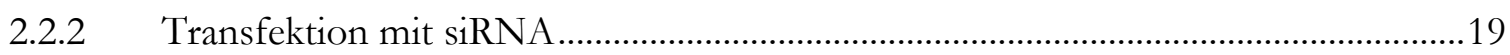

2.2.3 Zellernte für quantitative Real-Time Polymerase-Kettenreaktion ..............................20

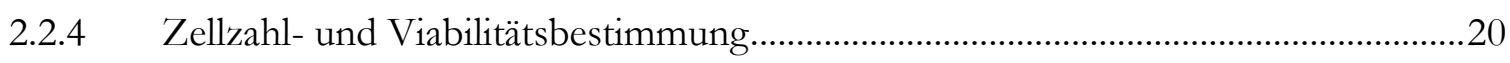

2.2.5 Gefrierkonservierung und Auftauen der Zelllinien..................................................21

2.2.6 Bestimmung der Zellvermehrungsrate ………................................................................21 
2.2.7 ROS-Messung und Durchflusszytometrie ...................................................................22

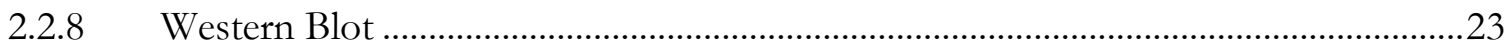

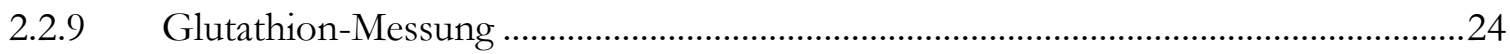

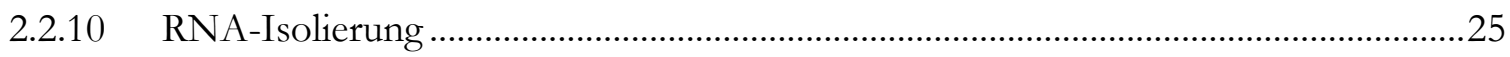

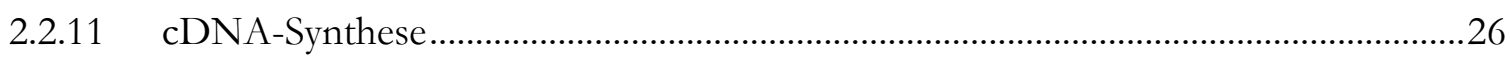

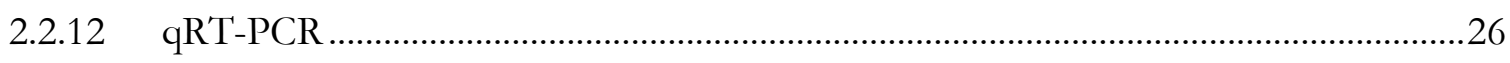

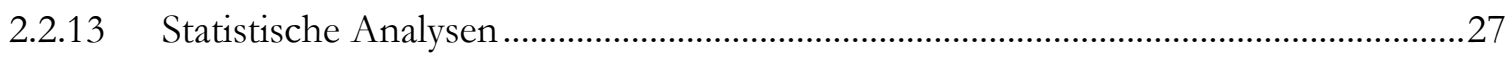

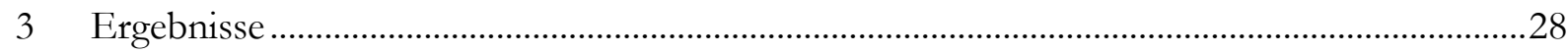

3.1 STAT3 und NF- $x$ B/RelA vermitteln gemeinsam die IL10- und CpG-induzierte

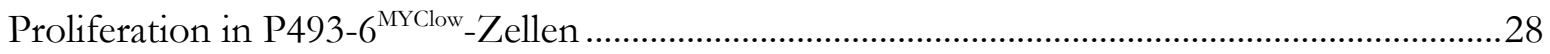

3.2 Die Rolle von STAT3, RelA und GOT2 in P493-6 MYClow $_{-}$Zellen .........................................30

3.2.1 STAT3 und NF- $x$ B/RelA steigern die IL10- und CpG-vermittelte Genexpression

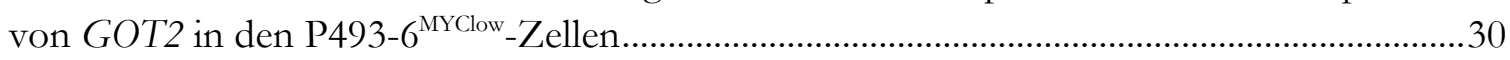

3.2.2 Reduzierte Expression von GOT2 führt zu einer reduzierten IL10- und CpG-

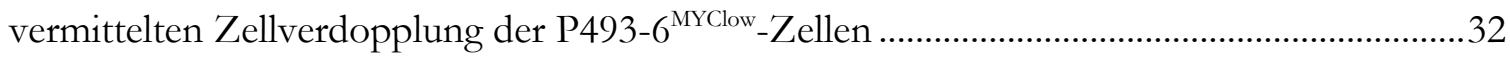

3.3 Untersuchung des Zusammenhangs zwischen der Glutaminolyse und der Redoxbalance

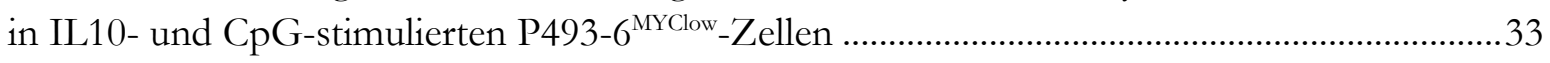

3.3.1 Einfluss von $\mathrm{H}_{2} \mathrm{O}_{2}$ auf IL10- und CpG-stimulierte P493-6 $6^{\text {MYClow }}$-Zellen....................33

3.3.2 Glutaminabhängiger ROS-Abbau in IL10- und CpG-stimulierten P493-6 ${ }^{\text {MYClow }}$

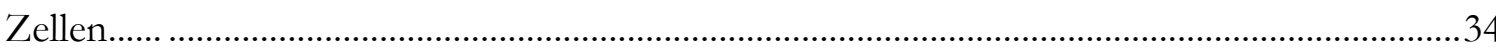

3.3.3 Keine IL10- und CpG-vermittelte Reduktion der relativen ROS-Menge der P493-

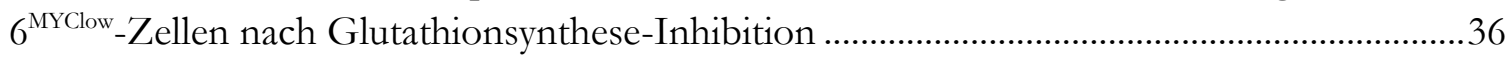

3.3.4 Glutaminabhängig erhöhte Glutathion-Konzentration nach IL10- und CpG-

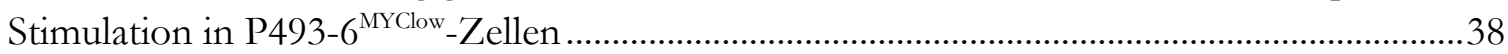

3.3.5 Analyse des Einflusses von GOT2 sowie STAT3 und NF- $x$ B auf die relative ROS-

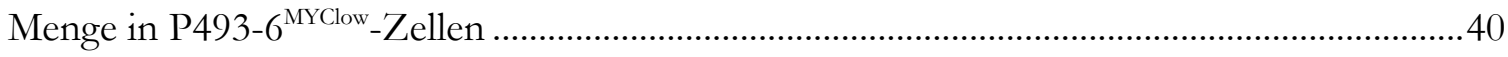

3.3.6 Analyse des Einflusses von GOT2 sowie STAT3 und RELA auf die Konzentration

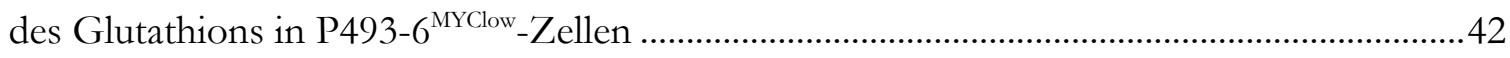

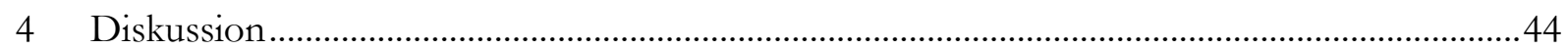

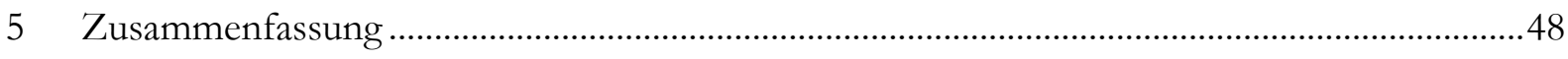

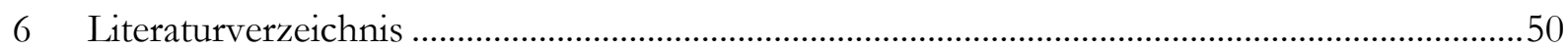




\section{Abbildungsverzeichnis}

Abbildung 1: Schematische Darstellung des STAT3- und TLR9-Signalwegs...................................... 5

Abbildung 2: Schematische Darstellung der Glutaminolyse der Zelle ..................................................

Abbildung 3: Die Proliferation IL10- und CpG-stimulierter P493-6 $6^{\text {MYClow }}$-Zellen ist abhängig von der gemeinsamen Wirkung von STAT3 und NF-xB (RelA) .........................................................29

Abbildung 4: Verstärkte GOT2-Expression durch IL10 und CpG ist abhängig von STAT3 und

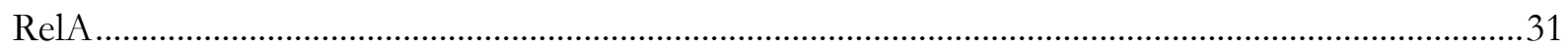

Abbildung 5: Die Zellverdopplung der P493-6 ${ }^{\text {MYClow }}$ Zellen ist abhängig von GOT2. .....................32

Abbildung 6: Die IL10- und CpG-vermittelte Zellproliferation ist abhängig von Glutamin und

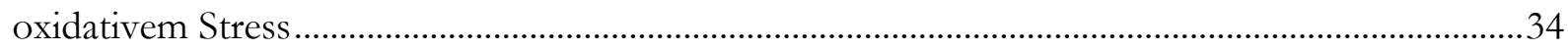

Abbildung 7: Glutaminabhängige ROS-Reduktion durch IL10 und CpG .......................................35

Abbildung 8: In IL10- und CpG-stimulierten Zellen wird die relative ROS-Menge im Vergleich zu unstimulierten P493-6 ${ }^{\text {MYClow }}$-Zellen nach Glutathionsynthese-Inhibition nicht reduziert...........37 Abbildung 9: Durch die Stimulation mit IL10 und CpG wird glutaminabhängig die GlutathionKonzentration in P493-6 ${ }^{\text {MYClow }}$-Zellen erhöht.

Abbildung 10: Reduzierte ROS-Mengen nach GOT2- oder STAT3- und RELA-Knockdown ...41 Abbildung 11: Reduzierte Glutathion-Konzentration nach STAT3- und RELA-, aber nicht nach 


\section{Tabellenverzeichnis}

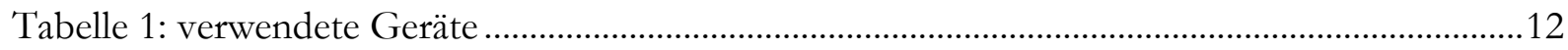

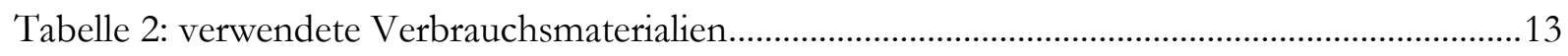

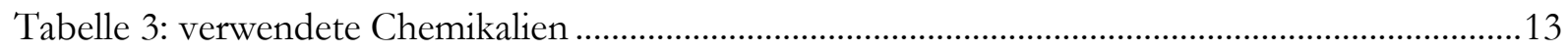

Tabelle 4: verwendete Puffer, Lösungen und Ansätze ...................................................................15

Tabelle 5: verwendete Antikörper...................................................................................................... 17

Tabelle 6: verwendete small interfering RNA (siRNA) ........................................................................17

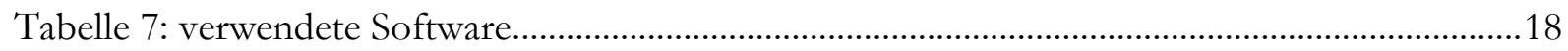

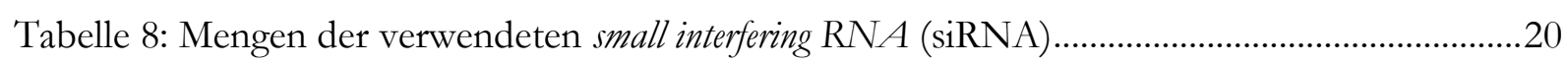

Tabelle 9: Stimuli und Inhibitoren für Zellvermehrungsversuche .....................................................22 


\section{Abkürzungsverzeichnis}

4-IPBA 4-Iodophenylboronic acid, 4-Iodphenylborsäure

$\alpha-K G \quad$ alpha-Ketoglutarat

ABC-DLBCL activated B-cell like DLBCL

ANOVA analysis of variance, Varianzanalyse

APS Ammoniumperoxodisulfat

BSA bovine serum albumin, bovines Serumalbumin

BSO Buthioninsulfoximin

CHOP Cyclophosphamid+Hydroxydaunorubicin+Oncovin+Prednisolon

cDNA complementary DNA, komplementäre DNA

$\mathrm{CO}_{2} \quad$ Kohlenstoffdioxid

$\mathrm{ddH}_{2} \mathrm{O} \quad$ destilliertes Wasser

DLBCL diffuse large B-cell lymphoma, diffuses großzelliges B-Zell-Lymphom

DMSO Dimethylsulfoxid

DNA deoxyribonucleic acid, Desoxyribonukleinsäure

dNTPs Desoxyribonukleosidtriphosphate

EDTA Ethylendiamintetraacetat

FACS fluorescence activated cell sorting

FCS fetal calf serum, fetales Kälberserum

g Erdbeschleunigungskonstante

GAPDH Glycerinaldehyd-3-phosphat-Dehydrogenase

GCB-DLBCL germinal center B-cell like DLBCL

Glc Glukose

Gln Glutamin

GLS Genname der Glutaminase

GLUD1 Genname der Glutamat-Dehydrogenase

GOT1 Genname der zytosolischen Aspartat-Aminotransferase

GOT2 Genname der mitochondrialen Aspartat-Aminotransferase

GSH reduziertes Glutathion 


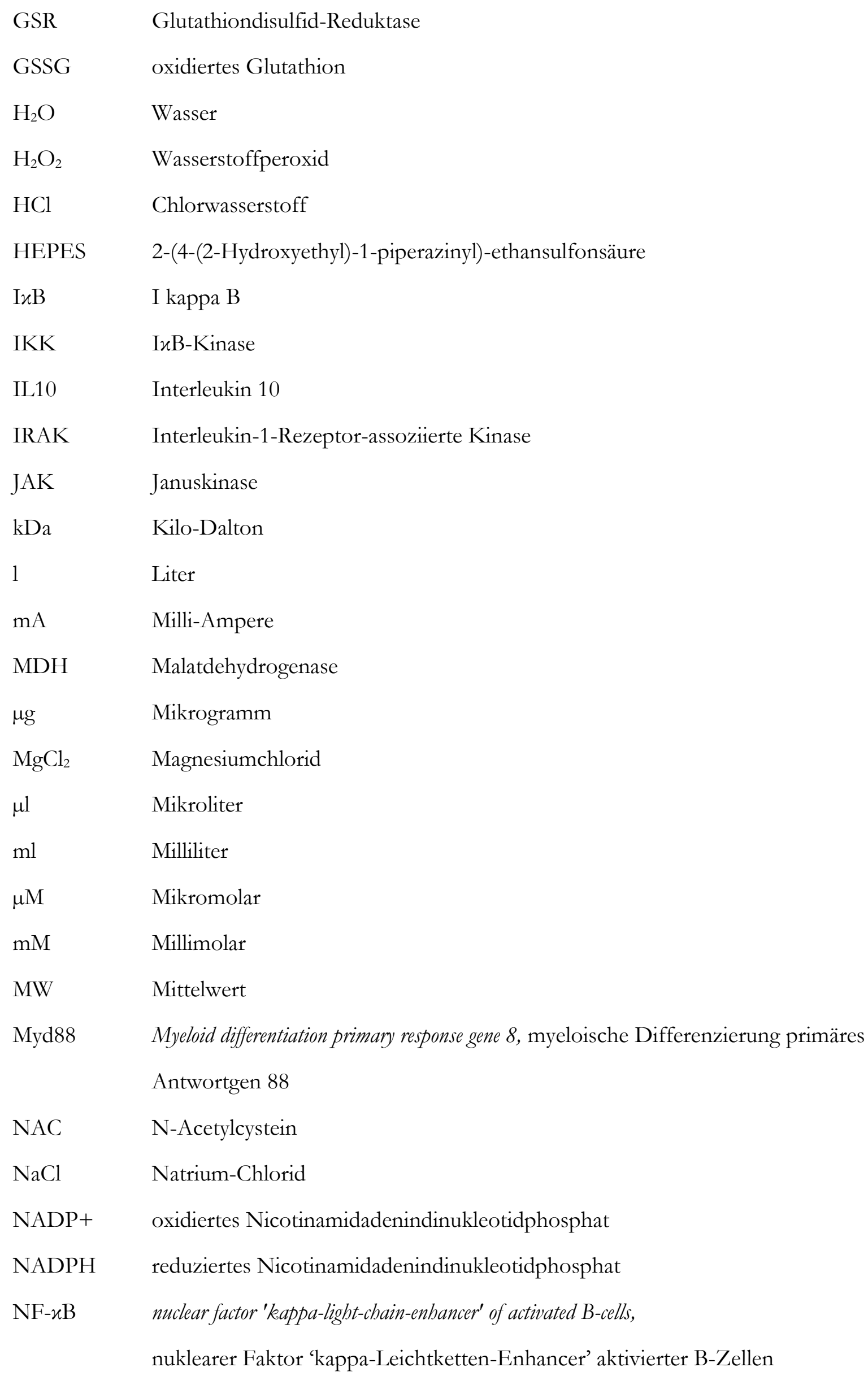


ng Nanogramm

NHL Non-Hodgkin-Lymphom

$\left(\mathrm{NH}_{4}\right)_{2} \mathrm{SO}_{4} \quad$ Ammoniumsulfat

$\mathrm{O}_{2} \quad$ Sauerstoff

OA Oxalacetat

p Signifikanzwert

PBS phosphate-buffered saline, phosphatgepufferte Salzlösung

PCR polymerase chain reaction, Polymerase-Kettenreaktion

PMSF Phenylmethylsulfonylfluorid

PVDF Polyvinylidenfluorid

qRT-PCR quantitative real-time PCR, quantitative Echtzeit-PCR

RIPA radioimmunoprecipitation assay, Radioimmunpräzipitationsassay

RNA ribonucleic acid, Ribonukleinsäure

ROS reactive oxygen species, reaktive Sauerstoffspezies

scr scrambled, gemischt

SD Standardabweichung

SDS sodium dodecyl sulfate, Natriumdodecylsulfat

siRNA small interfering $\mathrm{RN} A$, kleine eingreifende RNA

STAT signal transducer and activator of transcription, Signalvermittler und Aktivator der Transkription

TBS-T tris-buffered saline-tween, Tris-gepufferte Salzlösung mit Tween

TEMED Tetramethylethylendiamin

TGF-beta transforming growth factor beta, transformierender Wachstumsfaktor beta

TLR toll-like receptor, Toll-like Rezeptor

V Volt

z. B. zum Beispiel 


\section{Einleitung}

\subsection{Maligne Lymphome}

Maligne Lymphome sind bösartige Neubildungen des lymphatischen Systems. Seit einer Beschreibung verschiedener Krankheitsverläufe innerhalb dieser Krankheitsgruppe durch den britischen Pathologen Thomas Hodgkin werden Hodgkin-Lymphome (HL) und die heterogene Gruppe der Non-Hodgkin-Lymphome (NHL) unterschieden (Hodgkin 1832). Dabei betrug die Inzidenz der NHL im Jahr 2012 9,8 pro 100.000 Personen in Europa bei einer Mortalität von 3,5 pro 100.000 Personen (Ferlay et al. 2013). Der Begriff der NHL beinhaltet eine Vielzahl verschiedener B- und T-Zell-Lymphome. Im Folgenden wird ausschließlich auf das diffuse großzellige B-Zell-Lymphom (engl. diffuse large B-cell lymphoma (DLBCL)) als häufigsten Vertreter der aggressiven NHL bei Erwachsenen eingegangen (Naresh et al. 2000; Al-Hamadani et al. 2015).

\subsection{Diffuses großzelliges Non-Hodgkin-Lymphom}

Klassischerweise tritt das DLBCL mit einem mittleren Erkrankungsalter zwischen der sechsten und siebten Lebensdekade eher bei älteren Personen auf, es können jedoch auch Kinder betroffen sein (Martelli et al. 2013). Obwohl die Ätiologie der Lymphome und somit auch der DLBCLs größtenteils unbekannt ist, wurden einige mögliche Risikofaktoren wie Zustände der Immunsuppression oder Infektionen mit verschiedenen Viren und Bakterien beschrieben (Blinder und Fisher 2008). Die Standardtherapie dieser großzelligen B-Zell-Lymphome ist die CHOP-Kombinationschemotherapie in Kombination mit Rituximab, einem monoklonalen Antikörper gegen den B-ZellOberflächenmarker CD20 (Pfreundschuh et al. 2011; Ghielmini et al. 2013). Eine Erweiterung der Standardkombinationstherapie um das Zytostatikum Etoposid zeigt insbesondere bei jungen Patienten mit ungünstiger Prognose gute Ergebnisse (Glass et al. 2010). Als weitere Therapieoption bei jungen Patienten ohne Ansprechen des Tumors auf die Erstlinienchemotherapie steht eine Hochdosischemotherapie in Kombination mit einer autologen Stammzelltransplantation zur Verfügung. Die Idee einer gezielteren Tumortherapie wird aktuell durch den Test einiger neuer Medikamente wie des Tyrosinkinase-Inhibitors Ibrutinib verfolgt (Wilson et al. 2015; Mondello und Younes 2015). 


\subsubsection{Prognostische Faktoren der DLBCLs}

DLBCLs zählen aufgrund ihres schnellen Wachstums zu den aggressiven, aber potenziell heilbaren Lymphomen. Bei sehr heterogenem klinischen Verlauf und großen Unterschieden im Therapieansprechen errechnet sich die jeweilige Prognose nach klinischen Faktoren mit Hilfe des Internationalen Prognostischen Index (IPI), den es für Patienten unter 60 Jahren auch als altersadaptierten IPI gibt (Martelli et al. 2013). Da jedoch auch das Tumorproliferationsverhalten auf Grundlage verschiedener Signalkaskaden und Stoffwechselvorgänge immer besser verstanden wird, gewinnen molekulare Klassifikationen der DLBCLs zunehmend an Bedeutung. Nach Genexpressionsprofilen lassen sich innerhalb der DLBCLs die Gruppe der oxidativen Phosphorylierung, die des B-Zell-Rezeptors/der Proliferation und die der inflammatorischen Wirtsreaktion unterscheiden, was auch metabolische Auswirkungen hat (Monti et al. 2005; Caro et al. 2012). Des Weiteren zeigten DNA-microarray-Untersuchungen Unterschiede in der Genexpression, die mit dem Differenzierungs- und Proliferationsgrad der Zellen korrelieren. So lassen sich die DLBCLs nach ihrem Genexpressionsmuster verschiedenen Reifungsstadien gesunder B-Zellen sowie unterschiedlichen Krankheitsverläufen zuordnen. Es werden keimzentrums-B-Zell-ähnliche Zellen (germinal center B-cell like DLBCL, GCB) von aktivierten peripheren B-Zell-ähnlichen Zellen (activated B-cell like DLBCL, ABC) unterschieden (Alizadeh et al. 2000). Charakteristische Unterschiede finden sich zudem in der Mikroumgebung der Zellen. So ließen sich in ABC-DLBCL-Zellen bemerkenswerterweise unter anderem Mutationsmuster finden, die zu einer konstitutiven Aktivierung des JAK-STAT-Signalwegs und des NF- $x$ B-Signalwegs führen (Davis et al. 2001; Lam et al. 2008; Scuto et al. 2011). Dabei zeigten Patienten mit ABCDLBCL gegenüber denen mit GCB-DLBCL interessanterweise eine deutlich längere durchschnittliche Überlebenszeit (Alizadeh et al. 2000). Zudem ist in DLBCLs eine Zuordnung zu unterschiedlichen Genexpressionssignaturen beschrieben worden, die die Krankheitsprognose beeinflusst (Lenz et al. 2008). Da auch die metabolischen Zellveränderungen in Tumoren die Krankheitsprognose deutlich modulieren, sind Signalkaskaden wie der STAT3- und NF- $x$ BSignalweg schon seit vielen Jahren ein zentrales Thema der Tumorforschung (Tornatore et al. 2012; Poli und Camporeale 2015). Diese Transkriptionsfaktoren steuern wichtige Zellvorgänge wie Immunantwort, Angiogenese, Zellwachstum, -proliferation und -überleben (He und Karin 2011; Didonato et al. 2012). In malignen Zellen verursachen sie durch die hervorgerufene Inflammation Mutationen, die die Tumorinitiation begünstigen. Zudem unterstützen sie Gewebeinvasionen, Metastasierungen und die tumorspezifischen Veränderungen der Mikroumgebung. Nicht zuletzt aufgrund der beschriebenen konstitutiven Aktivierung von STAT3 und NF- $x$ B in Tumorzellen stellen diese Signalkaskaden potenzielle Angriffsmöglichkeiten in der Tumortherapie dar. 
Problematisch für eine STAT3- und NF-xB-Signalweg-basierte dauerhafte Tumortherapie ist jedoch der große Einfluss dieser beiden Transkriptionsfaktoren auf andere Immunzellen und eine damit einhergehende Immunschwäche und Infektionsneigung der Patienten (Bollrath und Greten 2009; Baud und Karin 2009). Obwohl in STAT3-überexprimierenden Brustkrebszellen und Xenograftmodellen durch die Inhibition von STAT3 bereits Proliferationshemmungen erzielt werden konnten, müssen für die längerfristige Tumortherapie im Patienten auch limitierende Nebenwirkungen betrachtet werden (Song et al. 2005; Siddiquee et al. 2007). Aus diesem Grund bedarf es einer genaueren Untersuchung der STAT3- und NF- $x$ B-vermittelten Veränderungen des Zellmetabolismus, die einer spezifischeren Tumortherapie zugrunde liegen könnten.

Unabhängig von der Zuordnung zu den B-Zell-Entwicklungsstadien wurden bei einem kleinen Anteil der DLBCLs genetische Veränderungen oder eine veränderte Proteinexpression des in vielen verschiedenen Zellprozessen beteiligten Transkriptionsfaktors c-Myc (Myc) beschrieben. Die beschriebenen Deregulationen stellen oft Überexpressionen dar und sind mit einer schlechteren Prognose für die DLBCL-Patienten assoziiert (Barrans et al. 2010; Schrader et al. 2012; Horn et al. 2013; Valera et al. 2013). Myc reguliert in den Zellen wichtige zellmetabolische Vorgänge, die Zelldifferenzierung sowie den Zellzyklus (Meyer und Penn 2008). Die Bedeutung der Myc-Deregulation wurde für B-Zellen zu einem großen Teil mit Hilfe der auch im Rahmen dieser Arbeit verwendeten Modellzelllinie P493-6 untersucht, die ein Modell für konstitutionelle Myc-Expression darstellt (Schuhmacher et al. 1999; Pajic et al. 2000; Le et al. 2012).

\subsection{Tumorumgebung und Signalwege}

Eine besondere und prognostische Rolle in der intrazellulären Signalübertragung wird den JAKSTAT- sowie NF- $x$ B-einschließenden Signalwegen zuteil (He und Karin 2011; Didonato et al. 2012; Sinkovics 2015).

\subsubsection{JAK-STAT-Signalweg}

Als Transkriptionsfaktoren und Signalvermittler in der Zelle werden eine Vielzahl wichtiger Zellprozesse durch die STAT(Signal transducer and activator of transcription)-Proteine beeinflusst, unter anderem regulieren sie Zellproliferation, Angiogenese und Apoptose (Bromberg 2002). STAT-Proteine wurden bereits vor über 20 Jahren im Rahmen von Interferon-Signaltransduktionen 
beschrieben und kommen bei allen Tieren in verschiedenen Varianten vor (Darnell et al. 1994; Rawlings et al. 2004). Ein besonderes Augenmerk wurde in dieser Arbeit auf STAT3 gelegt, da dieses durch das prognostisch wichtige Interleukin 10 (IL10) aktiviert wird, dem eine besondere Rolle in der Lymphomentwicklung zugeschrieben wird (Lech-Maranda et al. 2006; Béguelin et al. 2015). Für dieses Zytokin wurde beschrieben, dass erhöhte Konzentrationen im Serum oder Plasma bei Patienten mit DLBCLs und anderen hämatologischen Erkrankungen, aber auch soliden Tumoren, mit einer schlechteren Prognose und einem aggressiveren Krankheitsverlauf assoziiert sind (Lech-Maranda et al. 2006; Gupta et al. 2012; Zhao et al. 2015). IL10 führt unter anderem über die Aktivierung von Januskinasen (JAK) durch den IL10-Rezeptor zu einer Phosphorylierung und Dimerisierung von STAT3-Proteinen (Rawlings et al. 2004; Gupta et al. 2012) (Abbildung 1). Durch die Dimerisierung der zuvor ruhend im Plasma vorliegenden STAT3-Proteine wird der Transport in den Zellkern ermöglicht. Letztendlich führt der beschriebene JAK-STAT-Signalweg durch die spezifische Bindung der dimerisierten STAT-Proteine an regulatorische DNASequenzen zu einer verstärkten Transkription von Zielgenen (Rawlings et al. 2004).

\subsubsection{NF- $x \mathrm{~B}-$ Signalweg}

Der Transkriptionsfaktor NF-xB (nuclear factor 'kappa-light-chain-enhancer' of activated B-cells) reguliert wichtige Zellvorgänge wie die Immunantwort, die Proliferation und den programmierten Zelltod (Verma et al. 1995). Zuerst beschrieben wurde NF- $x$ B als ein Protein, das in reifen B-Zellen an eine spezifische DNA-Sequenz im enhancer-Bereich des Gens der kappa-Leichtkette von Immunglobulinen bindet (Sen und Baltimore 1986). Heutzutage ist klar, dass dieser Tanskriptionsfaktor in einer Vielzahl unterschiedlicher Zellen mannigfaltige Wirkungen hat, indem er an ein spezifisches $x$ B-Motiv der DNA bindet (Lenardo und Baltimore 1989; Snapper et al. 1996; Guttridge et al. 1999; Duckett 2002; Smale 2011). Aufgebaut ist NF-xB in seiner aktiven Form als Homo- oder Heterodimer aus jeweils zwei Untereinheiten, wobei in einem Großteil der Fälle als Gemeinsamkeit die gleiche aus ungefähr 300 Aminosäuren bestehende Rel-homologe Domäne (Rel homology domain, RHD) ein Bestandteil am N-Terminus ist (Siebenlist et al. 1994). Als Untereinheiten sind die RelProteine RelA (p65), RelB und c-Rel bekannt. Weitere Untereinheiten sind die Nicht-Rel-Proteine NF- $x$ B1 (p50) und NF-xB (p52), die durch proteolytische Spaltung aus den Proteinen p105 bzw. p100 entstehen. Klassischerweise ist NF- $\varkappa$ B dabei ein Heterodimer aus einem Rel- und einem Nicht-Rel-Protein und wirkt in dieser Form transkriptionsaktivierend, es kommen aber auch eher transkriptionshemmend wirkende Homodimere vor. Die Interaktion von RelA (p65) und p50 führt 
dabei zum klassischen Heterodimer (Ghosh et al. 1990; Siebenlist et al. 1994). Hinweisgebend für eine genauere Beleuchtung des NF- $x \mathrm{~B}$-Signalwegs waren in den letzten Jahren gewonnene Erkenntnisse über das Protein Myd88 (Myeloid differentiation primary response gene 88) in DLBCLs, bei dem es sich um ein Bindeglied zwischen dem Toll-like-Rezeptor (TLR) und nachgeschalteten Signalkaskaden handelt (Ishii und Akira 2006; Kawai und Akira 2010). So zeigten Exom- und RNASequenzierungen vermehrt Mutationen des zugehörigen Gens MYD88 bei DLBCLs (Ngo et al. 2011; Lohr et al. 2012). Auch Überexpressionen des Proteins wurden beobachtet und korrelierten mit einem schlechteren Krankheitsverlauf für den Patienten (Choi et al. 2013). Aber auch die mit Myd88 assoziierten und ihm vorgeschalteten Toll-like-Rezeptoren (TLR) lassen sich vermehrt in malignen Zellen finden. Sie können Entzündungsreaktionen modulieren und die Tumor-Mikroumgebung verändern (Sato et al. 2009). TLR vermitteln eine Immunantwort, indem sie Pathogenassoziierte molekulare Muster (pathogen-associated molecular patterns, PAMPs), wie die für Bakterien typischen CpG-Oligodeoxynukleotide oder Lipo-polysaccharide, erkennen können (Krieg et al. 1995; Lim und Staudt 2013). Im Menschen werden zehn TLR unterschieden, wobei in dieser Arbeit primär der klassischerweise CpG erkennende und in Endosomen lokalisierte TLR9 betrachtet werden soll (Hemmi et al. 2000; Kawai und Akira 2010; Blasius und Beutler 2010) (Abbildung 1). Über verschiedene Zwischenschritte wie die Phosphorylierung und Degradation von I kappa B (IxB) wird eine Translokation des kanonischen NF- $x$ B (p50/RelA) in den Zellkern ermöglicht. Somit kann NF- $x$ B an die DNA binden und die Transkription abhängiger Gene regulieren (Bours et al. 1990; Ghosh und Baltimore 1990; Régnier et al. 1997; Mercurio et al. 1997; Lim und Staudt 2013).

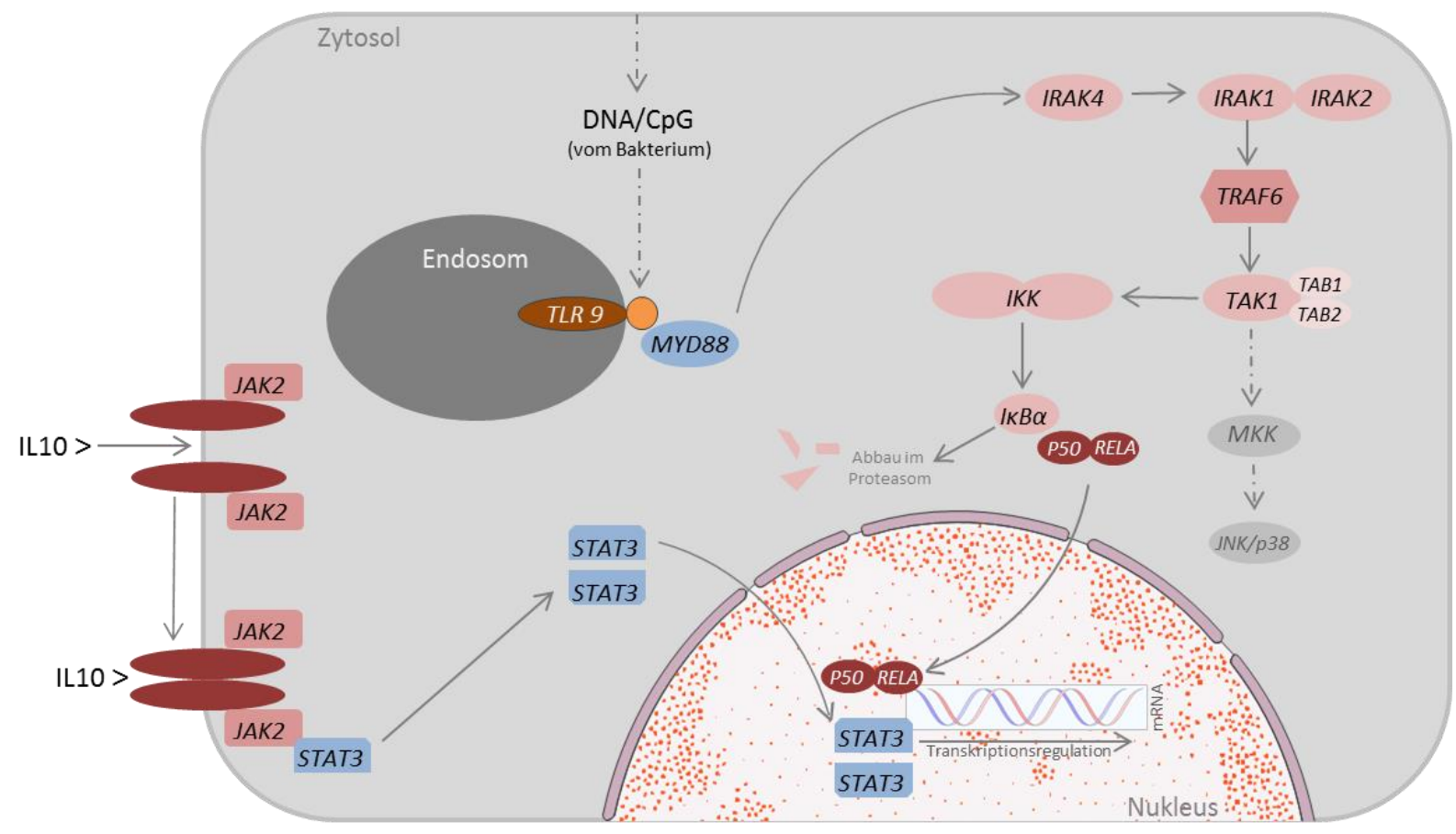

Abbildung 1: Schematische Darstellung des STAT3- und TLR9-Signalwegs 
Gezeigt ist die Signalkaskade um STAT3 sowie TLR9 und NF- $x$ B in schematischer Form. Eine Aktivierung des endosomalen TLR9 durch CpG oder andere bakterielle DNA-Bruchstücke führt über das Adaptormolekül Myd88 unter anderem zu einer Aktivierung von IRAKs (Interleukin-1-receptor-associated kinase). Diese Kinasen führen über eine Modifikation von TRAF6 (TNF receptor associated factor 6) zur TAK1 (TGFbeta activated kinase 1) -Aktivierung. Als Folge werden die IKKs (IxB kinase) phosphoriliert, die wiederum durch Phosphorilierung zur I B-Degradation führen. Somit kann dieser NF- $x$ B-Inhibitor seine Funktion nicht mehr ausüben, NF- $x$ B wird in den Zellkern transportiert und reguliert die Transkription abhängiger Gene. In der dargestellten STAT3-Signalkaskade führt eine Aktivierung des IL10Rezeptors durch IL10 zu einer Multimerisierung der Rezeptoruntereinheiten. Die gekoppelten Januskinasen 2 (JAK2) werden selber durch die räumliche Nähe zueinander transphosphoriliert, woraufhin sie als Tyrosinkinasen den Rezeptor und ihr Hauptsubstrat STAT3 phosphorilieren können. Diese ruhend im Zytoplasma vorliegenden Proteine dimerisieren, werden in den Zellkern transportiert und wirken mit Hilfe ihrer SH2-Domäne an regulatorischen DNA-Sequenzen als Transkriptionsfaktor. Diese schematische Darstellung wurde mit Hilfe der Graphikelemente von SERVIER Medical Art erstellt (www.servier.de).

\subsection{Zellmetabolismus}

Die Voraussetzungen für das Wachstum und Überleben von Tumorzellen sind Mutationen und Veränderungen, die sie von gesunden Zellen unterscheiden. So wird häufig das ungehemmte Wachstum durch autarke Proliferationsregulation, die fehlende Sensitivität gegenüber wachstumshemmenden Signalen sowie die Umgehung der Apoptose beschrieben. Zudem zeichnen sich Tumorzellen durch ständige Angiogenese und die Möglichkeit der Gewebeinvasion und Metastasenbildung aus (Hanahan und Weinberg 2000). In den letzten Jahren kristallisierten sich jedoch weitere existenzielle Veränderungen und Merkmale für Tumorzellen heraus - ein veränderter, an die Bedürfnisse angepasster Zellmetabolismus und die Schaffung einer auf die Tumorzelle abgestimmten „Mikro-Umgebung“ (microenvironment). Auch in DLBCLs spielen in dieser Tumorumgebung Signale an umgebende scheinbar gesunde Zellen und deren Antwort eine wichtige Rolle für das Überleben der Tumorzellen und die damit verbundene Krankheitsprognose (Hanahan und Weinberg 2011; Ward und Thompson 2012). Speziell zur Tumorgenese scheint die Mikroumgebung der Tumorzellen einen wichtigen Beitrag zu liefern (Lenz et al. 2008; Aldinucci et al. 2010). Dabei ist schon lange bekannt, dass Tumorzellen sich in ihrem Metabolismus von gesunden Zellen unterscheiden. So besagt der Warburg-Effekt, dass Tumorzellen vermehrt Glukose in Abwesenheit von Sauerstoff in Form der anaeroben Glykolyse verbrauchen (Warburg et al. 1927; DeBerardinis et al. 2008). Neben Glukose stellt Glutamin das wichtigste Metabolit als Grundlage zur Zellproliferation dar (Vander Heiden et al. 2009). Auch Lymphomzellen zeigen durch ihr verändertes genetisches Profil einen Metabolismus, der vermehrt Glukose und Glutamin verbraucht (Dang 2012). Interessanterweise stellte sich für DLBCLs Glutamin in Vorergebnissen dieser Arbeit als proliferationsbegrenzender Faktor heraus (Abschnitt 1.5). Auch für die in dieser Arbeit verwendete Zelllinie P493-6 wurde eine Glutaminaseabhängigkeit des Wachtums und der Tumorgenese beschrieben, die eine 
genauere Untersuchung der Glutaminolyse verlangt (Le et al. 2012; Liu et al. 2012; Xiang et al. 2015).

\subsubsection{Glutaminolyse}

Glutamin ist essenziell für die Zellproliferation und liefert durch seinen Abbau wichtige Zellprodukte wie Glutamat, Aspartat und Kohlenstoffdioxid $\left(\mathrm{CO}_{2}\right)$ (Brand 1985). Speziell Tumorzellen zeigen einen modulierten Metabolismus. Es wurde bereits gezeigt, dass die Glutaminolyse in vitro über das notwendige Maß funktioniert oder sogar hinsichtlich der gelieferten Zell- und Molekülbausteine die Glykolyse teilweise ersetzt (Reitzer et al. 1979; DeBerardinis et al. 2007). Der erste Schritt der Glutaminolyse der Zelle ist dabei die Desaminierung des Glutamins zu Glutamat durch die Glutaminase (Genname: GLS). In P493-Lymphomzellen wurden bereits in vivo Auswirkungen der Hemmung der GLS auf die Umwandlung von Pyruvat zu Alanin beschrieben, was die klinische Bedeutung der Glutaminolyse in Tumorzellen unterstreicht (Dutta et al. 2013). Um das mit Hilfe der GLS entstandene Glutamat in den Citratzyklus einzuspeisen, ist eine Umwandlung in $\alpha$-Ketoglutarat $(\alpha-K G)$ durch die Glutamat-Dehydrogenase (Genname: GLUD1) oder durch die mitochondriale Aspartat-Aminotransferase (Genname: GOT2) notwendig (Newsholme et al. 1985; DeBerardinis und Cheng 2010; Le et al. 2012; Son et al. 2013). Indem aus Glutamat $\alpha$-Ketoglutarat entsteht, katalysiert die mitochondriale GOT2 die Reaktion von Oxalacetat zu Aspartat. Die entsprechende Rückreaktion wird über die zytosolische Aspartat-Aminotransferase (Genname: GOT1) vermittelt (Abbildung 2). Glutamin ist für die Zelle dabei nicht nur ein Kohlenstoff- und Stickstoff-Lieferant, sondern auch ein wichtiges Atmungssubstrat. Durch seinen Abbau wird die Synthese von nicht-essenziellen Aminosäuren, Nukleotiden und anderen Zellmetaboliten ermöglicht. Durch die Glutaminolyse wird außerdem die vermehrte Reduktion des Wasserstoffüberträgers Nicotinamidadenindinukleotidphosphat (NADPH) ermöglicht, indem Malat über das Malatenzym zu Pyruvat umgewandelt wird (DeBerardinis und Cheng 2010). Malat entsteht dabei sowohl direkt im Citratzyklus als auch über eine Aspartat-Synthese durch die zytosolische GOT1. Entstandenes NADPH spielt eine zentrale Rolle für den Redoxstatus der Zelle und dabei im Besonderen die Reduktion von Glutathion (Son et al. 2013).

\subsubsection{Die Redoxbalance der Zelle}


Die Redoxbalance ist ein Gleichgewicht zwischen Antioxidantien und entstandenen radikalen Molekülen in der Zelle, von denen ein Großteil reaktive Sauerstoffspezies (reactive oxygen species, ROS) sind. ROS werden durch eine Gruppe verschiedener Sauerstoffradikale gebildet, die aufgrund ihrer hohen Reaktionsbereitschaft potenziell schädlich für die Zelle sind. Sie können der Zelle aber auch exogen zugeführt werden (z. B. durch Schwermetalle oder Zigarettenrauch) oder endogen entstehen. Dabei wird zwischen einer enzymatischen und einer nicht-enzymatischen (z. B. Zellatmungsassoziierten) Entstehung der ROS unterschieden. Erhöhte ROS-Konzentrationen führen zu oxidativem Zellstress, der wiederum diverse Krankheiten begünstigen kann. Während hohe ROSKonzentrationen und eine unausgeglichene Redoxbalance in gesunden Zellen schädlich sein können, werden in Tumorzellen häufig erhöhte Mengen von ROS und eine entsprechend ,verschobene“ Redoxbalance gefunden. Diese erhöhten ROS-Mengen sind sowohl im Hinblick auf den veränderten Tumormetabolismus als auch für die Modulation der Tumormikroumgebung relevant (Szatrowski und Nathan 1991; Toyokuni et al. 1995; Marnett 2000; Peng und Gandhi 2012; Jezierska-Drutel et al. 2013; Anso et al. 2013). Die Menge der reaktiven Sauerstoffverbindungen in der Zelle hängt dabei sowohl von der Menge der enstandenen Radikale als auch von der Effektivität ihres Abbaus ab. Ein für eine ausgeglichene Redoxbalance wichtiges antioxidatives Molekül ist neben den mit der Nahrung zugeführten Antioxidantien und anderen endogenen Antioxidantien, wie zum Beispiel der Superoxid-Dismutase oder der Katalase, das Glutathion (GSH) (Pham-Huy et al. 2008; Cairns et al. 2011). GSH ist ein Tripeptid aus den Aminosäuren L-Cystein, Glycin und L-Glutamin. Die Neusynthese wird über die Enzyme Glutamatcysteinligasen (GCLC) und Glutathion-Synthetase (GSS) reguliert. In der reduzierten Form des GSH können zwei Moleküle GSH mit Sauerstoffradikalen reagieren. Durch die Glutathion-Peroxidase (GPX) wird Wasserstoff von GSH auf z. B. Wasserstoffperoxid übertragen und GSH wird oxidiert. Somit bildet sich die oxidierte Form des GSH, das Glutathion-Disulfid (GSSG), indem zwei der GSH-Moleküle eine Disulfidbindung eingehen. Das entstandene GSSG kann dann mit Hilfe der Glutathion-Reduktase (GSR) und NADPH als Cofaktor reduziert werden, um in der Zelle wieder als Antioxidans zur Verfügung zu stehen (Kalinina et al. 2014). Die Neubildung von GSH kann zum Beispiel bei Glutaminmangel durch N-Acetylcystein (NAC) als Cysteinlieferant gefördert werden (Abbildung 2). 


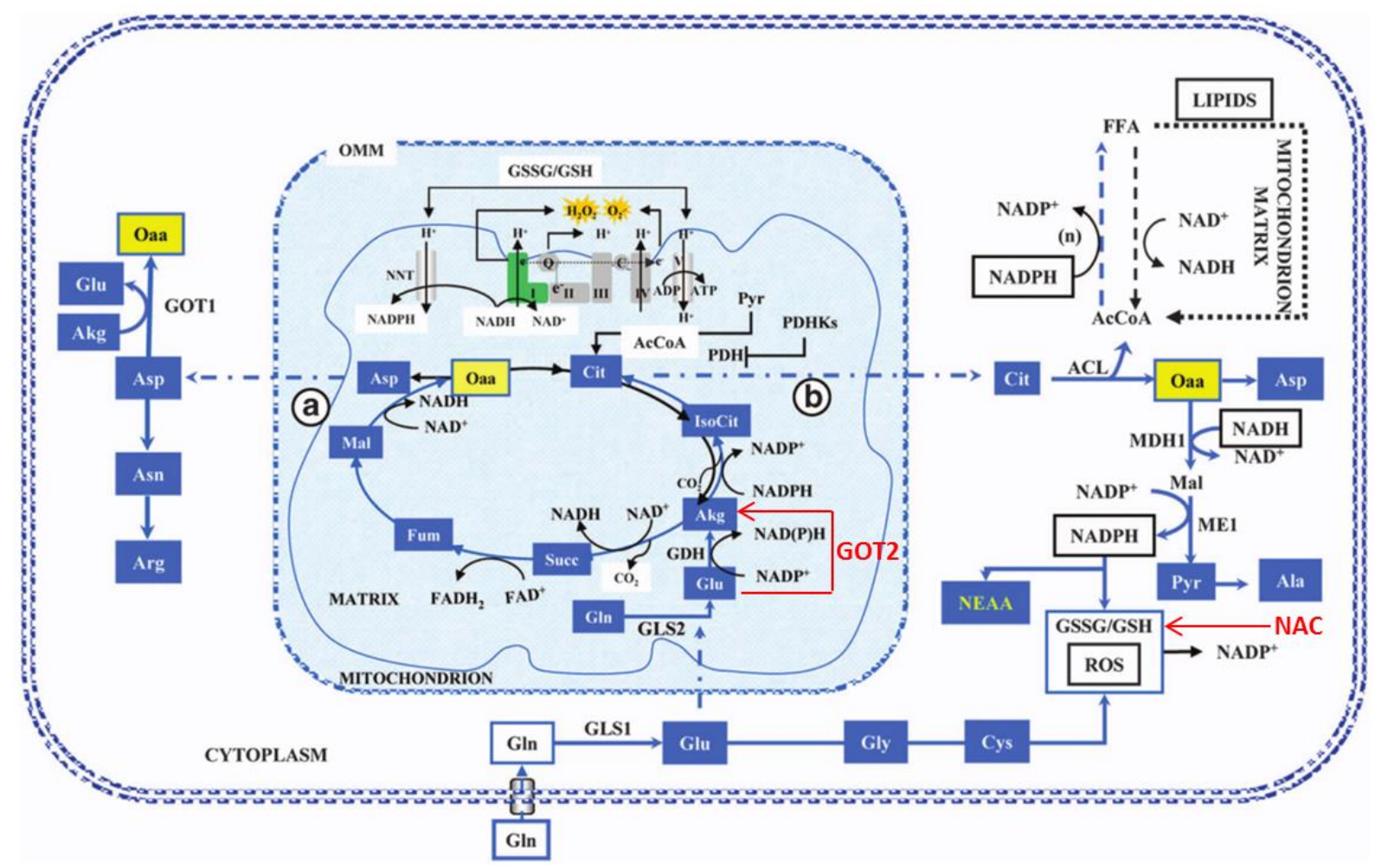

Abbildung 2: Schematische Darstellung der Glutaminolyse der Zelle

Gezeigt ist die kanonische und nicht-kanonische Glutaminolyse in der Zelle. Im kanonischen Abbauweg wird das Glutamin (Gln) über die Glutaminase zu Glutamat (Glu) desaminiert, woraufhin Glutamat nach Verstoffwechselung durch die Glutamat-Dehydrogenase (GDH) zu $\alpha-\mathrm{KG}$ in den Citratzyklus eingespeist wird. Im nicht-kanonischen Abbauweg wird die Reaktion von Glutamat zu $\alpha-K G$ von der mitochondrialen Aspartat-Aminotransferase (Genname: GOT2) katalysiert, wodurch gleichzeitig das als Zwischenprodukt des Citratzyklus entstehende Oxalacetat (OA) zu Aspartat (Asp) umgebaut wird. Nach dem Transport des Aspartats ins Zytosol findet durch die zytosolische AspartatAminotransferase (Genname: GOT1) die Rückreaktion statt, also ein Umbau zu OA. Die weiteren Reaktionen, ausgehend von OA über Malat zu Pyruvat, werden durch die Enzyme Malat-Dehydrogenase (Genname: MDH1) und Malatenzym (Genname: ME1) katalysiert, wobei bei der Pyruvat-Entstehung Kohlenstoffdioxid $\left(\mathrm{CO}_{2}\right)$ und das reduzierte NADPH als Nebenprodukte entstehen. NADPH ermöglicht unter anderem die Reduktion von Glutathion (GSH) mit Hilfe der Glutathion-Reduktase (Genname: GSR), woraufhin das reduzierte GSH in der Zelle entstandene reaktive Sauerstoffspezies (ROS) reduzieren kann, indem es selber wieder oxidiert und zum Glutathion-Disulfid (GSSG) wird. N-Acetylcystein (NAC) kann dabei als Cysteinlieferant für das Glutathion dienen und wurde in Vorarbeiten der Arbeitsgruppe experimentell genutzt (modifiziert nach Alberghina und Gaglio 2014, S. 2).

\subsection{Vorarbeiten der Arbeitsgruppe}

Die auch in Vorarbeiten der Arbeitsgruppe genutzte B-Zell-Modellzelllinie P493-6 zeichnet sich durch ein mit Hilfe von Tetrazyklin kontrollierbar exprimiertes MYC-Gen aus (Schuhmacher et al. 1999). Durch Zugabe von Tetrazyklin wird eine Myc-Repression (Myc ${ }^{\text {low }}$-Zustand) erreicht, dadurch arretieren die Zellen in der G0- oder G1-Phase des Zellzyklus (Pajic et al. 2000). 
Während die P493-6 im Mychigh-Zustand als ein Modell für aggressive B-Zell-Lymphomzellen wie die des Burkitt-Lymphoms dient, können im Myc ${ }^{\text {low }}$-Zustand Eigenschaften normaler B-Zellen untersucht werden. Experimente im Myc ${ }^{\text {low }}$ ZZustand lassen auch Interventionen/Manipulationen zu, die zu weitestgehend Myc-unabhängigen Veränderungen der Zellen führen.

In der Arbeitsgruppe konnte nun kürzlich gezeigt werden, dass die nicht proliferierenden $\mathrm{Myc}^{\mathrm{low}_{-}}$ Zellen nach einer Kostimulation mit IL10 und CpG wieder proliferieren (Feist et al. 2017). Es konnte die Hypothese aufgestellt werden, dass die Synergie aus dem JAK-STAT3- und dem NFxB-Signalweg hierfür verantwortlich ist, da die CpG-Wirkung durch ACHP, einen chemischen Inhibitor der I $\varkappa$ B-Kinase (IKK), sowie die Wirkung von IL10 durch den JAK-Inhibitor Ruxolitinib aufgehoben wurde (Feist et al. 2017). Weiterhin konnte gezeigt werden, dass diese IL10- und CpGvermittelte Proliferation der Zelllinie P493-6 glutaminabhängig ist und sich sowohl durch Zugabe des GLS-Inhibitors CB-839 als auch des Transaminase-Inhibitors AOA hemmen lässt (Feist 2016). Interessanterweise bewirkte auch eine Zugabe von NAC zu IL10- und CpG-stimulierten MYC ${ }^{\text {low }}$ Zellen eine Wiederaufnahme der Zellproliferation, was einen Hinweis auf die Beteiligung der Redoxbalance lieferte (Feist 2016). In weiterführenden Analysen konnte M. Feist zeigen, dass auch in DLBCL-Zellen mit aberrantem JAK-STAT- und NF- $x$ B-Signalweg eine ähnliche Glutaminabhängigkeit beobachtet werden kann.

\subsection{Ziele und Fragestellung}

Das Ziel dieser Arbeit bestand darin, zu klären,

1. ob spezifisch STAT3 und NF- $x$ B/RelA in die IL10- und CpG-vermittelte Aktivierung der Zellproliferation von P493-6-Zellen im Myc $\mathrm{c}^{\text {low }}$-Zustand involviert sind.

2. inwieweit die mitochondriale Aspartat-Aminotransferase (GOT2) spezifisch durch die beiden genannten Transkriptionsfaktoren reguliert wird und somit mitverantwortlich für den Glutaminstoffwechsel ist.

3. ob sich ein Fehlen von Glutamin auch auf den Glutathionmetabolismus und die Fähigkeit des Umgangs mit reaktiven Sauerstoffradikalen der stimulierten Zellen auswirkt.

Deshalb wurden im Rahmen der vorliegenden Arbeit folgende Fragen bearbeitet:

- Ist die durch IL10 und CpG vermittelte Proliferation der P493-6 ${ }^{\text {MYClow }}$-Zellen STAT3- und $\mathrm{NF}-\varkappa \mathrm{B} /$ RelA-abhängig? 
- Wird die GOT2 durch STAT3 und NF- $x$ B/RelA reguliert und ist GOT2 wichtig für die

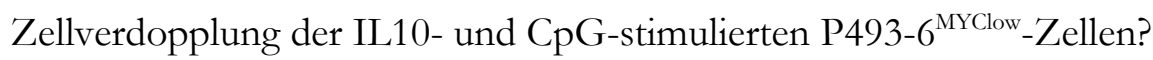

- Wirkt sich im Bezug auf die IL10- und CpG-vermittelte Proliferation der P493-6 ${ }^{\text {MYClow }}$ Zellen ein Glutaminmangel auf die Fähigkeit des ROS-Umgangs der Zellen aus und welche Rolle spielt Glutathion hierbei möglicherweise?

Zur Beantwortung dieser Fragen wurden IL10- und CpG-stimulierte P493-6-Zellen mit niedriger MYC-Expression durch Knockdown von STAT3, NF-xB/RelA und GOT2 charakterisiert. Weiterhin wurden erste Untersuchungen zur Rolle von ROS und Glutathion durchgeführt. 


\section{Material und Methoden}

Im folgenden Materialteil (2.1) sind alle regelmäßig verwendeten Geräte, Materialien und Substanzen sowie verwendete Software mit Herstellernamen aufgeführt. Der Methodenteil (2.2) beinhaltet alle durchgeführten zellbiologischen und proteinbiochemischen Methoden sowie die statistische Analyse.

\subsection{Material}

\subsubsection{Geräte}

Tabelle 1: verwendete Geräte

\begin{tabular}{|l|l|}
\hline Gerät & Hersteller \\
\hline Accu Jet & $\begin{array}{l}\text { Brand GmbH \& Co. KG, Wertheim, } \\
\text { Deutschland }\end{array}$ \\
\hline Bioruptor Standard Sonication Device & Diagenode Inc., Denville, NJ, USA \\
\hline Elektrophoresekammer und Wet-Blot-System & Bio-Rad GmbH, München, Deutschland \\
\hline FACScan Durchflusszytometer & $\begin{array}{l}\text { Becton, Dickinson and Company, Franklin } \\
\text { Lakes, NJ, USA }\end{array}$ \\
\hline Heraeus Multifuge 3 L-R & $\begin{array}{l}\text { Thermo Fisher Scientific Inc., Waltham, MA, } \\
\text { USA }\end{array}$ \\
\hline HERAfreeze, -80 ${ }^{\circ}$ C Freezer & $\begin{array}{l}\text { Thermo Fisher Scientific Inc., Waltham, MA, } \\
\text { USA }\end{array}$ \\
\hline Ikamag RCT Magnetrührer/Heizplatte & $\begin{array}{l}\text { IKA-Werke GmbH \& Co. KG, Staufen, } \\
\text { Deutschland }\end{array}$ \\
\hline Infinite F50 & Tecan Group Ltd., Männedorf, Schweiz \\
\hline Inkubator Cytoperm & $\begin{array}{l}\text { Thermo Fisher Scientific Inc., Waltham, MA, } \\
\text { USA }\end{array}$ \\
\hline Inverses Durchlichtmikroskop Telaval 31 & Carl Zeiss AG, Jena, Deutschland \\
\hline Luminescent Image Analyzer LAS-4000 & Fujifilm, Minato, Japan \\
\hline Microflow Laminar Downflow Workstation & Bioquell Ltd., Andover, Großbritannien \\
\hline NanoDrop ND-1000 Spectrophotometer & $\begin{array}{l}\text { Thermo Fisher Scientific Inc., Waltham, MA, } \\
\text { USA }\end{array}$ \\
\hline Neubauer-Zählkammer & $\begin{array}{l}\text { LO Laboroptik GmbH, Friedrichsdorf, } \\
\text { Deutschland }\end{array}$ \\
\hline Nucleofactor II & Lonza, Basel, Schweiz \\
\hline Pipetboy acu & $\begin{array}{l}\text { Integra Biosciences AG, Fernwald, Deutsch- } \\
\text { land }\end{array}$ \\
\hline Sanyo Ultra Low -152 ${ }^{\circ}$ C Freezer & Panasonic Healthcare Co. Ltd., Tokio, Japan \\
\hline T3000 Thermocycler & Biometra GmbH, Göttingen, Deutschland \\
\hline Tischzentrifuge 1-15k & $\begin{array}{l}\text { Sigma Laborzentrifugen GmbH, Osterode, } \\
\text { Deutschland }\end{array}$ \\
\hline Vortex Genie 2 & Schütt Labortechnik, Göttingen, Deutschand \\
\hline Waage L2200S & Sartorius AG, Göttingen, Deutschland \\
\hline TriStar LB 941 & $\begin{array}{l}\text { Berthold technologies, Bad Wildbad, } \\
\text { Deutschland }\end{array}$ \\
\hline & \\
\hline
\end{tabular}




\subsubsection{Verbrauchsmaterialien}

Tabelle 2: verwendete Verbrauchsmaterialien

\begin{tabular}{|l|l|}
\hline Verbrauchsmaterial & Hersteller \\
\hline $384-$ Well-Platte & $\begin{array}{l}\text { Greiner Bio-One International GmbH, } \\
\text { Kremsmünster, Österreich }\end{array}$ \\
\hline 96-Well-Platte (Rund-/Flachboden) & Sarstedt AG \& Co., Nümbrecht, Deutschland \\
\hline $\begin{array}{l}\text { Cellstar Tissue Culture Dishes (24-Well, 6- } \\
\text { Well) }\end{array}$ & $\begin{array}{l}\text { Greiner Bio-One International GmbH, } \\
\text { Kremsmünster, Österreich }\end{array}$ \\
\hline Cryo.s Einfriergefäße & $\begin{array}{l}\text { Greiner Bio-One International GmbH, } \\
\text { Kremsmünster, Österreich }\end{array}$ \\
\hline Deckgläser & Menzel, Braunschweig, Deutschland \\
\hline Falcon Röhrchen $(15 \mathrm{ml}, 50 \mathrm{ml})$ & Sarstedt AG \& Co., Nümbrecht, Deutschland \\
\hline Filter Tips $(10 \mu l, 100 \mu l, 1000 \mu \mathrm{l})$ & Sarstedt AG \& Co., Nümbrecht, Deutschland \\
\hline Transparente Mikroplatten Abdeckfolie & $\begin{array}{l}\text { Greiner Bio-One International GmbH, } \\
\text { Kremsmünster, Österreich }\end{array}$ \\
\hline Immobilon PVDF Membrane Advantages & Merck Millipore, Darmstadt, Deutschland \\
\hline Glaspasteurpipetten & $\begin{array}{l}\text { Brand GmbH \& Co.KG, Wertheim, Deutsch- } \\
\text { land }\end{array}$ \\
\hline Polystyrene Round-Bottom Tube $5 \mathrm{ml}$ & Becton Dickinson, Franklin Lakes, NJ, USA \\
\hline Reaktionsgefäße $(0,5 \mathrm{ml}, 1,5 \mathrm{ml}, 2 \mathrm{ml})$ & Eppendorf, Hamburg, Deutschland \\
\hline Serologische Pipetten $(5 \mathrm{ml}, 10 \mathrm{ml}, 25 \mathrm{ml})$ & Sarstedt AG \& Co., Nümbrecht, Deutschland \\
\hline $\begin{array}{l}\text { Whatman-Filterpapier }(\text { Diethylaminoethyl- } \\
\text { Zellulose) }\end{array}$ & $\begin{array}{l}\text { GE Healthcare Bio-Sciences, Pittsburgh, PA, } \\
\text { USA }\end{array}$ \\
\hline $\begin{array}{l}\text { Zellkulturflaschen mit Belüftungskappe }(25 \\
\left.\text { cm }^{2}, 75 \mathrm{~cm}^{2}, 175 \mathrm{~cm}{ }^{2}\right) \text { für Suspensionszellen }\end{array}$ & Sarstedt AG \& Co., Nümbrecht, Deutschland \\
\hline Combitips advanced $0.1 \mathrm{ml}$ & Eppendorf, Hamburg, Deutschland \\
\hline
\end{tabular}

\subsubsection{Chemikalien}

Tabelle 3: verwendete Chemikalien

\begin{tabular}{|l|l|}
\hline Chemikalien & Hersteller \\
\hline 4-Iodphenylborsäure (4-IPBA) & $\begin{array}{l}\text { Sigma-Aldrich Corporation, St. Louis, MO, } \\
\text { USA }\end{array}$ \\
\hline Acrylamid/Bisacrylamid $40 \%$ & $\begin{array}{l}\text { Serva Electrophoresis GmbH, Heidelberg, } \\
\text { Deutschland }\end{array}$ \\
\hline Ammoniumpersulfat (APS) $\left(10 \%\right.$ in $\left.\mathrm{H}_{2} \mathrm{O}\right)$ & Bio-Rad GmbH, München, Deutschland \\
\hline bovines Serum-Albumin (BSA) & Carl Roth GmbH, Karlsruhe, Deutschland \\
\hline Bromphenolblau & Merck KGaA, Darmstadt, Deutschland \\
\hline Complete Proteinaseninhibitor Cocktail Tablets & F. Hoffmann-La Roche Ltd, Basel, Schweiz \\
\hline
\end{tabular}




\begin{tabular}{|c|c|}
\hline Dimethylsulfoxid (DMSO) & $\begin{array}{l}\text { Sigma-Aldrich Corporation, St. Louis, MO, } \\
\text { USA }\end{array}$ \\
\hline Ethylendiamintetraacetat (EDTA) & Merck KGaA, Darmstadt, Deutschland \\
\hline Ethanol 99\% & J.T. Baker, Center Valley, PA, USA \\
\hline Fetales Kälberserum (FCS) & $\begin{array}{l}\text { Biochrom, Merck Millipore, Darmstadt, } \\
\text { Deutschland }\end{array}$ \\
\hline $\begin{array}{l}\text { Full Range Rainbow Molecular Weight Markers } \\
\text { RPN800E }\end{array}$ & $\begin{array}{l}\text { GE Healthcare Bio-Sciences, Pittsburgh, PA, } \\
\text { USA }\end{array}$ \\
\hline Glycin & Carl Roth GmbH, Karlsruhe, Deutschland \\
\hline Isopropanol & J.T. Baker, Center Valley, PA, USA \\
\hline Luminol & $\begin{array}{l}\text { Sigma-Aldrich Corporation, St. Louis, MO, } \\
\text { USA }\end{array}$ \\
\hline Methanol 99\% & $\begin{array}{l}\text { Th. Geyer GmbH \& Co.KG, Renningen, } \\
\text { Deutschland }\end{array}$ \\
\hline Milchpulver & Carl Roth GmbH, Karlsruhe, Deutschland \\
\hline Natriumchlorid $(\mathrm{NaCl})$ & Merck KGaA, Darmstadt, Deutschland \\
\hline Natriumdodecylsulfat (SDS) & $\begin{array}{l}\text { Serva Electrophoresis GmbH, Heidelberg, } \\
\text { Deutschland }\end{array}$ \\
\hline Natrium-Desoxycholat & Merck KGaA, Darmstadt, Deutschland \\
\hline NP-40 Igepal (Nonidet P-40) & $\begin{array}{l}\text { Sigma-Aldrich Corporation, St. Louis, MO, } \\
\text { USA }\end{array}$ \\
\hline Penicillin/Streptomycin $(\mathrm{P} / \mathrm{S})$ & Lonza Group Ltd., Basel, Schweiz \\
\hline Phos-Stop & F. Hoffmann-La Roche Ltd, Basel, Schweiz \\
\hline Phosphat gepufferte Salzlösung (PBS) & Pan-Biotech GmbH, Aidenbach, Deutschland \\
\hline Phenylmethylsulfonylfluorid (PMSF) & $\begin{array}{l}\text { Sigma-Aldrich Corporation, St. Louis, MO, } \\
\text { USA }\end{array}$ \\
\hline $\begin{array}{l}\text { Ponceau S-Lösung ( } 0,1 \% \text { Ponceau S in 5\% } \\
\text { Essigsäure) }\end{array}$ & $\begin{array}{l}\text { Sigma-Aldrich Corporation, St. Louis, MO, } \\
\text { USA }\end{array}$ \\
\hline ReBlot Plus Mild & Merck Millipore, Darmstadt, Deutschland \\
\hline Roti-Load (4x Probenpuffer) & Carl Roth GmbH, Karlsruhe, Deutschland \\
\hline Roti-Quant & Carl Roth GmbH, Karlsruhe, Deutschland \\
\hline RPMI-1640 mit L-Glutamin & Lonza Group Ltd., Basel, Schweiz \\
\hline Tetramethylethylendiamine (TEMED) & $\begin{array}{l}\text { Sigma-Aldrich Corporation, St. Louis, MO, } \\
\text { USA }\end{array}$ \\
\hline Trisbase Salzlösung (TBS) & Carl Roth GmbH, Karlsruhe, Deutschland \\
\hline Trypanblau $0.4 \%$ in PBS & $\begin{array}{l}\text { Sigma-Aldrich Corporation, St. Louis, MO, } \\
\text { USA }\end{array}$ \\
\hline Tween-20 (T) & $\begin{array}{l}\text { Serva Electrophoresis GmbH, Heidelberg, } \\
\text { Deutschland }\end{array}$ \\
\hline Wasser HPLC Grad & J.T. Baker, Center Valley, PA, USA \\
\hline SYBR Green I Nukleinsäure Gelfärbung, 1:100 & F. Hoffmann-La Roche Ltd, Basel, Schweiz \\
\hline$(\mathrm{D}+)$-Trehalose-Dihydrat & Carl Roth GmbH, Karlsruhe, Deutschland \\
\hline Triton X 100 & Carl Roth GmbH, Karlsruhe, Deutschland \\
\hline Diethylpyrocarbonat (DEPC) & Carl Roth GmbH, Karlsruhe, Deutschland \\
\hline Hot FIREPol DNA-Polymerase, Hotstart & Solis BioDyne OÜ, Tartu, Estland \\
\hline Desoxyadenosintriphosphat (dATP), $100 \mathrm{mM}$ & Prime'Tech ALC, Minsk, Weißrussland \\
\hline Desoxycytidintriphosphat (dCTP), $100 \mathrm{mM}$ & Prime'Tech ALC, Minsk, Weißrussland \\
\hline Desoxythymidintriphosphat (dTTP), $100 \mathrm{mM}$ & PrimeTech ALC, Minsk, Weißrussland \\
\hline Desoxyguanosintriphosphat (dGTP), $100 \mathrm{mM}$ & PrimeTech ALC, Minsk, Weißrussland \\
\hline Magnesiumchlorid $\left(\mathrm{MgCl}_{2}\right)$ & Solis BioDyne OÜ, Tartu, Estland \\
\hline
\end{tabular}




\begin{tabular}{|c|c|}
\hline $\begin{array}{l}\text { 2-(4-(2-Hydroxyethyl)-1-piperazinyl)- } \\
\text { ethansulfonsäure (HEPES Buffer solution), } \\
10 \mathrm{mM}\end{array}$ & $\begin{array}{l}\text { Gibco by Life Technologies, Carlsbad, CA, } \\
\text { USA }\end{array}$ \\
\hline Sodium Pyruvate, $1 \mathrm{mM}$ & $\begin{array}{l}\text { Sigma-Aldrich Corporation, St. Louis, MO, } \\
\text { USA }\end{array}$ \\
\hline L-Glutamin & Biochrom, Berlin, Deutschland \\
\hline Recombinant Human IL10 & PeproTech, Rocky Hill, NJ, USA \\
\hline Klasse B CpG Oligonukleotide, $0.5 \mu \mathrm{M}$ & InvivoGen, San Diego, CA, USA \\
\hline DL-Buthionine-sulfoximine (BSO), $500 \mu \mathrm{M}$ & $\begin{array}{l}\text { Sigma-Aldrich Corporation, St. Louis, MO, } \\
\text { USA }\end{array}$ \\
\hline Epigallocatechin Gallate (EGCG), $20 \mu \mathrm{M}$ & $\begin{array}{l}\text { Sigma-Aldrich Corporation, St. Louis, MO, } \\
\text { USA }\end{array}$ \\
\hline Glutathion reduced ethyl ester, $1 \mathrm{mM}$ & $\begin{array}{l}\text { Sigma-Aldrich Corporation, St. Louis, MO, } \\
\text { USA }\end{array}$ \\
\hline Doxycyclin & $\begin{array}{l}\text { Sigma-Aldrich Corporation, St. Louis, MO, } \\
\text { USA }\end{array}$ \\
\hline CellROX Green & Life Technologies, Carlsbad, CA, USA \\
\hline
\end{tabular}

\subsubsection{Puffer, Lösungen und Medien}

Tabelle 4: verwendete Puffer, Lösungen und Ansätze

\begin{tabular}{|c|c|}
\hline Puffer / Lösung / Ansatz & Zutaten \\
\hline $10 \%$ Trenngel & $\begin{array}{l}10 \% \text { Acrylamid/Bis Solution } \\
250 \mathrm{mM} \text { Trisbase } \mathrm{pH} 8,8 \\
0,0004 \% \text { APS } \\
0,00125 \% \text { TEMED }\end{array}$ \\
\hline 4x SDS-Probenpuffer & $\begin{array}{l}500 \mu \mathrm{l} \text { Roti-Load } 1(4 \mathrm{x}) \\
1 \% \text { gesättigte Bromphenolblau-Lösung }\end{array}$ \\
\hline $5 \%$ Sammelgel & $\begin{array}{l}5 \% \text { Acrylamid/Bis Solution } \\
250 \mathrm{mM} \text { Tris-Base } \mathrm{pH} 6,8 \\
0,0004 \% \text { APS } \\
0,00125 \% \text { TEMED }\end{array}$ \\
\hline Blockierlösung I & $5 \%$ BSA in TBS-T $0,1 \%$ \\
\hline Blockierlösung II & $5 \%$ Milchpulver in TBS-T $0,1 \%$ \\
\hline cDNA-Master Mix (pro Probe) & $\begin{array}{l}4 \mu \mathrm{l} 5 \mathrm{x} \text { first strand buffer } \\
2 \mu \mathrm{l} 0,1 \mathrm{M} \text { Dithiothreitol (DTT) } \\
1 \mu \mathrm{l} \text { SuperScript II reverse Transkriptase } \\
1 \mu \mathrm{l} 10 \mathrm{mM} \text { dNTPs }\end{array}$ \\
\hline Einfriermedium & $\begin{array}{l}90 \% \text { FCS } \\
10 \% \text { DMSO }\end{array}$ \\
\hline
\end{tabular}




\begin{tabular}{|c|c|}
\hline Laufpuffer (10x) für Western Blot & $\begin{array}{l}250 \mathrm{mM} \text { Tris } \\
1,92 \mathrm{M} \text { Glycin } \\
1 \% \text { SDS }\end{array}$ \\
\hline Luminol-Lösung (ECL-Lösung Teil I) & $\begin{array}{l}100 \mathrm{mM} \text { Tris/ } \mathrm{HCl} \mathrm{pH} 8,8 \\
2,5 \mathrm{mM} \text { Luminol } \\
4 \mathrm{mM} \text { 4-IPBA }\end{array}$ \\
\hline Peroxid-Lösung (ECL-Lösung Teil II) & $\begin{array}{l}100 \mathrm{mM} \text { Tris/HCl } \mathrm{pH} 8,8 \\
10,6 \mathrm{mM} \mathrm{H}_{2} \mathrm{O}_{2}\end{array}$ \\
\hline $\begin{array}{l}\text { SYBR-Green-Mix (für qRT-PCR) } \\
\text { (Ansatz für } 2.500 \text { Proben) }\end{array}$ & 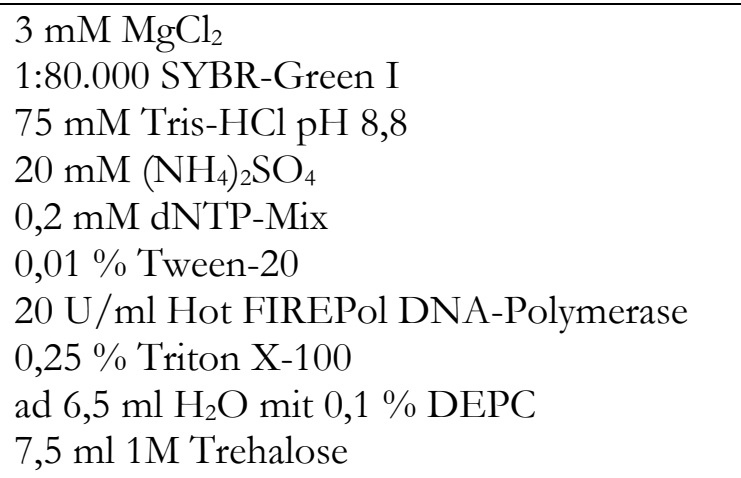 \\
\hline TBS $(1 \mathrm{x})$ & $\begin{array}{l}20 \mathrm{mM} \text { Tris-Base pH 7,6 } \\
137 \mathrm{mM} \mathrm{NaCl} \mathrm{pH} \mathrm{7,6}\end{array}$ \\
\hline TBS-T & $\begin{array}{l}1 \times \text { TBS pH 7,6 } \\
0,1 \% \text { Tween-20 }\end{array}$ \\
\hline Transferpuffer $(1 \mathrm{x})$ & $\begin{array}{l}2,5 \mathrm{mM} \text { Tris-Base } \mathrm{pH} 8,3 \\
192 \mathrm{mM} \text { Glycin } \\
15 \% \text { Methanol }\end{array}$ \\
\hline Trypanblau-Lösung & 0,4 \% Trypanblau in PBS \\
\hline Zellkulturmedium I & $\begin{array}{l}\text { RPMI-1640 mit } 4 \text { mM L-Glutamin } \\
10 \% \text { FCS } \\
1 \% \text { Penicillin/Streptomycin }\end{array}$ \\
\hline Zellkulturmedium II (ohne Glutamin) & $\begin{array}{l}\text { RPMI-1640 ohne Glutamin; ohne Glukose } \\
10 \% \text { FCS } \\
1 \% \text { Penicillin/Streptomycin } \\
11 \text { mM Glukose }\end{array}$ \\
\hline Zellkulturmedium III (ohne Glukose) & $\begin{array}{l}\text { RPMI-1640 ohne Glutamin; ohne Glukose } \\
10 \% \text { FCS } \\
1 \% \text { Penicillin/Streptomycin } \\
2 \text { mM Glutamin }\end{array}$ \\
\hline $\begin{array}{l}\text { Zellkulturmedium IV (ohne Glukose und ohne } \\
\text { Glutamin) }\end{array}$ & $\begin{array}{l}\text { RPMI-1640 ohne Glutamin; ohne Glukose } \\
10 \% \text { FCS } \\
1 \% \text { Penicillin/Streptomycin }\end{array}$ \\
\hline Transfektionsmedium & $\begin{array}{l}\text { RPMI-1640 mit } 4 \text { mM L-Glutamin } \\
1 \text { mM Pyruvat } \\
10 \text { mM 2-(4-(2-Hydroxyethyl)-1-piperazinyl)- } \\
\text { ethansulfonsäure (HEPES) }\end{array}$ \\
\hline RIPA-Gebrauchslösung & $\begin{array}{l}\text { RIPA-Stocklösung } \\
10 \mu \mathrm{l} / \mathrm{ml} \text { PMSF } \\
40 \mu \mathrm{l} / \mathrm{ml} \text { Complete } \\
40 \mu \mathrm{l} / \mathrm{ml} \text { Phosphostop }\end{array}$ \\
\hline
\end{tabular}




\begin{tabular}{|l|l|}
\hline RIPA-Stocklösung & $150 \mathrm{mM} \mathrm{NaCl}$ \\
& $1 \% \mathrm{NP}-40$ \\
& $0,1 \% \mathrm{SDS}$ \\
& $50 \mathrm{mM}$ TrisHCl $\mathrm{pH} 7,4$ \\
& $0,25 \% \mathrm{Na}-\mathrm{Deoxycholat}$ \\
\hline NP-40 Lysepuffer & $50 \mathrm{mM}$ Tris-Base $\mathrm{pH} 7,4$ \\
& $150 \mathrm{mM} \mathrm{NaCl}$ \\
& $1 \mathrm{mM}$ EDTA \\
& $0,5 \%$ NP-40 \\
\hline
\end{tabular}

\subsubsection{Western Blot-Antikörper}

Tabelle 5: verwendete Antikörper

\begin{tabular}{|c|c|c|}
\hline Antikörper & $\begin{array}{c}\text { Verdünnung für Immu- } \\
\text { noblot }\end{array}$ & Hersteller \\
\hline anti-Tubulin, mouse & $1: 10000$ in $5 \% \mathrm{BSA}$ & $\begin{array}{l}\text { Millipore, Schwalbach, } \\
\text { Deutschland }\end{array}$ \\
\hline anti-GAPDH, mouse & $1: 20000$ in $5 \% \mathrm{BSA}$ & Abcam, Cambridge, England \\
\hline anti-STAT3, rabbit & $1: 1000$ in $5 \% \mathrm{BSA}$ & $\begin{array}{l}\text { CellSignaling, Leiden, Nie- } \\
\text { derlande }\end{array}$ \\
\hline anti-RelA, rabbit & $1: 1000$ in $5 \% \mathrm{BSA}$ & $\begin{array}{l}\text { CellSignaling, Leiden, Nie- } \\
\text { derlande }\end{array}$ \\
\hline anti-GOT2, rabbit & 1:5000 in 5\% Milch & $\begin{array}{c}\text { Proteintech, Chicago, IL, } \\
\text { USA }\end{array}$ \\
\hline anti-rabbit, goat & $1: 2000$ in $5 \%$ BSA & $\begin{array}{l}\text { Santa Cruz, Heidelberg, } \\
\text { Deutschland }\end{array}$ \\
\hline anti-mouse, goat & $1: 2000$ in $5 \% \mathrm{BSA}$ & $\begin{array}{c}\text { Santa Cruz, Heidelberg, } \\
\text { deutschland }\end{array}$ \\
\hline
\end{tabular}

\subsubsection{Small interfering $R N A$ (siRNA)}

Tabelle 6: verwendete small interfering $R N A$ (siRNA)

\begin{tabular}{|l|l|l|}
\hline siRNA & Konzentration & Hersteller \\
\hline $\begin{array}{l}\text { Silencer select Negative Control } \\
\text { No.1 siRNA }\end{array}$ & $0.5 \mu \mathrm{g} / \mu \mathrm{l}$ & $\begin{array}{l}\text { Life Technologies, Carlsbad, } \\
\text { CA, USA }\end{array}$ \\
\hline STAT3 siRNA & $0.5 \mu \mathrm{g} / \mu \mathrm{l}$ & $\begin{array}{l}\text { Dharmacon, Lafayette, CO, } \\
\text { USA }\end{array}$ \\
\hline REL $A$ siRNA & $\begin{array}{l}\text { Dharmacon, Lafayette, CO, } \\
\text { USA }\end{array}$ \\
\hline
\end{tabular}




\begin{tabular}{|l|l|l|}
\hline GOT2 siRNA & $0.5 \mu \mathrm{g} / \mu \mathrm{l}$ & $\begin{array}{l}\text { Dharmacon, Lafayette, CO, } \\
\text { USA }\end{array}$ \\
\hline
\end{tabular}

\subsubsection{Software}

Tabelle 7: verwendete Software

\begin{tabular}{|l|l|}
\hline Software & Hersteller \\
\hline Graph Pad Prism 6.04/7.04 for Windows & Graph Pad Software Inc., San Diego, USA \\
\hline Image J 1.48v & $\begin{array}{l}\text { Wayne Rasband, National Institutes of Health, } \\
\text { Bethesda, MD, USA }\end{array}$ \\
\hline $\begin{array}{l}\text { Microsoft Office 2010 (Word, Powerpoint, Ex- } \\
\text { cel) }\end{array}$ & Microsoft, Redmont, USA \\
\hline Magellan for F50 7.0 & Tecan Group Ltd., Männedorf, Schweiz \\
\hline RQ Manager 1.2.1 & $\begin{array}{l}\text { Applied Biosystems, Thermo Fisher Scientific } \\
\text { Inc., Waltham, MA, USA }\end{array}$ \\
\hline Sequence Detection System SDS 2.4 & $\begin{array}{l}\text { Applied Biosystems, Thermo Fisher Scientific } \\
\text { Inc., Waltham, MA, USA }\end{array}$ \\
\hline MicroWin 2000 & $\begin{array}{l}\text { Mikrotek Laborsysteme GmbH, Overath, Ger- } \\
\text { many }\end{array}$ \\
\hline
\end{tabular}

\subsection{Methoden}

\subsubsection{Kultivierung und Stimulation der P493-6-Zelllinie}

Die Suspensionszelllinie P493-6, deren Ursprung und Eigenschaften bereits beschrieben wurden (Abschnitt 1.5), wurde in Medium I bei einer Konzentration von $5 \cdot 10^{5}$ Zellen/ml kultiviert. Dazu wurden die Zellen alle 48 Stunden mit Hilfe der Neubauer-Zählkammer gezählt, für 5 Minuten bei $100 \mathrm{~g}$ und Raumtemperatur zentrifugiert und der Überstand anschließend mit Hilfe einer Absaugpumpe und einer Pasteurpipette abgesaugt. Das Zellpellet wurde in dem entsprechenden Volumen des vorgewärmten Mediums I resuspendiert, um dann in eine neue Zellkulturflasche überführt und bei $37^{\circ} \mathrm{C}$ gelagert zu werden.

Alle beschriebenen Versuche und Methoden wurden mit der Modellzellinie P493-6 im Myc ${ }^{\text {low }}$ Zustand durchgeführt. Um die Zellen in diesen $\mathrm{Myc}^{\text {low }}$-Zustand zu überführen, erfolgte bereits 24 Stunden vor dem Versuchsansatz und am Versuchstag nach der Aussaat eine Behandlung mit 1 ng/ml Doxycyclin. Eine Ausnahme davon bildete die Transfektion von Zellen mit siRNA, hier 
wurde als Stressprophylaxe die Überführung in den Myc ${ }^{\text {low }}$-Zustand erstmalig 3 Stunden nach der Transfektion durchgeführt.

Die Stimulationen der Zellen wurden in den Konzentrationen $0.5 \mu \mathrm{M}$ CpG und $25 \mathrm{ng} / \mathrm{ml}$ IL10 durchgeführt.

\subsubsection{Transfektion mit siRNA}

Bei der small interfering RNA (siRNA) handelt es sich um kurze einzel- oder doppelsträngige RNAMoleküle, die durch Bindung an komplementäre einzelsträngige RNA-Abschnitte in der Zelle deren Funktion unterbinden können. Mit dem Ziel der Einbringung dieser Fremd-RNA in die Zellen wurde eine Elektroporation mit dem Nucleofactor Kit V (Amaxa Biosystems) nach Angaben und Gebrauchshinweisen des Herstellers durchgeführt. Dabei wurden, nachdem die Zelldichte 24 Stunden vor dem Versuch auf $1 \cdot 10^{6}$ Zellen/ml eingestellt worden war, am Versuchstag zunächst $4 \cdot 10^{6}$ Zellen pro zu transfizierender Probe 10 Minuten bei $87 \mathrm{~g}$ zentrifugiert, woraufhin eine Resuspension in jeweils $100 \mu \mathrm{l}$ der Nukleofektionslösung (nucleofactor solution) erfolgte. Nach Zugabe von jeweils 2-4 $\mu$ g siRNA zu 4.10 Zellen wurde die Transfektion mit dem Programm C-009 durchgeführt. Darauf schloss sich direkt die Überführung der transfizierten Zellen in jeweils $2 \mathrm{ml}$ vorgewärmtes Transfektionsmedium (mit $10 \mathrm{mM}$ HEPES und $1 \mathrm{mM}$ Pyruvat) pro 4·10 Zellen und eine Inkubation bei $37^{\circ} \mathrm{C}$ an. Zusätzlich wurden 3 Stunden später erneut $2 \mathrm{ml}$ desselben Mediums zu jeweils $4 \cdot 10^{6}$ ausgesäten Zellen gegeben. Im Gegensatz zu allen anderen durchgeführten Versuchen erfolgte aufgrund der zusätzlichen Stressbelastung für die Zellen erst 3 Stunden nach der Transfektion die Behandlung mit Doxycyclin, um die Zellen in einen Myc ${ }^{\text {low }}$-Zustand zu versetzen.

24 Stunden nach der Transfektion erfolgten eine Zellzählung und eine Ernte von jeweils $2 \cdot 10^{5}$ Zellen für eine Kontrolle des Knockdowns im Western Blot. Dafür wurden die Zellen 5 Minuten bei $900 \mathrm{~g}$ und $4{ }^{\circ} \mathrm{C}$ zentrifugiert, nach dem Absaugen noch in jeweils $1 \mathrm{ml}$ PBS gewaschen und die Trockenpellets anschließend bei $-20{ }^{\circ} \mathrm{C}$ eingefroren. Vor der Auftragung der Proben in das SDSGel wurden die Trockenpellets in jeweils $20 \mu \mathrm{l}$ des 1:4 in RIPA-Puffer vorverdünnten 4x SDSProbenpuffer Roti-Load resuspendiert, für 10 Minuten bei $95{ }^{\circ} \mathrm{C}$ aufgekocht, sechsmal für $10 \mathrm{Se}$ kunden sonifiziert und abschließend 1 Minute bei 11000 g zentrifugiert. Die Durchführung des Western Blots erfolgte wie im Abschnitt 2.2.8 beschrieben.

Zudem wurde 24 Stunden nach der Transfektion ein Teil der Zellen in Medium I für eine Bestimmung der Zellvermehrungsrate ausgesät und stimuliert, um sie nach 48 Stunden zu zählen, wie im 
Abschnitt 2.2.6 beschrieben. Pro Behandlungsvariante mit siRNA wurden die Zellen dabei entweder mit IL10, mit CpG, mit IL10 und CpG oder als Kontrollprobe gar nicht stimuliert.

Tabelle 8: Mengen der verwendeten small interfering RNA (siRNA)

\begin{tabular}{|l|l|}
\hline siRNA & eingesetzte Menge \\
\hline $\begin{array}{l}\text { Silencer select Negative Control } \\
\text { No.1 siRNA }\end{array}$ & $4 \mu \mathrm{g}$ \\
\hline STAT3 siRNA & $2 \mu \mathrm{g}$ \\
\hline RELA siRNA & $2 \mu \mathrm{g}$ \\
\hline GOT2 siRNA & $4 \mu \mathrm{g}$ \\
\hline
\end{tabular}

\subsubsection{Zellernte für quantitative Real-Time Polymerase-Kettenreaktion}

Um Zellen für eine Genexpressionsanalyse zu ernten, wurden ebenfalls 24 Stunden nach der Transfektion in einer 24-Well-Platte 0.5-1·10 Zellen in $1 \mathrm{ml}$ Medium I pro Well ausgesät und entsprechend mit IL10 und CpG stimuliert. Nach einer 24-stündigen Inkubation bei $37^{\circ} \mathrm{C}$ erfolgte eine Zellzählung (siehe Abschnitt 2.2.6) und die Zugabe von $1 \cdot 10^{5}$ für die Normierung wichtigen Schneiderzellen aus der Fliegenart Drosophila melanogaster pro $1 \cdot 10^{6}$ Lymphomzellen. Indem in der späteren Analyse das Haushaltsgen ACT42A der Schneiderzellen mitbestimmt wird, können durch diese interne Kontrolle Variationen der eingesetzten RNA-Menge ausgeglichen werden (Feist 2016). Für die Zellernte folgte auf eine 5-minütige Zentrifugation der Proben bei 900 g ein Waschschritt in jeweils $1 \mathrm{ml}$ PBS, woraufhin die Trockenpellets bei $-80{ }^{\circ} \mathrm{C}$ eingefroren wurden. Die sich anschließende RNA-Isolation mit Bestimmung der RNA-Menge, die cDNA-Synthese sowie die quantitative Real-Time Polymerase-Kettenreaktion (quantitative real-time polymerase chain reaction, $q R T$ PCR) wurde, wie in den Kapiteln 2.2.10 bis 2.2.12 beschrieben, durchgeführt.

\subsubsection{Zellzahl- und Viabilitätsbestimmung}


Nach einer makroskopischen und mikroskopischen Beurteilung der kultivierten Suspensionszellen im Hinblick auf Mediumfärbung, Flaschenverunreinigung, Zelldichte, Zellform und Zellgranularität wurden diese durch Auf- und Abpipettieren gemischt und anschließend ein Aliquot von $10 \mu \mathrm{l}$ abgenommen. Um abgestorbene Zellen mikroskopisch identifizieren zu können, erfolgte eine Mischung der Zellsuspension im Verhältnis 1:2 mit einer Trypanblau-Lösung und eine Zellzählung mit Hilfe der Neubauer-Zählkammer. Ausschließlich abgestorbene oder beschädigte Zellen nehmen diesen blauen Farbstoff auf, wohingegen lebende Zellen keine blaue Färbung zeigen. Somit ist mit Hilfe der Zählkammer neben der Zellzahlbestimmung auch eine Viabilitätsbestimmung möglich, indem das Verhältnis von lebenden zu toten Zellen berechnet wird.

\subsubsection{Gefrierkonservierung und Auftauen der Zelllinien}

Für die Lagerung und Konservierung bei $-150^{\circ} \mathrm{C}$ wurden jeweils $5 \cdot 10^{6}$ Zellen in $1 \mathrm{ml}$ Einfriermedium in spezielle Kryotubes überführt. Für eine langsame und schonende Temperaturreduktion erfolgte eine Kühlung mit Hilfe spezieller, mit Isopropanol gefüllter Einfrierboxen um $1{ }^{\circ} \mathrm{C}$ pro Minute bis auf $-80{ }^{\circ} \mathrm{C}$, woraufhin die Zellen ab dem Folgetag bei $-150{ }^{\circ} \mathrm{C}$ gelagert wurden.

Das Auftauen der gefrierkonservierten Lymphomzellen erfolgte durch einen schnellen Temperaturwechsel von $-150{ }^{\circ} \mathrm{C}$ zu einem $37{ }^{\circ} \mathrm{C}$ warmen Wasserbad. Auf eine 2-minütige Auftauphase schloss sich die Überführung von jeweils $5 \cdot 10^{6}$ Zellen in $5 \mathrm{ml}$ Zellkulturmedium I an. Um überschüssiges Einfriermedium zu entfernen, wurden die Zellen für 5 Minuten bei $100 \mathrm{~g}$ zentrifugiert, nach dem Absaugen des Überstandes in $5 \mathrm{ml}$ Zellkulturmedium I resuspendiert, in eine Zellkulturflasche überführt und anschließend bei $37^{\circ} \mathrm{C}$ im Brutschrank gelagert und in Kultur gehalten.

\subsubsection{Bestimmung der Zellvermehrungsrate}

Nachdem die Zelldichte am Vortag auf $1 \cdot 10^{6}$ Zellen/ml eingestellt worden war und die Zellen mit Doxycyclin vorbehandelt worden waren, erfolgte eine Aussaat von jeweils $5 \cdot 10^{4}$ Zellen in $100 \mu \mathrm{l}$ des jeweiligen Mediums in eine 96-Well-Platte und die gewünschte Stimulation bzw. Inhibition der Zellen. Eine Stimulation mit IL10 und CpG erfolgte sowohl direkt im Anschluss als auch erneut nach 24 Stunden. Die Zellen wurden nach einer insgesamt 48 -stündigen Inkubation bei $37^{\circ} \mathrm{C}$ mit Hilfe einer Neubauer-Zählkammer gezählt (siehe 2.2.4). 
Tabelle 9: Stimuli und Inhibitoren für Zellvermehrungsversuche

\begin{tabular}{|l|l|}
\hline Stimuli/Inhibitoren & Konzentration \\
\hline $\mathrm{IL} 10$ & $25 \mathrm{ng} / \mathrm{ml}$ \\
\hline $\mathrm{CpG}$ & $0,5 \mu \mathrm{M}$ \\
\hline $\mathrm{BSO}$ & $500 \mu \mathrm{M}$ \\
\hline $\mathrm{H}_{2} \mathrm{O}_{2}$ & $50 \mu \mathrm{M}$ \\
\hline $\mathrm{GSH}$ & $1 \mathrm{mM}$ \\
\hline
\end{tabular}

\subsubsection{ROS-Messung und Durchflusszytometrie}

Die Durchflusszytometrie ermöglicht es, Zellen mit Hilfe eines Lasers nach bestimmten Eigenschaften zu sortieren. Dabei fließen die Zellen in Suspension einzeln hintereinander durch eine Messkammer, sodass ihr jeweiliges Streulicht nach Passion des Laserstrahls erfasst und von einem Detektor ausgewertet werden kann. Das Vorwärtsstreulicht (FSC = forward scatter) ist abhängig vom Zellvolumen, während das seitliche Streulicht (SSC = sideward scatter) eine Aussage über die Granularität der Zelle und Zellstrukturen erlaubt.

Zusätzlich dazu können im FACS (fluorescence activated cell signaling) fluoreszierende Farbstoffe, mit denen die Zellen zuvor markiert worden sind, detektiert und die Zellen mit Hilfe gegensätzlicher Polarisierungen je nach detektiertem Signal in verschiedene Gefäße sortiert und gezählt werden. Um tote Zellen zu detektieren, wurde der Farbstoff Propidiumiodid eingesetzt, der nur in tote Zellen eindringen, mit der DNA interkalieren und so detektiert werden kann.

Die Messung des oxidativen Stresslevels durch die Erfassung der Menge der reaktiven Sauerstoffspezies erfolgte mit Hilfe des Farbstoffs CellROX Green, der im oxidierten Zustand im Gegensatz zum reduzierten Zustand mit einem Emissionsmaximum von $520 \mathrm{~nm}$ stark fluoresziert. Somit sollte der Farbstoff CellROX Green nur dann zu detektieren sein, wenn er zuvor durch Radikale oxidiert wurde. Nachdem die Zellen am Vortag auf eine Konzentration von 1.10 Zellen/ml eingestellt und durch Zugabe von Doxycyclin in einen Myc ${ }^{\text {low }}$-Zustand versetzt worden waren, folgte die Aussaat von jeweils $5 \cdot 10^{5}$ Zellen in $1 \mathrm{ml}$ oder $2,5 \cdot 10^{5}$ Zellen in $500 \mu \mathrm{l}$ des entsprechenden Mediums in eine 24-Well-Platte und eine entsprechende Stimulation. Auf eine 24-stündige Inkubation bei $37^{\circ} \mathrm{C}$ folgte die Ernte der Zellen in speziellen FACS-Röhrchen (Polystyrene RoundBottom Tube) mit einer Zentrifugation bei $650 \mathrm{~g}$ für 10 Minuten bei Raumtemperatur und der Resuspension in jeweils $500 \mu \mathrm{l}$ PBS mit $1 \mu \mathrm{g} / \mathrm{ml}$ Propidiumiodid, worauf sich die Messung der ROS- 
Menge im FACS-Gerät anschloss. Als Positivkontrolle diente eine tert-Butylhydroperoxid-Lösung (TBHP), die in einer Verdünnung von 0,5 mM eine Stunde vor der Messung als ROS-Induzierer zu zwei Zellproben gegeben wurde. $2 \mathrm{mM}$ des antioxidativen Metaboliten NAC konnten als Negativkontrolle bei Zugabe zu einer der Proben zwei Stunden vor der Messung diese Zunahme der ROS-Menge verhindern. Ebenfalls eine Stunde vor der Messung wurde der in 1:10 in Dimethylsulfoxid (DMSO) vorverdünnte Farbstoff CellROX Green in einer Endkonzentration von $500 \mathrm{nM}$ zu den Zellen gegeben, woraufhin die Zellen bis zur Messung dunkel gehalten wurden.

\subsubsection{Western Blot}

Der Western Blot, auch Immunoblot genannt, ermöglicht den gezielten Nachweis von Proteinen. Dabei schließt sich an eine Sodiumdodecylsulfat-Polyacrylamid-Gelelektrophorese (SDS-PAGE) eine Übertragung der Proteinbanden auf eine Polyvinylidenfluorid-Membran (PVDF-Membran) an, woraufhin durch ausgewählte Primär- und Sekundär-Antikörper die gewünschten Proteine nachgewiesen werden können.

Als Vorbereitung der Proben für den Gellauf wurden diese nach Zugabe eines 1:4 in RIPA vorverdünnten vierfach-SDS-Ladepuffers (Roti-Load), der die Proben für die Auftragung beschwert und durch die negative Ladung die Auftrennung in der Elektrophorese erleichtert, sonifiziert und gekocht. Anschließend wurden jeweils $15 \mu \mathrm{l}$ der Zellsuspension in die Geltaschen geladen.

Während der Gelelektrophorese sammelten sich die Proteine zunächst bei einer Stromstärke von $20 \mathrm{~mA}$ in einer Linie im pH-neutralen Sammelgel, um dann im basischen Trenngel bei $40 \mathrm{~mA}$ nach ihrer Größe aufgetrennt zu werden. Dabei zeigten sich auch die Banden des Full-Range RainbowMarkers, von dem vor dem Gellauf $5 \mu$ l aufgetragen wurden und der die Bestimmung der Proteingröße ermöglicht, indem die Farbpalette bestimmte kDa-Grenzen anzeigt.

Nach abgeschlossenem Gellauf erfolgte die Übertragung der nach ihrer Größe aufgetrennten Proteine auf eine PVDF-Membran, die vorher für 15 Sekunden mit Methanol, für 2 Minuten mit sterilem Wasser und für 5 Minuten mit Transferpuffer vorbehandelt worden war. Dies geschah als Elektroblot durch Anlegen einer konstanten Spannung von $100 \mathrm{~V}$ für eine Stunde bei $4{ }^{\circ} \mathrm{C}$, woraufhin die Übertragung der Proteinbanden durch eine Färbung mit einer Ponceau S-Lösung überprüft wurde, um die Membran im Anschluss wie gewünscht zu zerschneiden und wieder vollständig durch Waschen mit einer Tris-gepufferten Salzlösung mit Tween (TBS-T) zu entfärben. Damit die eingesetzten Antikörper nur ihre spezifischen Bindungen eingehen konnten, mussten die freien, 
unspezifischen Antikörperbindestellen blockiert werden, was durch die einstündige Behandlung der Membran mit 5-prozentigem und in TBS-T gelöstem Rinderserumalbumin (BSA) geschah. Die sich gegen die Zielproteine richtenden vorverdünnten Primär-Antikörper (siehe Tabelle 5) wurden im Anschluss über Nacht bei $4{ }^{\circ} \mathrm{C}$ zu den gewünschten Membranstücken gegeben. Am Folgetag schlossen sich auf dreimaliges Waschen für jeweils 10 Minuten in TBS-T die einstündige Zugabe des passenden, an eine Peroxidase gekoppelten Sekundär-Antikörpers, welcher sich gegen die Spezies des Primär-Antikörpers richtet, sowie erneut drei 10-minütige Waschschritte an. Die Darstellung der gebundenen Proteine erfolgte über ein Cheminolumineszenz-Verfahren mit Hilfe einer aus Luminol- und Peroxid-Lösung bestehenden erweiterten Cheminolumineszenz (ECL)-Lösung. Indem die Peroxidase des gebundenen Sekundär-Antikörpers das Luminol oxidiert, entsteht ein Lumineszenz-Signal, das detektiert werden kann.

Für die Färbung weiterer Proteine auf den gleichen Membranabschnitten war eine Behandlung mit einer Reblot-Lösung für 15 Minuten erforderlich, um die gebundenen Antikörperkonjugate zu lösen. Darauf folgten eine erneute Blockade der Membran mit BSA für eine Stunde und die entsprechenden bereits beschriebenen Antikörperbehandlungen.

Die konstitutiv in der menschlichen Zelle vorhandenen Proteine Tubulin oder Glycerinaldehyd-3phosphat-Dehydrogenase (GAPDH) dienten als Kontrolle für eine gleichmäßige Beladung der Geltaschen. Die Auswertung der Knockdowns erfolgte dabei mit Hilfe des Programms ImageJ, indem das Verhältnis der jeweiligen Bandendichte zu der Bandendichte ihrer jeweiligen GAPDHoder Tubulin-Bande berechnet wurde, um dieses Verhältnis im Anschluss auf das Verhältnis der mit unspezifischer siRNA (scrambled siRNA) behandelten Kontrollprobe zu beziehen.

\subsubsection{Glutathion-Messung}

Die Messung der GSH-Konzentration erfolgte mit Hilfe des GSH/GSSG-Glo ${ }^{\mathrm{TM}}$-Assays (Promega) nach Herstellerangaben und -gebrauchsanweisungen. Die Gesamt-Glutathion-Messung wird ermöglicht, indem eine glutathionabhängige und durch die Glutathion-S-Transferase katalysierte Konversion von Luciferin stattfindet. Nach Zugabe einer Luciferase kann ein LumineszenzSignal detektiert werden, das proportional zur Luciferin- und somit auch zur Glutathion-Menge ist. Durch Zugabe von N-Ethylmaleimide (NEM) vor der Reaktion und somit Veränderung des reduzierten Glutathions (GSH), die zur Blockade der oben beschriebenen Reaktion führt, kann isoliert das vorhandene oxidierte Glutathion (GSSG) gemessen und nachfolgend auch das Verhältnis zwischen oxidierter (GSSG) und reduzierter (GSH) Form bestimmt werden. 
Nachdem die Zelldichte am Vortag auf eine Konzentration von $1 \cdot 10^{6}$ Zellen/ml eingestellt worden war und die Zellen durch Zugabe von Doxycyclin in einen Myc ${ }^{\text {low }}$ Zustand versetzt worden waren, folgte die Aussaat von jeweils 2,5·10 ${ }^{5}$ Zellen in $50 \mu \mathrm{l}$ des entsprechenden Mediums in eine 24-WellPlatte und eine entsprechende Stimulation. Die Zellen wurden nach einer sich anschließenden 24stündigen Inkubation bei $37{ }^{\circ} \mathrm{C}$ geerntet. An eine 5 -minütige Zentrifugation bei $300 \mathrm{~g}$ und $4{ }^{\circ} \mathrm{C}$ schloss sich ein Absaugen des Überstandes sowie eine Resuspension der Zellpellets in Ringer-Lösung und auf Eis an. In einer Konzentration von $3 \cdot 10^{5}$ Zellen $/ \mathrm{ml}$ wurden die Proben jeweils bei einer Messdauer von 0,25 Sekunden im Luminometer gemessen, wobei Proben mit reiner RingerLösung eine Leerwert-Messung ermöglichten. Dieser Leerwert wurde nach der Messung von allen Ergebnissen abgezogen und die bereinigten Werte ausgewertet.

Die Berechnung der reduzierten Glutathion-Werte erfolgte aufgrund der Entstehung zweier Moleküle reduzierten Glutathions (GSH) aus einem Molekül oxidierten Glutathions (GSSG) nach der Formel:

$$
\text { Verhältnis GSH } / \mathrm{GSSG}=\frac{\mu \mathrm{M} \text { totales Glutathion }-(\mu \mathrm{M} \mathrm{GSSG} \cdot 2)}{\mu \mathrm{M} \mathrm{GSSG}}
$$

\subsubsection{RNA-Isolierung}

Zur Isolierung der RNA aus einem zuvor geernteten Trockenpellet (siehe Abschnitt 2.2.3) von jeweils 0,5-1·10 Zellen wurde das Isolationskit „Nucleospin RNA II“ (Macherey-Nagel) entsprechend den Herstellerangaben und Gebrauchsanweisungen verwendet.

Dabei wurden die Zellpellets in Pufferlösungen resuspendiert, die sowohl die vorhandene RNAse inaktiviert als auch durch viele chaotrope, strukturbrechende Salze die Zellen lysiert und eine Umgebung für die Zellen schafft, die diese besonders affin für die Bindung an eine Silikat-membran macht. Die ebenfalls gebundene DNA wurde durch Inkubation mit DNAse gelöst und nachfolgend ausgespült, woraufhin in mehreren Waschschritten auch andere Makromoleküle, Metabolite und Salze entfernt wurden. Zum Lösen der gewonnenen RNA erfolgte eine Spülung der Membran mit RNAse-freiem, sterilem Wasser.

Mittels eines Spektralphotometers (NanoDrop) konnte die gewonnene RNA auf Reinheit geprüft und gleichzeitig ihre Konzentration gemessen werden. Die Bestimmung der Absorbtionskoeffizienten $\mathrm{A}_{260 / 280}$ und $\mathrm{A}_{260 / 230}$ gab dabei durch das charakteristische Absorbtionsspektrum der RNA einen Hinweis auf eventuelle Verunreingungen. 


\subsubsection{1 cDNA-Synthese}

Die Umschrift der gewonnenen RNA in komplementäre DNA (complementary DNA, cDNA) wurde mit dem Reverse-Transkriptase-Kit „SuperScript II“ (Invitrogen) nach Angaben sowie Gebrauchsanweisungen des Herstellers durchgeführt. Mit Hilfe der reversen Transkriptase wird dabei ein zur vorhandenen RNA komplementärer und für die folgende qRT-PCR benötigter DNA-Strang synthetisiert.

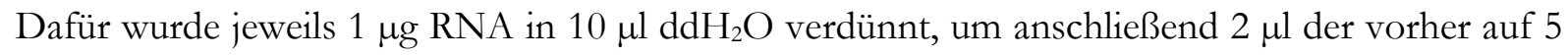
$\mu \mathrm{M}$ vorverdünnten Random-Hexamer-Primer hinzuzufügen. Nach Inkubation bei $70{ }^{\circ} \mathrm{C}$ für 10 Minuten und nachfolgender, für die Bindung der Primer an die RNA wichtige Abkühlung auf Eis wurden $8 \mu \mathrm{l}$ des cDNA-Master-Mixes zu den Proben gegeben. Im Anschluss erfolgte eine Inkubation für 10 Minuten bei $25^{\circ} \mathrm{C}$, für 60 Minuten bei $42^{\circ} \mathrm{C}$ und für 10 Minuten bei $65^{\circ} \mathrm{C}$. Ein kurzes Abkühlen der Proben bildete den Abschluss des Programms, woraufhin diese bei $-20{ }^{\circ} \mathrm{C}$ bis zur weiteren Verwendung gefrierkonserviert wurden.

\subsubsection{2 qRT-PCR}

Bei der Polymerase-Kettenreaktion handelt es sich um eine in-vitro-Amplifikation definierter DNAAbschnitte. Ermöglicht wird diese Reaktion durch die Taq-Polymerase, ein thermostabiles Enzym aus dem Bakterium Thermus aquaticus. Ein vollständiger Reaktionsansatz beinhaltet außerdem noch Desoxyribonukleosidtriphosphate (dNTPs) als Bausteine für die komplementäre Sequenz und die $\mathrm{zu}$ vervielfältigende DNA als cDNA (complementary DNA). Um den zu amplifizierenden Abschnitt zu definieren, werden Primer, spezifische Oligonukleotide, eingesetzt. Dabei ist ein Primer komplementär zu einer Basensequenz vor dem Zielabschnitt (forward primer) und der zweite Primer komplementär zu einer Basensequenz nach dem gewünschten DNA-Abschnitt (reverse primer).

Es werden 3 Phasen innerhalb der Polymerase-Kettenreaktion unterschieden. Während der Denaturierungsphase wird die DNA durch Hitzeeinwirkung in ihre beiden Einzelstränge zerlegt. In der darauffolgenden Phase der Primerhybridisierung lagern sich die Primer an ihre passenden Basensequenzen an und bilden somit die Startsequenz für die Synthese der komplementären DNAStränge aus den dNTPs in der Elongationsphase. Die häufige Wiederholung dieser Abfolge und 
die vielen Zyklen ermöglichen eine annähernd exponentielle Vermehrung eines bestimmten DNAAbschnittes.

Die quantitative Real-Time Polymerase-Kettenreaktion hat den Vorteil, dass während der Amplifikation auch gleichzeitig eine Quantifizierung des vervielfältigten DNA-Abschnittes erfolgen kann. Diese Mengenbestimmung wird durch den Farbstoff SYBR-Green ermöglicht, der mit einer hohen Affinität in doppelsträngige DNA interkalieren kann. Während er in der Denaturierungsphase kein Fluoreszenz-Signal aussendet, da die DNA in Einzelsträngen vorliegt, nimmt das Signal in jeder Elongationsphase proportional zur Menge der entstandenen doppelsträngigen DNA zu. Am Ende jeder Elongationsphase wird die Fluoreszenzzunahme gemessen, wobei das Emissionsmaximum von SYBR-Green bei $521 \mathrm{~nm}$ liegt. Neben der DNAMengenbestimmung ist durch die Auswertung des Verhältnisses von Fluoreszenz-Signal zu Temperatur auch eine Erfassung der Schmelztemperatur möglich.

In jedes Well wurden insgesamt $10 \mu \mathrm{l}$ Reaktionslösung gegeben, die 10 ng DNA, 5,6 $\mu$ l des SYBRGreen-Mixes sowie jeweils 3 pmol/ $\mu$ l des Vorwärts- und Rückwärtsprimers beinhaltet. Proben mit sterilem Wasser statt cDNA dienten als Negativkontrolle. Die endogene Kontrolle erfolgte durch Normalisierung der Zellen auf ein in Drosophila melanogaster-Fliegen konstitutiv exprimiertes AktinGen (ACT42A). Dieser Mengenvergleich war möglich, indem vor dem Ernten der Zellen (siehe Abschnitt 2.2.3) zu 1 Million humanen Zellen 1·10 Schneider 2 (S2)-Zellen, Makrophagenähnliche Suspensionszellen aus Drosophila melanogaster, gegeben worden waren. Diese Methode wurde von M. Feist etabliert (Feist 2016).

Mit Hilfe der Programme SDS 2.4 und dem RQ Manager von Applied Biosystems konnten die Ergebnisse ausgewertet werden. Dabei wurde zunächst der $\Delta \mathrm{Ct}$-Wert berechnet, indem der $\mathrm{Ct}($ cycle threshold)-Wert der jeweiligen ACT42A-Probe vom Ct-Wert der Probe des beobachteten Gens abgezogen wurde. Die Ct-Werte kennzeichnen dabei den jeweils kleinsten Wert, bei dem ein exponentielles Kurvenwachstum zu erkennen ist, hier also eine relevante Vermehrung des Gens detektiert wurde. Durch eine anschließende Subtraktion des $\Delta$ Ct-Werts einer festgelegten Kalibrator-Probe ließ sich der jeweilige $\Delta \Delta$ Ct-Wert berechnen. Die dargestellte relative Expression wurde nach der Formel $2^{-\Delta \Delta \mathrm{Ct}}$ berechnet und als Mittelwert mit seinem Positiv- und Negativfehler dargestellt.

\subsubsection{Statistische Analysen}

Der in den Abbildungen gezeigte Fehlerbalken stellt den Mittelwert \pm Standardabweichung der angegebenen Anzahl an biologischen Replikaten dar. Für die statistische Berechnung wurde dabei 
die Normalverteilung angenommen und eine One-Way-Analysis of Variance (One-Way-ANOVA) mit anschließender Bonferroni-Methode durchgeführt. Das Signifikanzniveau lag bei $* \mathrm{p}<0,05$; ** $\mathrm{p}<0,01 ;{ }^{* * *} \mathrm{p}<0,001$. Für alle statistischen Analysen wurde GraphPad Prism 6.04 oder 7.04 verwendet.

\section{Ergebnisse}

Ein Ziel dieser Arbeit war es, am Beispiel der P493-6-Zellen neue Einblicke in Mechanismen zu gewinnen, wie IL10 und CPG möglicherweise die Proliferation ruhender B-Zellen regulieren können. Besonderes Interesse galt in diesem Zusammenhang den in viele Zellvorgänge involvierten JAK-STAT- und NF- $x$ B-Signalwegen.

\subsection{STAT3 und NF- $\varkappa$ B/RelA vermitteln gemeinsam die IL10- und CpG-in- duzierte Proliferation in P493-6 MYClow-Zellen $^{\text {M }}$}

$\mathrm{Da}$ in Vorarbeiten bereits gezeigt werden konnte, dass chemische Inhibitoren für JAKs und IKK die Wirkung von IL10 und CpG auf P493-6-Zellen hemmen, sollte nun die Frage beantwortet werden, ob spezifisch STAT3 und NF-xB/RelA für die IL10- und CpG-vermittelte Zellproliferation wichtig sind. Die Hypothese war demnach, dass STAT3 und NF- $x$ B/RelA gemeinsam die IL10- und CpG-vermittelte Proliferation und den damit verbundenen Metabolismus in ruhenden B-Zellen regulieren können.

Dazu wurden die Proteinmengen von STAT3 und RelA in P493-6-Zellen durch einen RNA-Interferenz-vermittelten Knockdown reduziert. P493-6 $6^{\text {MYChigh }}-$ Zellen wurden mit spezifischen siRNAs gegen STAT3, RELA oder beide Transkriptionsfaktoren sowie als Kontrolle mit einer scr-siRNA nukleofiziert. Drei Stunden nach der Nukleofektion wurden die Zellen entsprechend mit Doxycyclin behandelt, um die Expression von MYC zu reduzieren (Myc $\left.{ }^{\text {low }}\right)$. 24 Stunden nach der Nukleofektion wurden Proben für den Western Blot zur Analyse der Proteinmengen von STAT3 und RelA geerntet (Abbildung 3 C +D). Sowohl die STAT3- als auch die RelA-Proteinmengen waren nach dem Knockdown reduziert. Der Knockdown von RELA war im Vergleich zum STAT3Knockdown ein wenig geringer ausgeprägt (Abbildung $3 \mathrm{C}+\mathrm{D}+\mathrm{E}$ ). Parallel wurden die verbliebenen Zellen mit IL10, CpG oder IL10+CpG behandelt oder unbehandelt kultiviert. 72 Stunden 
nach der Nukleofektion, also 48 Stunden nach der Stimulation, wurde die Zellverdopplungsrate sowie die Viabilität durch Zellzählung bestimmt (Abbildung 3 A+B).

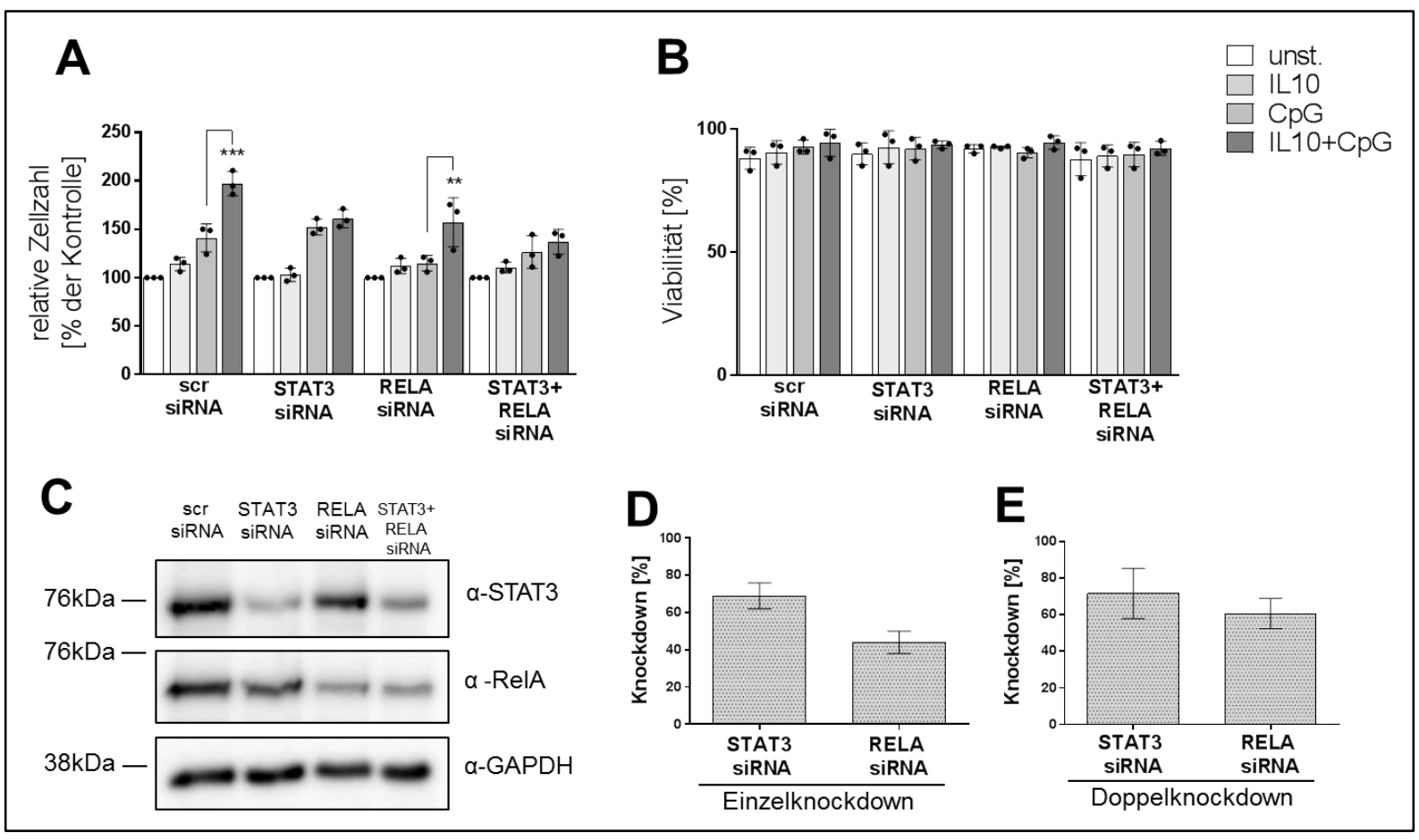

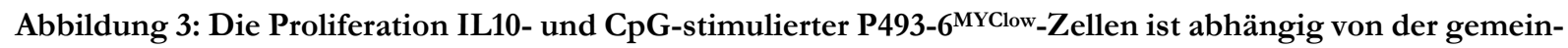
samen Wirkung von STAT3 und NF- $x$ B (RelA)

P493-6-Zellen wurden mit $2 \mu \mathrm{g}$ STAT3- und $2 \mu \mathrm{g}$ RELA-siRNA allein oder in Kombination transfiziert. Die Einzeltransfektionen wurden mit $2 \mu \mathrm{g}$ unspezfischer siRNA (scr-siRNA, scrambled-siRNA) aufgefüllt und als Kontrolle 4 $\mu \mathrm{g}$ scr-siRNA verwendet. Die MYC-Expression wurde mit Doxycyclin reprimiert und die Zellen nach 24 Stunden mit IL10, CpG oder IL10+CpG stimuliert. (A) Zellvermehrungsrate 48 Stunden nach Stimulation. Die Werte sind auf ihre jeweilige unstimulierte Kontrollprobe normiert. Zu erkennen ist eine synergistische proliferationssteigernde Wirkung durch IL10 und CpG, die sich durch den Knockdown von STAT3 und RELA abschwächen lässt. (B) Trotz Proliferationsunterschieden bleibt die Viabilität der Zellen nach dem Knockdown konstant. (C) Ein erfolgreicher Knockdown wurde durch Western Blot-Analyse verifiziert. Dargestellt ist ein repräsentativer Blot zur Knockdown-Kontrolle 24 Stunden nach der Transfektion. Die Expression von GAPDH dient als Ladekontrolle. (D+E) Die Quantifizierung der Knockdowneffizienzen nach Einzel- und Doppelknockdown erfolgte mit ImageJ. 100 Prozent entsprechen einem vollständigen Knockdown des jeweiligen Gens. Der Western Blot zeigt einen 72-prozentigen STAT3- und ein 48prozentigen RELA-Knockdown. Die Doppeltransfektion zeigt einen 56-prozentigen STAT3- und einen 54-prozentigen RELA-Knockdown. Auffällig ist ein stets etwas schwächerer Knockdown von RELA, während die Menge des STAT3-Proteins sich um bis zu 80 Prozent senken ließ. N=3, MW \pm SD. Getestet mit der One-Way-ANOVA und der Bonferroni-Methode. Signifikanzniveau $* \mathrm{p}<0,05 ; \quad$ * $\quad$ p $<0,01 ; * * * \mathrm{p}<0,001$.

Hierbei zeigte sich, dass die mit scr-siRNA nukleofizierten Zellen durch die Kostimulation mit IL10 und CpG proliferierten und diese Proliferationsrate deutlich über der der jeweiligen Einzelstimulation lag (Abbildung 3 A). Nach STAT3-Knockdown war die Zellverdopplung durch CpGStimulation vergleichbar zur unstimulierten Probe, die IL10-vermittelte Zellzahlverdopplungsrate veränderte sich jedoch nicht im Vergleich zur scr-Kontrolle. Im Gegensatz hierzu führte die 
reduzierte STAT3-Proteinmenge zu einer Reduktion der Zellproliferation bei IL10- und CpG-stimulierten Zellen. Noch deutlicher wurde diese Reduktion der Zellverdopplung nach RELAKnockdown. Auch eine vermehrte Proliferation nach CpG-Stimulation war hier nicht mehr zu beobachten. Zellen, in denen die Proteinmenge von sowohl STAT3 als auch RelA reduziert war, zeigten nach der Kostimulation mit IL10 und CpG den größten Abfall der Zellverdopplung. Wichtig war auch die Beobachtung, dass die Proliferationsunterschiede nicht durch Unterschiede in der Zellviabilität zu erklären sind (Abbildung 3 B). Daraus kann geschlussfolgert werden, dass IL10 und CpG die Proliferation der P493-6 MYClow $_{-Z}$ Zellen durch STAT3 und RelA regulieren.

\subsection{Die Rolle von STAT3, RelA und GOT2 in P493-6 ${ }^{\text {MYClow_Zellen }}$}

\subsubsection{STAT3 und NF- $\varkappa$ B/RelA steigern die IL10- und CpG-vermittelte Genexpression von GOT2 in den P493-6 ${ }^{\text {MYClow }-Z e l l e n ~}$}

Zu Beginn der Arbeit war bekannt, dass die Proliferation der Zelllinie P493-6 glutaminabhängig ist und sich sowohl durch Zugabe des GLS-Inhibitors CB-839 als auch des Transaminase-Inhibitors AOA hemmen lässt. Zudem zeigten RNA-Sequenzierungen sowohl in Myc ${ }^{\text {high }}$-Zellen als auch in IL10- und CpG-stimulierten Myc ${ }^{\text {low }}$-Zellen eine starke Erhöhung der Genexpression verschiedener Enzyme der Glutaminolyse (Feist 2016). Unter anderem wurde eine sehr starke synergistische Aktivierung der Genexpression von GOT2 nachgewiesen. Die zu beantwortende Frage war deshalb, ob GOT2 in P493-6-Zellen über die Stimulation mit IL10 und CpG durch STAT3 und NF- $x$ B reguliert wird. Hierfür wurde 24 Stunden nach der Transfektion mit STAT3- und/oder RELAsiRNA eine PCR-Analyse der GOT2-Genexpression durchgeführt. 


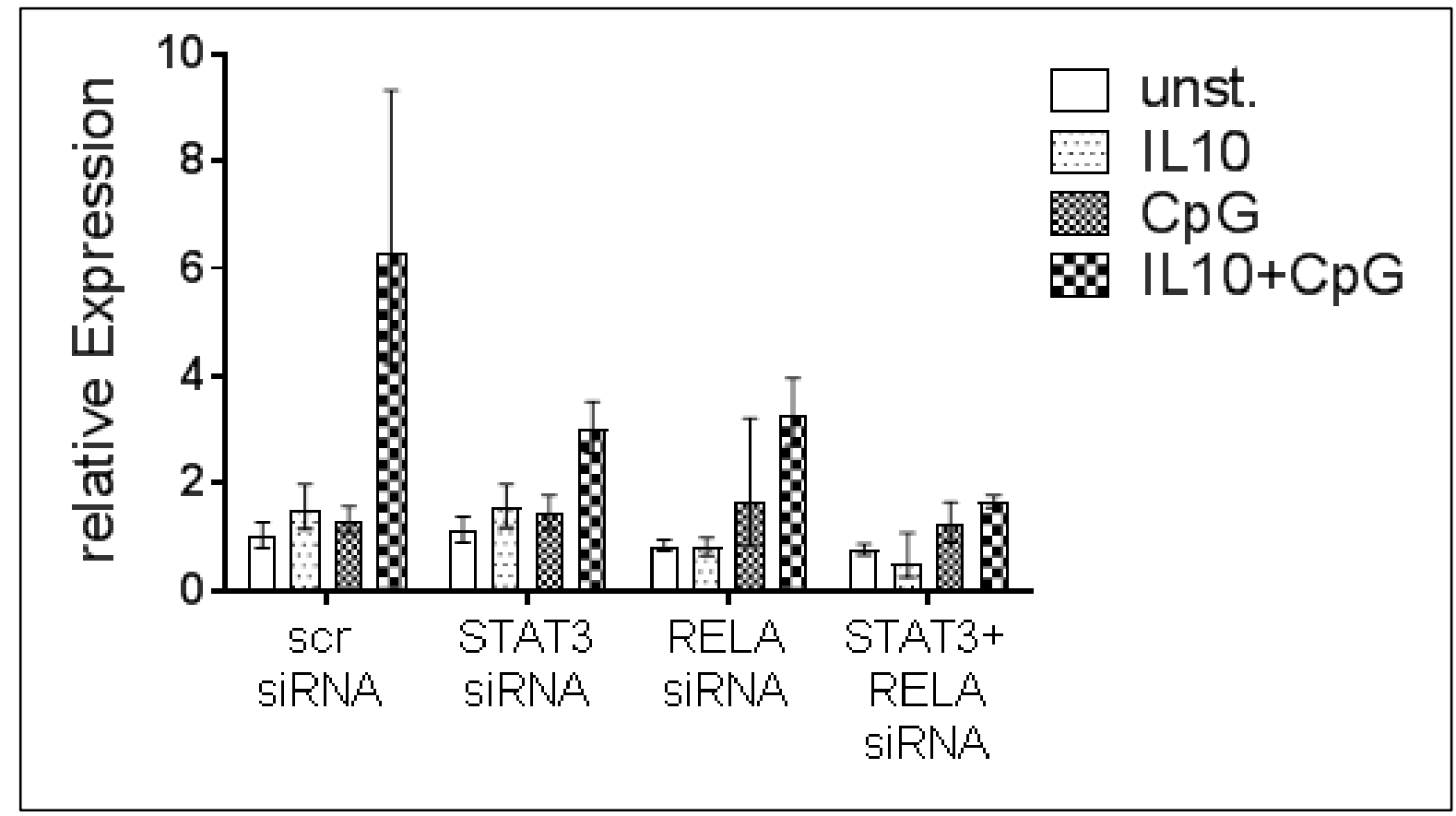

Abbildung 4: Verstärkte GOT2-Expression durch IL10 und CpG ist abhängig von STAT3 und RelA

P493-6-Zellen wurden mit $2 \mu \mathrm{g}$ STAT3- und $2 \mu \mathrm{g}$ RELA-siRNA allein oder in Kombination transfiziert. Die Einzeltransfektionen wurden mit $2 \mu \mathrm{g}$ unspezfischer siRNA (scr-siRNA, scrambled-siRNA) aufgefüllt und als Positivkontrolle $4 \mu \mathrm{g}$ scr-siRNA verwendet. Die MYC-Expression wurde mit Doxycyclin reprimiert und die Zellen nach 24 Stunden mit IL10, CpG oder IL10+CpG stimuliert. Gezeigt ist die Expression des Gens GOT2 24 Stunden nach der Stimulation. Unstimulierte Proben bilden die Kontrollproben. Zu erkennen ist eine deutliche Steigerung der Genexpression nach Stimulation mit IL10 und CpG, die nach dem Knockdown von STAT3 und RELA nicht mehr erreicht werden kann. Gezeigt ist ein repräsentatives Experiment von $n=3$, dargestellt ist die relative Expression als $M W \pm S D$.

In Abbildung 4 sind die Ergebnisse der GOT2-Genexpressionsanalyse nach STAT3- und RELAKnockdown zusammengefasst. Beobachtet werden konnte eine deutlich verstärkte Expression des Gens GOT2 nach der Doppelstimulation der mit scr-siRNA nukleofizierten P493-6 ${ }^{\text {MYClow-Zellen }}$ mit IL10 und CpG im Vergleich zur unstimulierten Kontrolle oder den Einzelstimulationen. Der Effekt der vermehrten Genexpression nach der Doppelstimulation war nach dem Knockdown des Transkriptionsfaktors STAT3 ebenso wie nach dem Knockdown von RELA nur noch in abgeschwächter Form zu sehen. Nach dem Doppelknockdown von STAT3 und RELA war die zuvor beobachtete GOT2-Expressionssteigerung nach der Doppelstimulation fast nicht mehr zu beobachten. Zusammenfassend konnte eine STAT3- und RelA-abhängige GOT2-Genexpressionsregulation nach IL10- und CPG-Stimulation beobachtet werden, welche möglicherweise eine entscheidende Rolle in der IL10- und CpG-vermittelten Proliferationssteigerung spielt. 


\subsubsection{Reduzierte Expression von GOT2 führt zu einer reduzierten IL10- und CpG-vermittelten Zellverdopplung der P493-6 ${ }^{\text {MYClow }-Z e l l e n ~}$}

Um zu klären, ob die GOT2-Genexpression relevant für die Proliferation der P493-6 ${ }^{\text {MYClow }}$-Zellen nach IL10- und CpG-Stimulation ist, wurde ein Knockdown von GOT2 durchgeführt. Zudem sollte untersucht werden, ob ein Zusammenhang zwischen der beobachteten Hemmwirkung durch den Transaminaseninhibitor AOA mit der GOT2-Genexpression besteht. Parallel wurde zum Vergleich in diesen Analysen auch ein Doppelknockdown von STAT3 und RELA durchgeführt. Wie im Abschnitt 3.1 beschrieben, wurden die Zellen nach der Nukleofektion mit spezifischen siRNAs in den $\mathrm{Myc}^{\text {low }}$-Zustand versetzt, es wurden Proben für die Analyse der Proteinmengen im Western Blot geerntet (Abbildung $5 \mathrm{C}+\mathrm{D}$ ) und die Zellverdopplung sowie Viabilität bestimmt (Abbildung 5 A+B). Die Knockdowns von RELA und GOT2 waren im Vergleich zum STAT3-Knockdown ein wenig geringer ausgeprägt (Abbildung $5 \mathrm{C}+\mathrm{D})$.

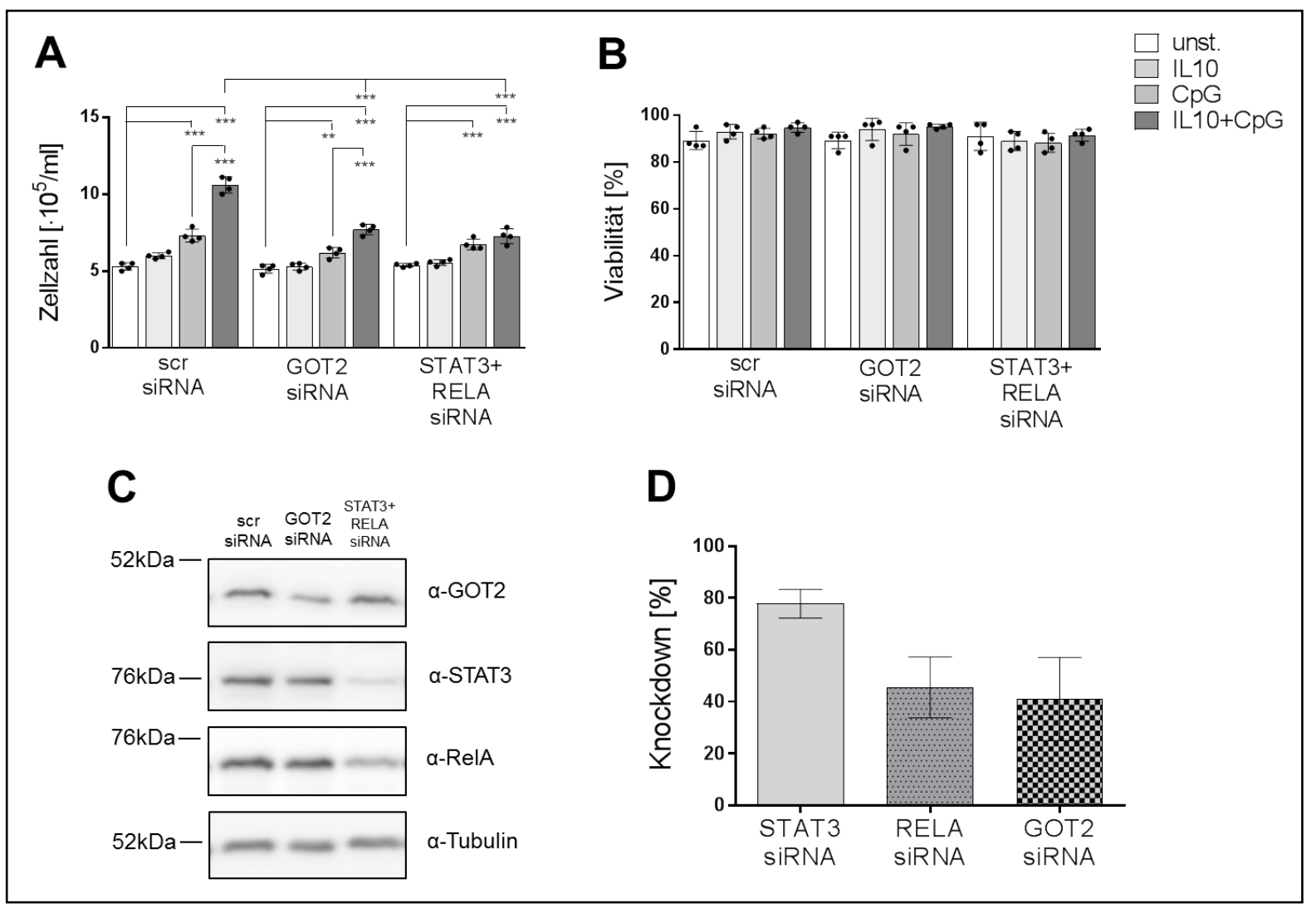

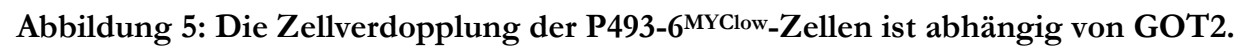

P493-6-Zellen wurden mit $2 \mu \mathrm{g}$ STAT3- und $2 \mu \mathrm{g}$ RELA-siRNA in Kombination oder mit $4 \mu \mathrm{g}$ GOT2 siRNA transfiziert. Als Kontrolle wurden $4 \mu \mathrm{g}$ scr-siRNA verwendet. Die $M Y C$-Expression wurde mit Doxycyclin reprimiert und die Zellen nach 24 und 48 Stunden mit IL10, CpG oder IL10+CpG stimuliert. (A) Zellvermehrungsrate 48 Stunden nach der Stimulation. Der in der Kontrollbehandlung zu erkennende Wachstumsvorteil durch die IL10- und CpG- 
Stimulation lässt sich durch den Knockdown von GOT2 oder STAT3 und RELA aufheben. (B) Trotz Proliferationsunterschieden bleibt die Viabilität der Zellen nach dem Knockdown konstant. (C) Ein erfolgreicher Knockdown wurde durch Western Blot-Analyse verifiziert. Dargestellt ist ein repräsentativer Blot zur Knockdown-Kontrolle 24 Stunden nach der Transfektion. Die Expression von Tubulin dient als Ladekontrolle. (D) Die Quantifizierung der Knockdowneffizienzen erfolgte mit ImageJ. 100 Prozent entsprechen einem vollständigen Knockdown des jeweiligen Gens. $\mathrm{N}=4$, $\mathrm{MW} \pm$ SD. Getestet mit der One-Way-ANOVA und der Bonferroni-Methode. Signifikanzniveau $\quad * \mathrm{p}<0,05 ; * *$ $\mathrm{p}<0,01 ; * * * \mathrm{p}<0,001$.

Auch in diesen Proben proliferierten die mit scr-siRNA nukleofizierten Zellen durch die Ko-stimulation mit IL10 und CpG. Diese Proliferationsrate lag deutlich über der der jeweiligen Einzelstimulation (Abbildung 5 A). Vergleichbar mit den Ergebnissen nach dem Doppelknockdown von STAT3 und RELA war auch nach dem Knockdown von GOT2 eine deutliche Reduktion der Zellproliferation nach der Kostimulation mit IL10 und CpG zu beobachten. Nach der Reduktion der GOT2-Proteinmenge wie auch nach STAT3-Knockdown war die Zellproliferation durch IL10 vergleichbar zur unstimulierten Probe. Die CpG-vermittelte Zellzahlverdopplungsrate veränderte sich jedoch im Vergleich zur scr-Kontrolle nicht. Zudem konnte beobachtet werden, dass die Proliferationsunterschiede nicht durch Unterschiede in der Zellviabilität zu erklären sind (Abbildung 5 B). Insgesamt sprechen diese Ergebnisse dafür, dass sowohl STAT3 und RelA als auch GOT2 essenziell für die durch IL10 und CpG vermittelte vermehrte Zellproliferation sind.

\subsection{Untersuchung des Zusammenhangs zwischen der Glutaminolyse und

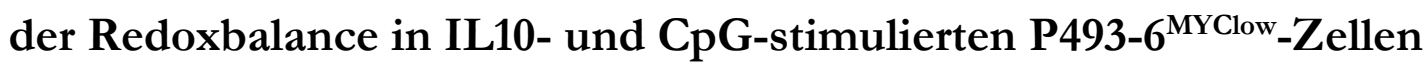

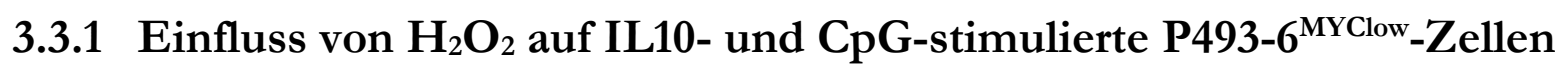

Aus Vorarbeiten der Arbeitsgruppe war bekannt, dass die IL10- und CpG-vermittelte Zellproliferation der P493-6 $6^{\text {MYClow }}$-Zellen nach Glutaminentzug durch eine Zugabe des Antioxidans NAC wieder rekonstituiert werden kann. Dies weist auf eine mögliche Regulation des Glutathion-Stoffwechsels und somit auch der ROS-Balance in der Zelle hin. Daher wurden Myc ${ }^{\text {low }}$ ZZellen der Zelllinie P493-6 zunächst mit Wasserstoffperoxid $\left(\mathrm{H}_{2} \mathrm{O}_{2}\right)$ behandelt oder ihnen Glutamin entzogen, daraufhin wurden sie mit IL10 und/oder CpG behandelt oder unbehandelt kultiviert und 48 Stunden nach der ersten Stimulation wurden Zellzahl sowie Viabilität bestimmt. 


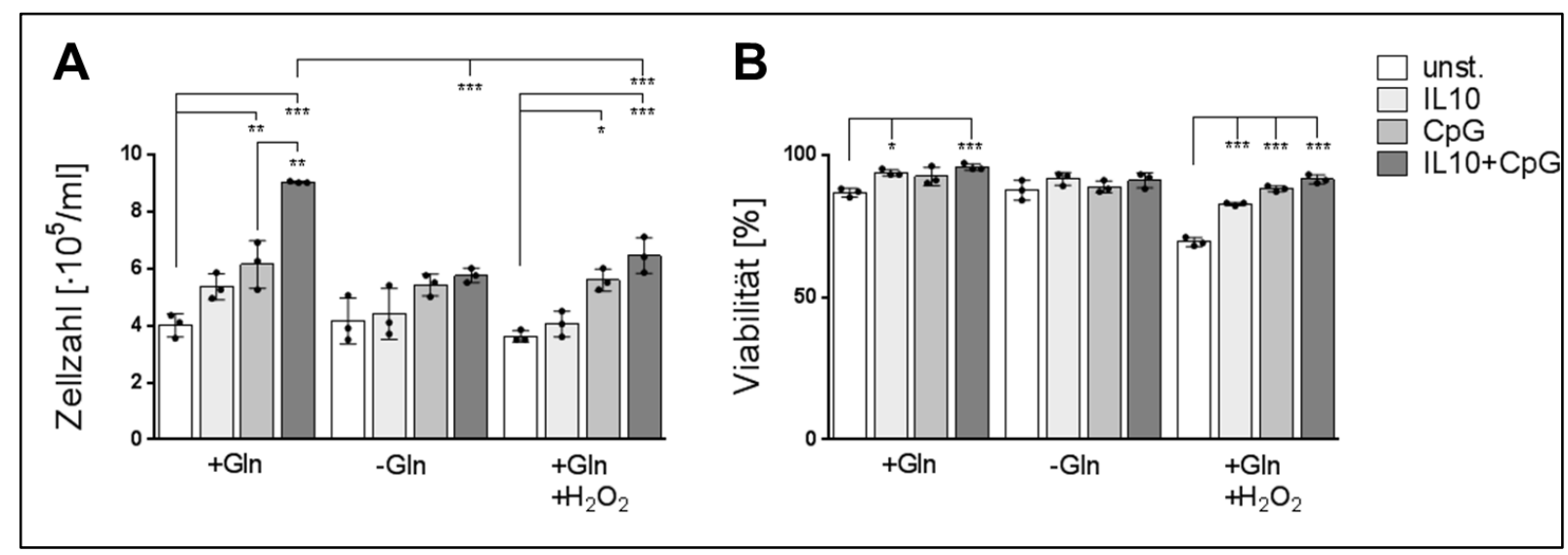

Abbildung 6: Die IL10- und CpG-vermittelte Zellproliferation ist abhängig von Glutamin und oxidativem Stress

P493-6-Zellen wurden mit Doxycyclin in ihrer MYC-Expression reprimiert und in Zellkulturmedium II ausgesät. Nach 24 Stunden wurde dem Zellkulturmedium teilweise $2 \mathrm{mM}$ Glutamin zugesetzt und die Zellen wurden teilweise mit 50 $\mu \mathrm{M} \mathrm{H}_{2} \mathrm{O}_{2}$ behandelt. Zellen ohne Glutaminentzug bilden die Positivkontrolle, solche mit Glutaminentzug die Negativkontrolle. Außerdem erfolgte eine Stimulation mit IL10, CpG oder IL10+CpG nach 24 und 48 Stunden. (A) Zellvermehrungsrate 48 Stunden nach der ersten Stimulation. Eine durch IL10- und CpG-Stimulation erreichte Zellproliferation ist nach Glutaminentzug nicht mehr zu beobachten. $\mathrm{H}_{2} \mathrm{O}_{2}$ führt zu einem Proliferationseinbruch, der sich mit Glutamin und einer IL10- und CPG-Doppelstimulation teilweise kompensieren lässt. (B) Trotz Proliferationsunterschieden bleibt die Viabilität der Zellen nach der Behandlung größtenteils konstant. Auffällig ist ein Einbruch der Viabilität nach Behandlung durch $\mathrm{H}_{2} \mathrm{O}_{2}$, der nach Doppelstimulation mit IL10 und CpG ausgeglichen werden kann. $\mathrm{N}=3, \mathrm{MW} \pm \mathrm{SD}$. Getestet mit der One-Way-ANOVA und der Bonferroni-Methode. Signifikanzniveau $* \mathrm{p}<0,05 ; * *$ $\mathrm{p}<0,01 ; * * * \mathrm{p}<0,001$.

Die mit $50 \mu \mathrm{M} \mathrm{H}_{2} \mathrm{O}_{2}$ behandelten, im Zellkulturmedium mit Glutamin wachsenden Zellen zeigten bereits im Grundzustand eine erniedrigte Zellzahl im Vergleich zu den unbehandelten Zellen (Abbildung 6 A). Dennoch ließen sich die Zellen etwas stärker zur Proliferation durch IL10 und CpG anregen als diejenigen, die in Abwesenheit von Glutamin behandelt wurden. Der Vergleich der Zellviabilität verdeutlicht, dass 48 Stunden nach der ersten Stimulation zwischen $84 \%$ und $97 \%$ der Zellen lebensfähig waren (Abbildung 6 B). Eine deutlich reduzierte Zellviabilität (72\%) war bei $\mathrm{H}_{2} \mathrm{O}_{2}$-behandelten Zellen zu sehen. Daraus lässt sich schließen, dass reaktive Sauerstoffspezies Einfluss auf die glutaminabhängige, IL10- und CpG-vermittelte Zellproliferation der P493-6-Zellen haben.

\subsubsection{Glutaminabhängiger ROS-Abbau in IL10- und CpG-stimulierten

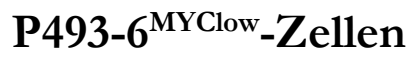

Um einen ersten Einblick in den Zusammenhang zwischen glutaminabhängigem Zellmetabolismus und der Redoxbalance der Zelle zu gewinnen, wurden die relativen ROS-Konzentrationen indirekt 
mit Hilfe des Farbstoffes CellROX Green durch FACS-Analysen bestimmt. Je mehr ROS durch die Zellen produziert wird, umso höher ist die Fluoreszenz des eingesetzten Farbstoffes. Messungen erfolgten dabei sowohl nach Glutamin- als auch nach Glukoseentzug. Die gleichzeitige Untersuchung der Effekte des Glukoseentzugs sollte die Frage beantworten, wie essenziell Glutamin im Vergleich zur Glukose hierbei ist. Hierfür wurde dem Zellmedium mit P493-6 ${ }^{\text {MYClow }}-$ Zellen Glukose und/oder Glutamin zugesetzt. Außerdem wurden die Zellen mit IL10, CpG oder IL10+CpG behandelt oder unbehandelt kultiviert. Mit Hilfe des Farbstoffs CellROX Green erfolgten nach 24 Stunden Analysen der Fluoreszenzintensitäten im FACS, die Rückschlüsse auf die ROS-Menge der Zellen zuließen.

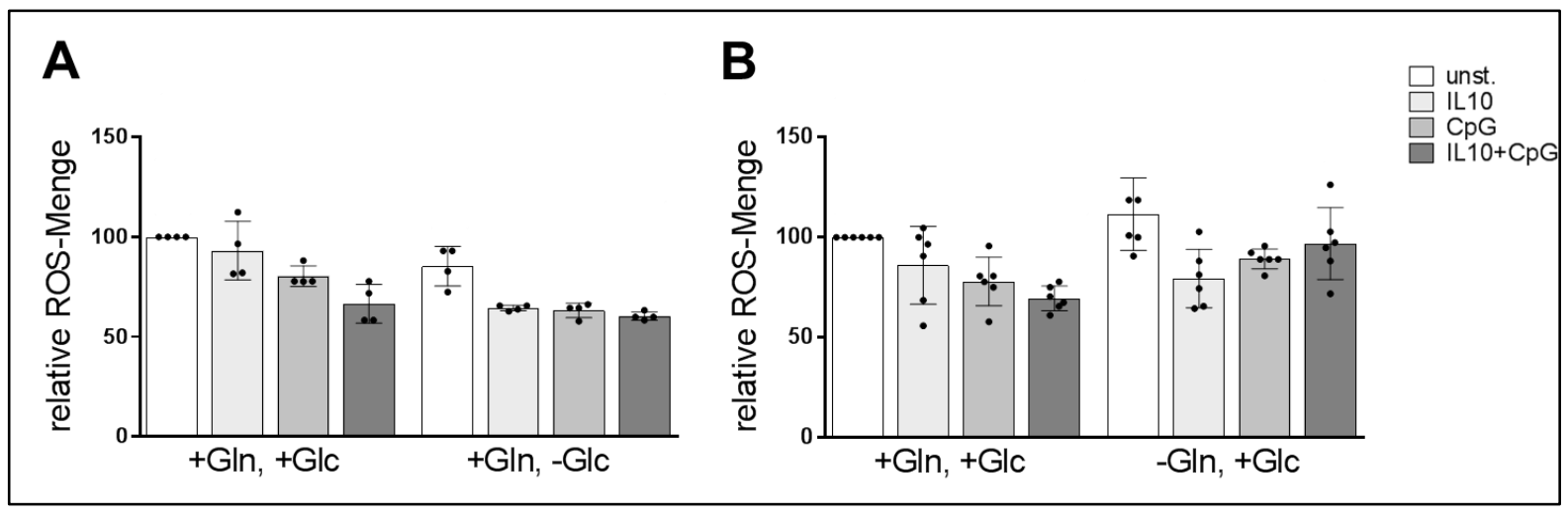

\section{Abbildung 7: Glutaminabhängige ROS-Reduktion durch IL10 und CpG}

P493-6-Zellen wurden mit Doxycyclin behandelt, um die MYC-Expression zu reduzieren. Die Zellen wurden in Zellkulturmedium IV, das weder Glukose noch Glutamin enthält, ausgesät. Nach 24 Stunden wurde dem Zellkulturmedium wieder $2 \mathrm{mM}$ Glutamin und/oder $2 \mathrm{~g} / \mathrm{l}$ Glukose zugesetzt. Zellen im Medium mit Glukose und Glutamin bildeten die Positivkontrolle. Außerdem erfolgte eine Stimulation mit IL10, CpG oder IL10+CpG. (A) Die Abnahme der relativen ROS-Menge durch IL10+CpG ist nicht abhängig von Glukose, während (B) die ROS-Menge in Abwesenheit von Glutamin nicht mehr so deutlich durch IL10 und CpG reduziert werden kann. Abgebildet ist die relative ROSMenge im FACS 24 Stunden nach der Stimulation als Mittelwerte der Mediane. (N=5), MW \pm SD.

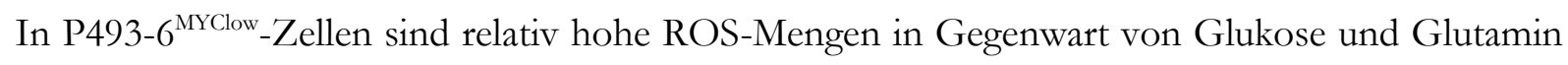
detektierbar. Nach der Stimulation durch IL10, CpG oder beide Stimulantien war eine Abnahme der relativen ROS-Mengen zu beobachten (Abbildung 7 A). Dabei war die Menge auch schon nach der Einzelstimulation mit CpG niedriger als in der Kontrolle. Durch die Doppelstimulation mit IL10 und CpG war eine zusätzliche deutliche Abnahme des ROS-Menge zu sehen, was für einen durch IL10 und CpG synergistisch vermittelten Abfang von Radikalen spricht. Nach Glukoseentzug war sowohl nach der Einzelstimulation mit IL10 oder CpG als auch nach der Doppelstimulation eine Senkung der ROS-Menge zu erkennen. Dabei bewirkten beide Einzelstimulationen eine Senkung der Menge an Sauerstoffradikalen, die vergleichbar mit der nach Doppelstimulation war. Somit wurde deutlich, dass die An- oder Abwesenheit von Glukose den ROS-Abfang der Zellen 
nicht beeinflusst. Gegensätzliche Ergebnisse erbrachten die gemessenen ROS-Mengen nach Glutaminentzug (Abbildung 7 B). Hier führte zwar die Einzelstimulation mit IL10 zu einer Senkung der ROS-Menge, nach CpG-Stimulation und Doppelstimulation blieb die ROS-Menge im Vergleich zu den Kontrollzellen jedoch unwesentlich niedriger, annähernd so hoch wie in den unstimulierten Kontrollzellen. Die Analysen wurden zum Teil bis zu fünfmal wiederholt, konnten jedoch nicht statistisch ausgewertet werden, da in jedem Experiment die Ausgangs-ROS-Mengen im FACS unterschiedlich waren. Es kann aus unserer Sicht jedoch davon ausgegangen werden, dass IL10 und CPG in Abhängigkeit von Glutamin die ROS-Menge in den P493-6 ${ }^{\text {MYClow }}$-Zellen reduzieren und so die Zellen schützen können. Unter Berücksichtigung einer früheren Beobachtung, dass NAC die Proliferation von IL10- und CpG-stimulierten Zellen in Abwesenheit von Glutamin unterstüzen kann, wurde im Folgenden der Frage nachgegangen, inwieweit GSH in die beobachteten Prozesse involviert ist (Feist 2016).

\subsubsection{Keine IL10- und CpG-vermittelte Reduktion der relativen ROS-Menge

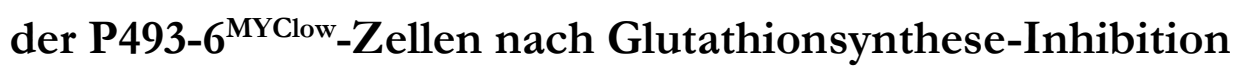

Wie in der Einleitung beschrieben, kann GSH in seiner reduzierten Form Sauerstoffradikale in der Zelle abfangen und ist somit ein wichtiges, die Redoxbalance regulierendes Molekül. Buthioninsulfoximin (BSO) ist ein spezifischer Inhibitor der Glutamatcysteinligase, welche das limitierende Enzym der Glutathionsynthese ist und deren Hemmung somit zu einem Absinken des Glutathionspiegels führt.

P493-6-Zellen wurden in Abwesenheit oder in Gegenwart von Glutamin kultiviert. Es erfolgte eine Zellzählung und Viabilitätsbestimmung sowie Messung der relativen ROS-Menge nach Glutamatcysteinligasen-Inhibition durch BSO. 


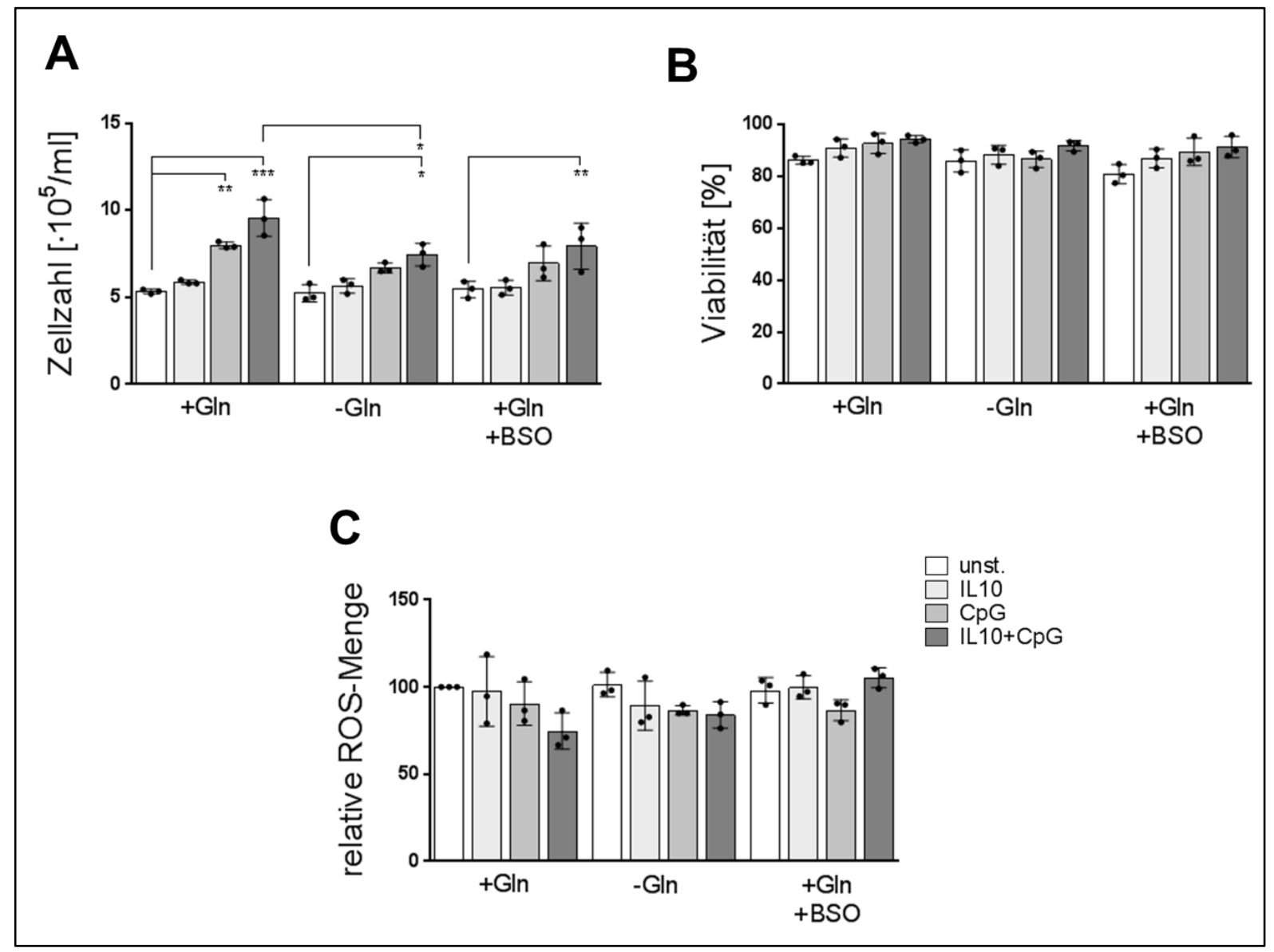

Abbildung 8: In IL10- und CpG-stimulierten Zellen wird die relative ROS-Menge im Vergleich zu

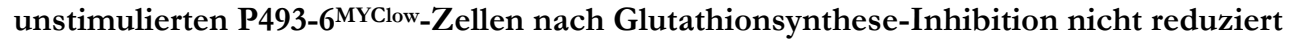

P493-6-Zellen wurden mit Doxycyclin in ihrer MYC-Expression reprimiert und in Zellkulturmedium II ausgesät. Nach 24 Stunden wurde zum Zellkulturmedium teilweise $2 \mathrm{mM}$ Glutamin und teilweise $50 \mu \mathrm{M}$ BSO hinzugegeben. Zellen ohne Glutaminentzug bildeten die Positivkontrolle, solche mit Glutaminentzug die Negativkontrolle. Außerdem erfolgte eine Stimulation mit IL10, CpG oder IL10+CpG nach 24 und 48 Stunden. (A) Zellvermehrungsrate 48 Stunden nach der ersten Stimulation. Eine durch IL10- und CpG-Stimulation erreichte Zellverdopplung ist nach Glutaminentzug nicht mehr und nach Glutathion-Inhibition minimal weniger zu beobachten. (B) Trotz Proliferationsunterschieden bleibt die Viabilität der Zellen nach Inhibition bis auf einen leichten Einbruch nach BSO-Zugabe konstant. (C) Relative ROS-Menge im FACS 24 Stunden nach der Stimulation als Mittelwerte der normierten Mediane. Während die Stimulation mit IL10 und CpG ohne Nährstoffentzug zu einer Senkung der ROS-Menge führt, ist dieser Effekt nach Glutaminentzug stark abgeschwächt und fehlt nach Glutathion-Inhibition. N=3, MW $\pm S D$. Getestet mit der One-WayANOVA und der Bonferroni-Methode. Signifikanzniveau * $\mathrm{p}<0,05 ; * * \mathrm{p}<0,01 ; \quad * * * \mathrm{p}<0,001$.

In Abbildung 8 ist dargestellt, dass die Zellproliferation nach Glutathionsynthese-Inhibition durch BSO nach der Stimulation mit IL10 und CPG nur unwesentlich steigerbar war (Abbildung 8 A). Sowohl die Einzelstimulationen als auch die Doppelstimulation mit IL10 und CpG führten zu einem weniger deutlichen Proliferationseffekt im Vergleich zu den Positivkontrollzellen. Die Zellviabilität war trotz der beschriebenen Proliferationsunterschiede relativ konstant (Abbildung 8 B). Lediglich die unstimulierten Zellen zeigten eine leicht reduzierte Viabilität nach der BSO-Zugabe. Eine Glutathionsynthese-Inhibition führte somit zu einem nachweisbaren Einfluss auf die Zellviabilität sowie die Fähigkeit von IL10 und CpG, die Zellproliferation in P493-6-Zellen zu aktivieren. Dieses Ergebnis passt zu der Beobachtung, dass auch $\mathrm{H}_{2} \mathrm{O}_{2}$-behandelte, unstimulierte P493-6- 
Zellen eine reduzierte Zellviabilitiät zeigten (Abschnitt 3.3.1). Nach IL10- und CpG-Stimulation war jedoch trotz Glutathionsynthese-Inhibition keine reduzierte Zellviabilität zu erkennen. Korrelierend mit der geringeren Zellverdopplung war nach der Glutathionsynthese-Inhibition trotz des Wachstums mit Glutamin keine Senkung der ROS-Menge durch IL10 oder die Doppelstimulation zu beobachten (Abbildung 8 C). Nur nach der CpG-Stimulation konnte die ROS-Menge teilweise gesenkt werden. Zudem zeigte sich erneut die bereits beschriebene ROS-Senkung durch IL10 und CpG, die durch einen Glutaminentzug gemindert wurde (vergleiche Abbildung 7). Diese Beobachtungen verdeutlichen, dass neben Glutamin, IL10 und CpG auch das Glutathion und somit der Redoxausgleich relevant für das Zellwachstum und Zellüberleben ist.

\subsubsection{Glutaminabhängig erhöhte Glutathion-Konzentration nach IL10- und

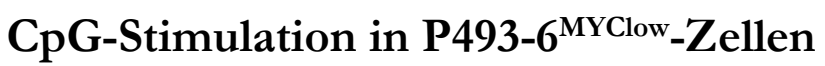

Da deutlich wurde, dass die Glutathionsynthese-Inhibition im Zusammenspiel mit IL10 und CpG sowohl die Zellviabilität als auch das Redoxlevel beeinflusst (Abbildung 8), wurden im Folgenden die Glutathion-Konzentrationen der P493-6 $6^{\text {MYClow }}$-Zellen bestimmt. Dabei wurde zwischen totalem, reduziertem und oxidiertem Glutathion unterschieden, da Glutathion in seiner reduzierten Form als Antioxidans (ROS-Fänger) wirkt. Hierfür wurde dem Zellkulturmedium IV mit P493-6Zellen im $\mathrm{Myc}^{\text {low }}$-Zustand Glukose und/oder Glutamin zugesetzt (siehe Abschnitt 3.3.2). Außerdem wurden die Zellen mit IL10, CpG oder IL10+CpG behandelt oder unbehandelt kultiviert. Mit Hilfe des GSH/GSSG-Glo ${ }^{\text {TM }}$-Assays erfolgte die Analyse des Lumineszenz-Signals im Luminometer, indem eine glutathionabhängige und durch die Glutathion-S-Transferase katalysierte Konversion von Luciferin stattfand. Diese ließ Rückschlüsse auf die Konzentration des Gesamt-Glutathions sowie des oxidierten Glutathions zu, woraufhin das Verhältnis zwischen oxidierter und reduzierter Form bestimmt wurde. 


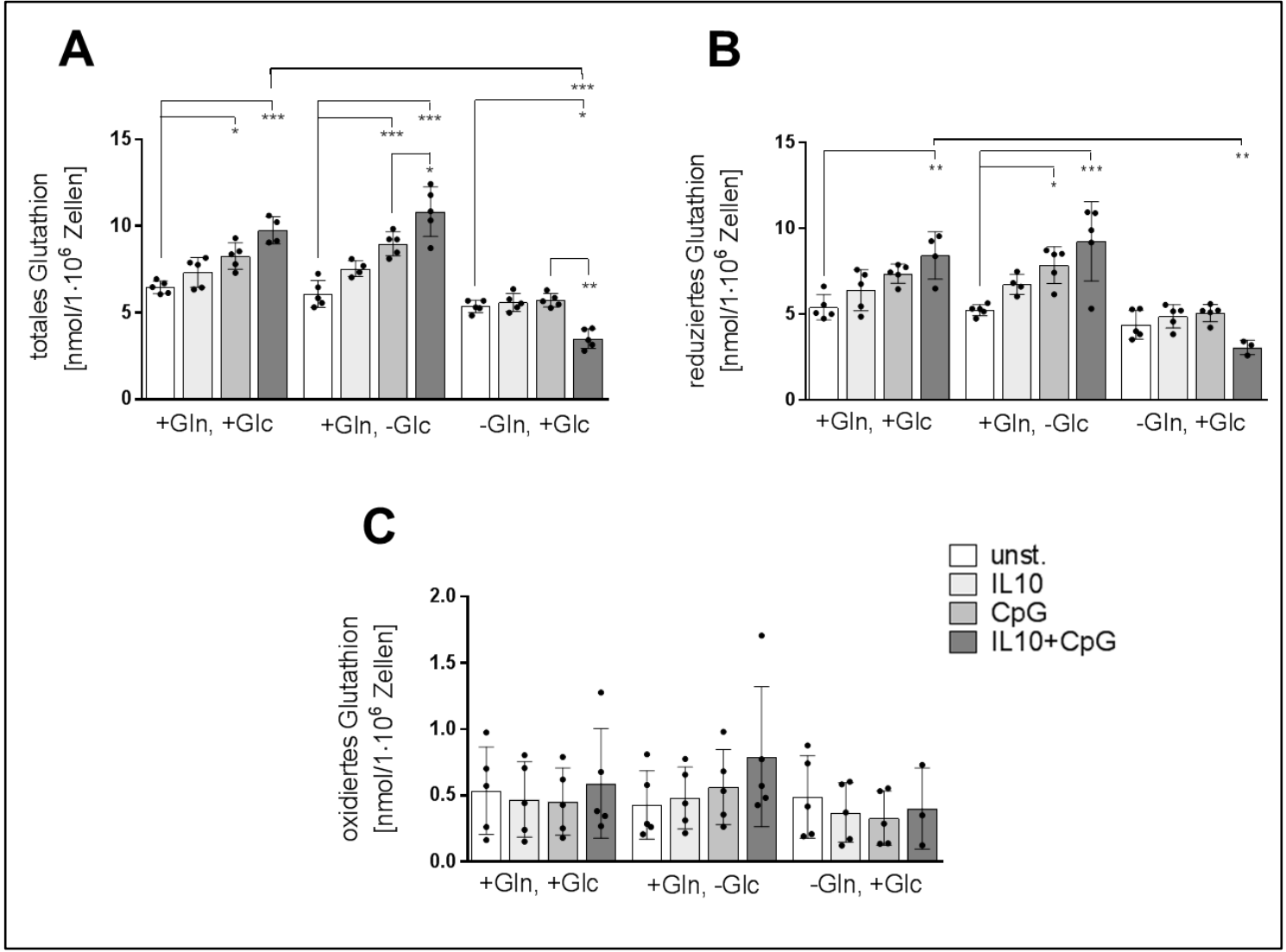

Abbildung 9: Durch die Stimulation mit IL10 und CpG wird glutaminabhängig die Glutathion-Konzentration in P493-6 ${ }^{\text {MYClow-Zellen erhöht }}$

P493-6-Zellen wurden mit Doxycyclin in ihrer MYC-Expression reprimiert und in Zellkulturmedium IV, das weder Glukose noch Glutamin enthält, ausgesät. Nach 24 Stunden wurde zu dem Zellkulturmedium 2 mM Glutamin und/oder $2 \mathrm{~g} / 1$ Glukose hinzugegeben. Zellen im Zellkulturmedium mit Glukose und Glutamin bildeten die Positivkontrolle. Außerdem erfolgte eine Stimulation mit IL10, CpG oder IL10+CpG. (A+B) Totale und reduzierte Glutathion-Konzentration im Luminometer 24 Stunden nach der Stimulation. Anstieg der Konzentration nach IL10- und CpG-Stimulation sowohl ohne Nährstoff- als auch nach Glukoseentzug, wohingegen Glutaminentzug diesen Effekt aufhebt oder sogar noch zu einer Senkung der Konzentration führt. (C) Die Konzentration des oxidierten Glutathions (GSSG) liegt bei $0,5 \mathrm{mmol} / 10^{6}$ Zellen, beträgt somit ca $10 \%$ und verändert sich dementsprechend nur unwesentlich. $\mathrm{N}=5$, MW \pm SD. Getestet mit der One-Way-ANOVA und der Bonferroni-Methode. Signifikanzniveau $\quad * \mathrm{p}<0,05 ; * * \mathrm{p}<0,01$; $* * * \mathrm{p}<0,001$

In Abbildung $9 \mathrm{~A}$ ist dargestellt, dass ein zunehmender Anstieg der Gesamtkonzentration von Glutathion durch die Einzelstimulation mit IL10 oder CpG beobachtet werden konnte, der bei der Doppelstimulation im Vergleich zur unstimulierten Probe am höchsten war. Demnach führte die Stimulation mit IL10 und CpG zu einer Steigerung der Glutathion-Konzentration in den Zellen. Diese GSH-Konzentrationssteigerung war auch zu beobachten, wenn den Zellen keine Glukose zur Verfügung stand. Nach dem Entzug von Glutamin zeigte die Einzelstimulation mit IL10 oder CpG, verglichen mit den unstimulierten Kontrollzellen, keine Veränderung der Konzentration an totalem Glutathion. Nach der Doppelstimulation hingegen kam es zu einem signifikanten Abfall der Glutathion-Konzentration. Dies spricht für einen Verbrauch des noch vorhandenen 
Glutathions, jedoch auch für eine fehlende GSH-Neusynthese. Die Veränderungen in der Konzentration des reduzierten GSH zeigen sich in ähnlicher Form auch in den gemessenen Konzentrationen des totalen Glutathions (Abbildung 9 B). In der parallel durchgeführten Messung der Konzentrationen des oxidierten Glutathions (GSSG) zeigte sich, dass die Konzentration des GSSG bei $0,5 \mathrm{mmol} / 10^{6}$ Zellen lag. Sie betrug somit ca. $10 \%$ der totalen Glutathion-Konzentration (Abbildung 9 C) und veränderte sich mit Ausnahme der Proben, die unter Glutaminentzug gemessen wurde, nur unwesentlich. Die GSSG-Konzentrationen nach Glutaminentzug waren verringert und wurden durch die Stimulationen weiter reduziert (Abbildung 9 C). Die Veränderungen des GSSG zeigten dabei jedoch eine an den Fehlerbalken zu erkennende große Streuung der Ergebnisse und waren somit nur eingeschränkt interpretierbar. Insgesamt führte die IL10- und CpG-Stimulation

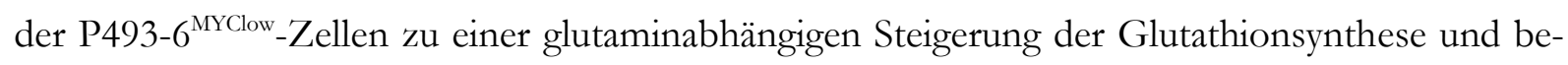
einflusste möglicherweise auch in geringerem Umfang das Verhältnis von Reduktion zu Oxidation des Glutathions.

Insgesamt stellte sich die Senkung der ROS-Menge und die Glutathionsynthese in P493-6 ${ }^{\text {MYClow }}$ Zellen als ein sowohl glutaminabhängiger als auch IL10- und CpG-regulierter Prozess dar. Die Proliferation der Zellinie P493-6 zeigte ebenfalls eine Abhängigkeit von IL10 und CpG. Da, wie im Abschnitt 3.2.1 gezeigt, STAT3 und NF-xB die Genexpression von GOT2 regulieren, sollte als nächstes untersucht werden, inwieweit STAT3 und NF- $x$ B oder GOT2 Einfluss auf die ROSMenge und die Konzentration von Glutathion haben.

\subsubsection{Analyse des Einflusses von GOT2 sowie STAT3 und NF- $x$ B auf die

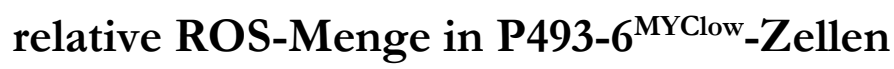

Weder nach GOT2- oder STAT3- und RELA-Knockdown noch nach Glutaminentzug konnte

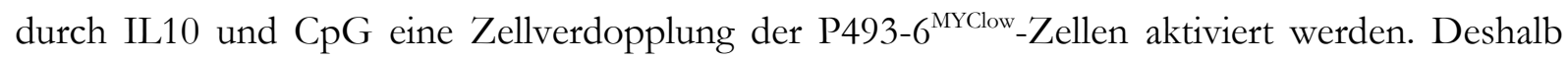
wurde geprüft, ob die relative Menge an reaktiven Sauerstoffspezies der Zellen nach entsprechendem Knockdown verändert ist, was für eine Regulation durch die Transkriptionsfaktoren und somit ggf. auch Korrelation mit der GOT2-Expression sprechen würde. Es wurde postuliert, dass die durch IL10 und CPG stimulierten P493-6-Zellen bei reduzierter Expression von GOT2 oder STAT3/RELA ROS-Mengen aufweisen, die im Bereich der unstimulierten Zellen liegen. 


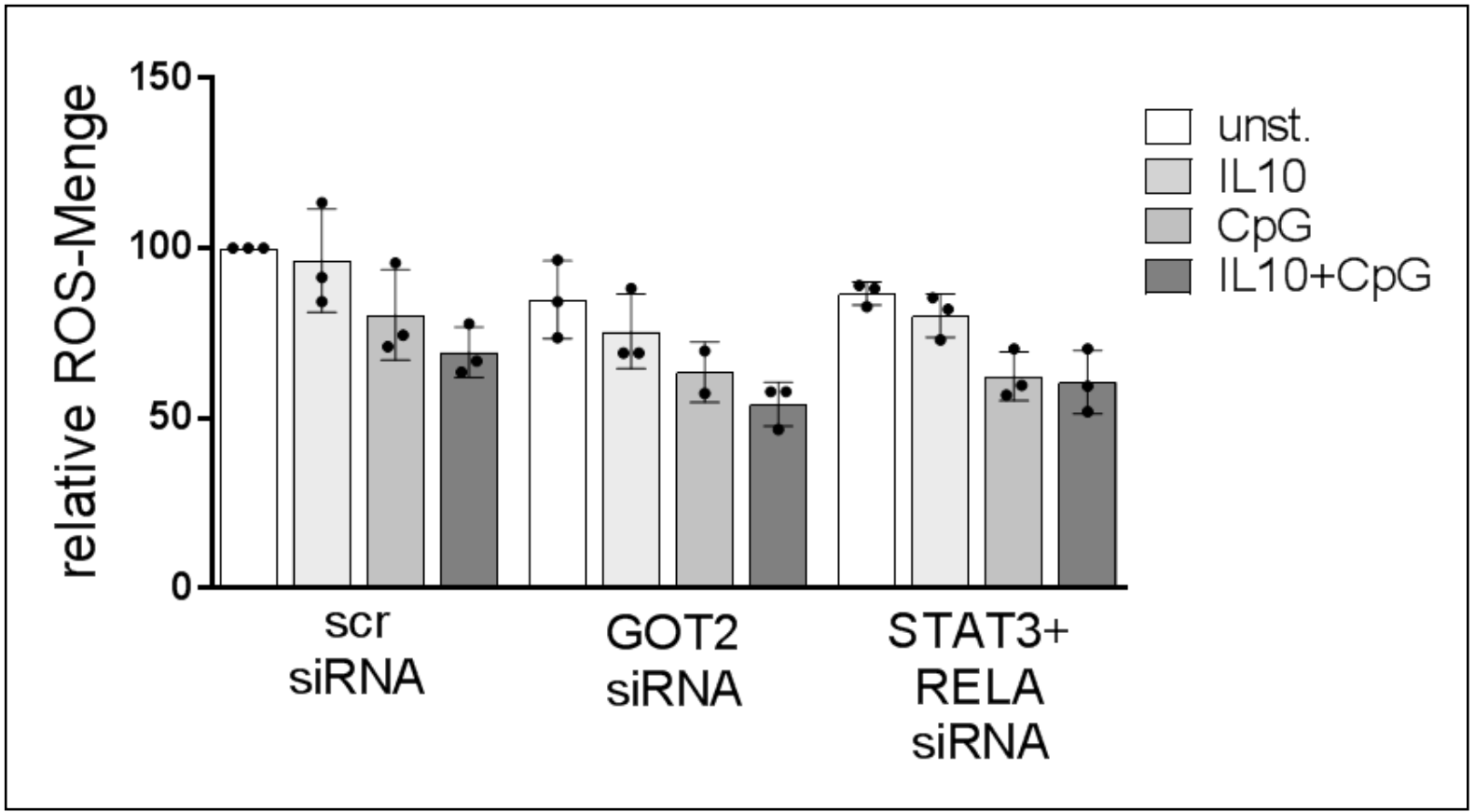

\section{Abbildung 10: Reduzierte ROS-Mengen nach GOT2- oder STAT3- und RELA-Knockdown}

P493-6-Zellen wurden mit $2 \mu \mathrm{g}$ STAT3- und $2 \mu \mathrm{g}$ RELA-siRNA in Kombination oder mit $4 \mu \mathrm{g}$ GOT2 siRNA transfiziert. Als Kontrolle wurden $4 \mu \mathrm{g}$ scr-siRNA verwendet. Die $M Y C$-Expression wurde mit Doxycyclin reprimiert und die Zellen nach 24 und 48 Stunden mit IL10, CpG oder IL10+CpG stimuliert. Abgebildet ist die ROS-Menge im FACS 24 Stunden nach der ersten Stimulation als Mittelwerte der normierten Mediane. Eine Senkung der ROS-Menge durch IL10 und CpG ist nach allen Behandlungen zu erkennen. Dabei ist nach dem Knockdown von GOT2 oder $S T A T 3$ und RELA bereits die ROS-Grundmenge leicht erniedrigt. $\mathrm{N}=3, \mathrm{MW} \pm \mathrm{SD}$.

Wie in Abbildung 10 dargestellt, wurde in mit scr-siRNA transfizierten P493-6 ${ }^{\text {MYClow }}-$ Zellen die relative ROS-Menge durch die Stimulation mit IL10 und/oder CpG reduziert (siehe auch Abschnitt 3.3.2). Deutlich wurde eine Senkung der ROS-Menge durch die IL10- und CpG-Stimulation bis hin zur Doppelstimulation. Trotz GOT2-Knockdown änderte sich jedoch an der Intensität der Reduktion der relativen ROS-Mengen nach Stimulation mit IL10 und CpG nichts im Vergleich zu den scr-Kontrollproben. Interessanterweise waren in den Zellen mit reduzierter GOT2-Proteinmenge gegenüber den entsprechenden scr-Proben bereits basal weniger Sauerstoffradikale zu detektieren. Ein statistischer Vergleich war aufgrund der interexperimentellen Varianz der basalen ROS-Mengen nach Nukleofektion nicht möglich. Auch die gemessenen ROS-Mengen nach der Transfektion mit STAT3- und RELA-siRNA waren möglicherweise schon im unstimulierten Grundzustand gegenüber der scr-transfizierten Zellen erniedrigt, jedoch nicht so deutlich wie nach GOT2-Knockdown. Während die IL10-Stimulation hier kaum zu einer Veränderung der ROSMenge führte, waren die Effekte der CpG- und Doppelstimulation miteinander vergleichbar, ähnlich wie nach dem GOT2-Knockdown. Somit blieb auch nach Transfektion mit GOT2- oder STAT3- und RELA-siRNA der ROS-senkende Effekt von IL10 und CpG erhalten, was unter Berücksichtigung der Ergebnisse der oben dargestellen Analysen so nicht zu erwarten war. GOT2 und STAT3/NF- $x$ B haben somit zwar einen Einfluss auf die ROS-Menge, der IL10- und CpG- 
vermittelte Effekt konnte im Rahmen der durchgeführten Analysen unter den dargestellten experimentellen Bedingungen jedoch nicht mit GOT2 oder STAT3 und NF- $x \mathrm{~B}$ in Verbindung gebracht werden und unsere Hypothese ließ sich somit nicht bestätigen. Um eine mögliche Erklärung für die Diskrepanz der Veränderungen der relativen ROS-Mengen zwischen den BSO-behandelten, IL10- und CpG-stimulierten P493-6-Zellen und den Zellen mit reduzierter GOT2- oder STAT3/RelA-Proteinmenge zu finden, wurden im Folgenden zusätzlich die GSH-Konzentrationen bestimmt.

\subsubsection{Analyse des Einflusses von GOT2 sowie STAT3 und RELA auf die Konzentration des Glutathions in P493-6 ${ }^{\text {MYClow }}-$ Zellen}

P493-6 ${ }^{\text {MYClow }}$-Zellen wurden mit GOT2- oder STAT3- und RELA-siRNA nukleofiziert (siehe Abschnitt 3.1 und 3.3.5). Außerdem wurden die Zellen mit IL10, CpG oder IL10+CpG behandelt oder unbehandelt kultiviert. 24 Stunden nach der Stimulation erfolgte die Analyse der GlutathionKonzentrationen wie im Abschnitt 3.3.4 beschrieben.

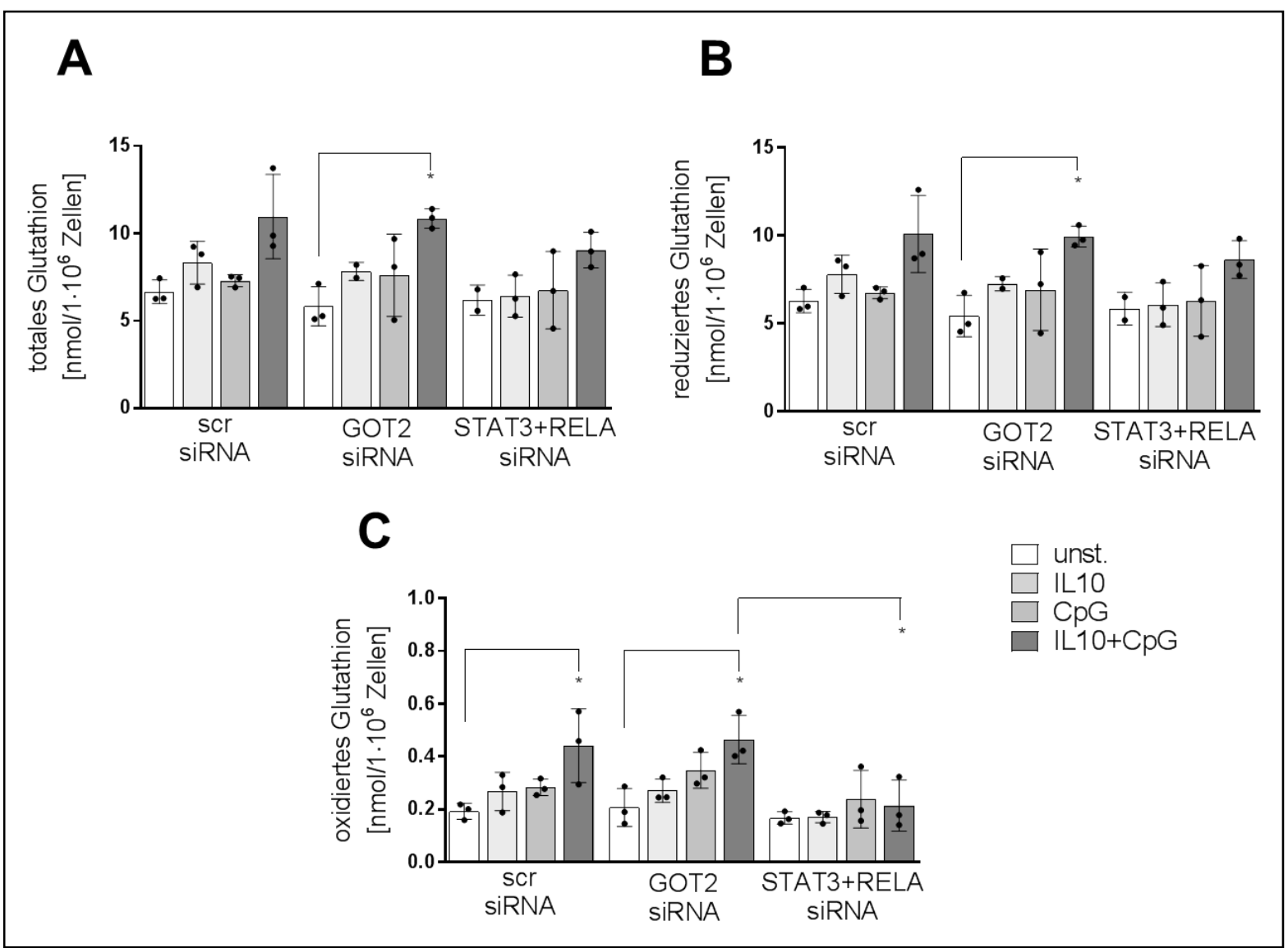




\begin{abstract}
Abbildung 11: Reduzierte Glutathion-Konzentration nach STAT3- und RELA-, aber nicht nach GOT2Knockdown

P493-6-Zellen wurden mit $2 \mu \mathrm{g}$ STAT3- und $2 \mu \mathrm{g}$ RELA-siRNA in Kombination oder mit $4 \mu \mathrm{g}$ GOT2 siRNA transfiziert. Als Kontrolle wurden $4 \mu \mathrm{g}$ scr-siRNA verwendet. Die $M Y C$-Expression wurde mit Doxycyclin reprimiert und die Zellen nach 24 Stunden mit IL10, CpG oder IL10+CpG stimuliert. (A)+(B)+(C) Konzentration von totalem, reduziertem und oxidiertem Glutathion im Luminometer 24 Stunden nach der Stimulation. Die Stimulation mit IL10 und CpG führt zu einer höheren Konzentration an totalem, reduziertem und oxidiertem Glutathion, nach GOT2Knockdown zeigt sich kein Unterschied zur scr-Probe. Nach STAT3+RELA-Knockdown zeigt sich eine im Vergleich zur doppelstimulierten scr-siRNA-Probe niedrigere Glutathion-Konzentration nach Doppelstimulation. $\mathrm{N}=5$, MW $\pm S D$. Getestet mit der One-Way-ANOVA und der Bonferroni-Methode. Signifikanzniveau * $\mathrm{p}<0,05$; $\mathrm{p}<0,01 ; * * * \mathrm{p}<0,001$.
\end{abstract}

In Abbildung $11 \mathrm{~A}$ ist dargestellt, dass ein Anstieg der Gesamtkonzentration von Glutathion durch die Einzelstimulation mit IL10 und noch deutlicher durch die Doppelstimulation beobachtet werden konnte. Demnach führte die Stimulation mit IL10 und CpG zu einer Steigerung der Glutathion-Konzentration in den Zellen nach scr-siRNA-Nukleofektion vergleichbar zu untransfizierten Zellen (vergleiche Abbildung 9). Der Anstieg der Glutathion-Konzentration nach IL10- und CpG-Stimulation innerhalb der Gruppe der mit scr-siRNA transfizierten Zellen war jedoch aufgrund der großen interexperimentellen Varianz nicht signifikant und zeigte keinen Synergismus, was eine Einschätzung der weiteren gemessenen Konzentrationen erschwerte und ihre Aussagekraft stark einschränkte. Dennoch war $\mathrm{zu}$ erkennen, dass die Konzentrationssteigerung des totalen Glutathions auch nach GOT2-Knockdown zu beobachten war. Nach STAT3- und RELA-Knockdown jedoch ließ sich die Konzentration des totalen Glutathions durch die Doppelstimulation mit IL10 und CpG schlechter steigern. Die Veränderungen der Konzentrationen des reduzierten Glutathions folgten in ihrem Verlauf den beschriebenen Konzentrationen des totalen Glutathions (Abbildung 11 B). In den parallel durchgeführten Messungen der Konzentrationen von oxidiertem Glutathion (GSSG) zeigte sich, dass die GSSG-Konzentrationen bei $0,5 \mathrm{mmol} / 10^{6}$ Zellen lagen. Sie betrugen somit ca. $10 \%$ der totalen Glutathion-Konzentration (Abbildung $11 \mathrm{C}$ ) und veränderten sich mit Ausnahme der Proben, die nach STAT- und RELA-Knockdown gemessen wurden, nur unwesentlich. Weniger STAT3- und RelA-Protein führte auch hier zu einem im Vergleich zu den scr-Vergleichsproben weniger durch IL10 und CPG stimulierbaren Konzentrationsanstieg, während der GOT2Knockdown keinen Effekt zeigte. Die Veränderungen des oxidierten Glutathions zeigten dabei jedoch eine an den Fehlerbalken zu erkennende große Streuung der Ergebnisse und waren somit nur eingeschränkt interpretierbar (Abbildung $11 \mathrm{C}$ ). Insgesamt führte die IL10- und CpG-

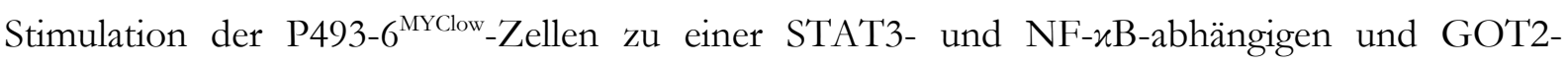
unabhängigen Steigerung der Glutathion-Konzentration und beeinflusste möglicherweise auch in geringerem Umfang das Verhältnis von Reduktion zu Oxidation des Glutathions. 
Bezüglich der ROS-Menge und Glutathion-Konzentration in P493-6 ${ }^{\text {MYClow }}$-Zellen konnte somit zusammenfassend festgestellt werden:

1. Die relativen ROS-Mengen sind glutamin-, aber nicht glukoseabhängig (Abbildung 7)

2. Die Proliferation nach IL10- und CpG-Stimulation und die ROS-Mengen sind abhängig von einer Glutathionsynthese (Abbildung 8)

3. Das totale, reduzierte und oxidierte Glutathion wird glutaminabhängig durch IL10 und CpG reguliert (Abbildung 9)

4. Weder der GOT2-, noch der STAT3- und RELA-Knockdown haben unter den gewählten experimentellen Bedingungen Einfluss auf die IL10- und CpG-vermittelte ROS-Reduktion (Abbildung 10)

5. Der STAT3- und RELA-, aber nicht der GOT2-Knockdown führt zu Veränderungen der Konzentration des totalen, reduzierten und oxidierten Glutathions (Abbildung 11)

Die Glutathionanalysen müssen zukünftig jedoch durch unabhängige Analysen mit noch präziserer Probenernte und -behandlung, zum Beispiel auch unter Sauerstoffentzug, sowie entsprechender Zellkultur unter verschiedenen normoxischen/hypoxischen Bedingungen gestützt werden.

\section{Diskussion}

Eine Hauptfragestellung dieser Arbeit war, ob spezifisch STAT3 und NF- $x$ B/RelA in die IL10und CpG-vermittelte Aktivierung der Zellproliferation von P493-6-Zellen im Myc ${ }^{\text {low }}$-Zustand involviert sind. Zellzahlbestimmungen nach dem Knockdown von STAT3 und der NF-xB-Untereinheit RELA bestätigten in diesem Zusammenhang eine von diesen Transkriptionsfaktoren abhängige Proliferation der IL10- und CpG-stimulierten P493-6 $6^{\text {MYClow }}-$ Zellen (Abbildung 3). Somit konnten die Vorergebnisse der Arbeitsgruppe, bei denen durch den Einsatz chemischer Inhibitoren für IKKs und JAKs eine Rolle für STAT3 und NF-xB/RelA postuliert wurde, wesentlich erweitert werden (Feist 2016). Dies ist wichtig, da aberrantes JAK-STAT- sowie NF- $x$ B-Signaling als ursächlich für eine schlechtere Krankheitsprognose und einen aggressiveren Krankheitsverlauf beschrieben wurden und da erhöhte IL10-Serumkonzentrationen in DLBCLs prognostisch relevant sind (Lech-Maranda et al. 2006; Huang et al. 2013; Ok et al. 2014; Béguelin et al. 2015). Interessanterweise wurde nicht nur eine konstitutive Aktivierung von STAT3 und NF- $x$ B in DLBCLs beschrieben, sondern STAT3 stellt auch in anderen Tumorentitäten wie dem Hepatozellulären Karzinom eine vielversprechende Zielstruktur der spezifischen Tumortherapie dar (Kube et al. 2001; 
Yu und Jove 2004; Compagno et al. 2009; Scuto et al. 2011; Hung et al. 2014; Odqvist et al. 2014). So wurde nach STAT3-Inhibition in DLBCL-Zelllinien bereits eine reduzierte Zellproliferation mit vermehrter Apoptose und weniger Tumorwachstum beobachtet (Ding et al. 2008). NF- $x$ B kann in malignen Zellen neben der Tumorinitiation tumorspezifische Eigenschaften wie Invasion und Metastasierung regulieren (Aggarwal 2004; Inoue et al. 2007; Dong et al. 2007; Ben-Neriah und Karin 2011). In der Literatur beschriebene Mechanismen der tumorspezifischen Proliferationsförderung des NF- $x$ B-Signalwegs sind, neben den bereits genannten Mutationen des TLR-Adaptormoleküls Myd88, in der ABC-Subgruppe der DLBCLs vermehrt zu findende atypische I $\varkappa$ B-Moleküle (Lohr et al. 2012; Nogai et al. 2013). Auch die bereits in Vorarbeiten der Arbeitsgruppe beobachtete synergistische Proliferationssteigerung nach IL10- und CpG-Stimulation wird durch Publikationen gestützt, die sowohl auf Gen- als auch auf Proteinebene eine Kooperation von STAT3 und NFxB beschreiben (Yoshida et al. 2004; Lam et al. 2008; Lee et al. 2009; Grivennikov und Karin 2010).

Vorarbeiten der Arbeitsgruppe zeigten hinsichtlich der vermehrten Zellproliferation unter anderem eine Genexpressionsregulation des Zellzyklusregulators CDK4 durch STAT3 und NF- $x$ B (Feist 2016). Zudem führten durchgeführte Inhibitionsversuche sowie RNA-Sequenzierungen in diesem Zusammenhang zu einer Fokussierung auf das Gen GOT2, sodass sich die Frage ergab, ob GOT2 durch STAT3 und NF- $x$ B / RelA reguliert wird und somit wichtig für die Zellverdopplung der IL10und CpG-stimulierten P493-6 ${ }^{\text {MYClow }}$-Zellen ist (Feist 2016). Als Antwort auf diese Frage konnte mit Hilfe von Knockdowns eine GOT2-Transkriptionsregulation durch STAT3 und NF- $x$ B/RelA nachgewiesen werden (Abbildung 4). Passend zu diesem Ergebnis wurden kürzlich mit Hilfe der Chromatin-Immunpräzipitation (Chromatin Immuno Precipitation, ChIP) Bindestellen für NF- $x \mathrm{~B}$ im Genlokus des Gens GOT2 gefunden (Yang et al. 2013). In weiterführenden Analysen der Arbeitsgruppe konnte mittlerweile eine kooperative Bindung von STAT3 und RelA an den proximalen Promotor von GOT2 nachgewiesen werden (Feist 2016). Weiterhin wichtig ist, dass ein negativer prognostischer Einfluss der GOT2-Expression in DLBCLs beschrieben werden konnte (Feist 2016).

Übereinstimmend mit der Hypothese einer GOT2-beeinflussten Zellproliferation wurde deutlich, dass die Proliferationsförderung der P493-6 MYClow $_{-}$Zellen durch IL10 und CpG nicht nur abhängig von STAT3 und NF-xB, sondern auch von GOT2 ist (Abbildung 5). Für die korrespondierende zytosolische Aspartat-Aminotransferase wurde in anderen Tumoren, wie dem Mammakarzinom, bereits eine proliferationssteigernde Regulation beschrieben (Thornburg et al. 2008). AspartatAminotransferasen wie die GOT2 greifen in die Glutaminolyse der Zellen ein, was sich aufgrund einer demonstrierten Glutaminabhängigkeit der IL10- und CpG-vermittelten Proliferation in P493$6^{\text {MYClow }}$-Zellen gut nachvollziehen lässt (Abbildung 6). Nachdem die Relevanz der Glutaminolyse 
im Tumorzellmetabolismus schon lange Thema der Forschung ist, wurde kürzlich treffenderweise für Malignomzellen und die Zelllinie P493-6 eine verminderte Proliferation nach einem Eingriff in die Glutaminolyse, z. B. durch die Hemmung der Glutaminase, beschrieben (Xiang et al. 2015; Jin et al. 2016). Die tumorspezifische Glutaminase kann sowohl durch Myc, als auch durch NF- $x \mathrm{~B}$ und die RhoGTPase reguliert sein (Wang et al. 2010; Dang et al. 2011). Dies und die hier vorliegenden Befunde deuten darauf hin, dass Myc sehr dominant die Glutaminolyse in transformierten Zellen regulieren kann, es aber auch alternative Regulationsmechanismen und Transkriptionsfaktoren gibt, durch die Glutamin-verstoffwechselnde Enzyme reguliert werden.

Unter Berücksichtigung der bisherigen Beobachtungen entstand die Idee eines Modells, in dem IL10- und CpG-vermittelt eine Koaktivität von STAT3 und NF- $\varkappa$ B/RelA durch die transkriptionelle Regulation von GOT2 zu einer gesteigerten Glutaminolyse beiträgt, um so die Proliferation

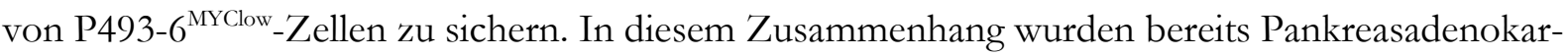
zinomzellen beschrieben, in denen das durch die GOT2 über die Glutaminolyse entstandene Aspartat durch die zytosolische Aspartat-Aminotransferase in Oxalacetat und dieses durch die Malatdehydrogenase (MDH) in Malat umgewandelt wurde (Son et al. 2013). Interessant ist dabei der sich anschließende Umbau zu Pyruvat durch das Malatenzym, der zu einer Entstehung von NADPH führt, das wiederum die Reduktion des Antioxidans GSH begünstigt (Abbildung 2)(Alberghina und Gaglio 2014; Wise und Thompson 2010; Duckwall et al. 2013). Aber auch andere Aminotransferasen dürfen in der Onkogenese nicht außer Acht gelassen werden. Beispielsweise in Kolonkarzinomzellen ist der gesteigerte Glutaminkatabolismus durch eine vermehrte Aktivität der mitochondrialen Alanin-Aminotransferase (Genname: GPT2) reguliert (Smith et al. 2016).

Um sich dennoch im vorgeschlagenen Modell dem Mechanismus der glutaminabhängigen, IL10und CpG-vermittelten Zellproliferation zu nähern, stellte sich im Kontext der beschriebenen Literatur die Frage, ob sich ein Glutaminmangel auf die Fähigkeit des ROS-Umgangs der Zellen auswirkt und welche Rolle Glutathion hierbei möglicherweise spielt. In diesem Zusammenhang wurde zunächst deutlich, dass die Anwesenheit von Glutamin den Zellen ermöglichte, oxidativen Stress mit Hilfe der IL10- und CpG-Stimulation auszugleichen, auch wenn dies unter den gewählten experimentellen Bedingungen der externen Zugabe von $\mathrm{H}_{2} \mathrm{O}_{2}$ nicht vollständig gelang (Abbildung 6). Passend dazu zeigten die Messungen der intrinsischen ROS-Menge der Zellen eine glutaminabhängige und glukoseunabhängige Senkung nach Stimulation mit IL10 und CpG (Abbildung 7). Demnach ist von einer gemeinschaftlich von IL10, CpG sowie Glutamin abhängigen Fähigkeit der Zelle auszugehen, anfallende oder vorhandene radikale Sauerstoffspezies in der Zelle zu reduzieren. Glutathion ist in diesem Zusammenhang ein wichtiges, möglicherweise involviertes Molekül, da GSH in seiner reduzierten Form zu den wichtigsten Radikalfängern zählt 
(Ames et al. 1995; Pham-Huy et al. 2008). Eine durchgeführte Hemmung der Glutamatcysteinligase mit BSO ließ erkennen, dass sowohl die Proliferation der P493-6 $6^{\text {MYClow }}-Z e l l e n$ nach IL10- und CpG-Stimulation als auch die ROS-Konzentration abhängig von der Glutathionsynthese sind (Abbildung 8). Die Glutamatcysteinligase wurde schon vor vielen Jahren mit einer zentralen Rolle in der Therapieresistenz für Tumoren in Verbindung gebracht (Meister 1991). Auch in Therapiestudien $\mathrm{zu}$ verschiedenen Tumoren wurde für eine Verbesserung des Therapieansprechens bereits zusätzlich zur Standardtherapie eine Glutathion-Hemmung mit BSO durchgeführt, was für einen möglichen therapeutischen Nutzen der Glutathionsynthese-Inhibition spricht (Balendiran et al. 2004). Passend dazu wurde in einer Glutathion-Konzentrationsmessung deutlich, dass das totale, reduzierte und oxidierte Glutathion glutaminabhängig durch IL10 und CpG reguliert wird (Abbildung 9). Einschränkend muss jedoch auf die mit nur etwa 1/20 des Gesamt-Glutathions vergleichsweise sehr geringen Konzentrationen an oxidiertem Glutathion hingewiesen werden, die demnach im normalen Schwankungsbereich der Totalwerte lagen und daher nur begrenzt aussagekräftig waren. Insgesamt sprechen diese Beobachtungen dennoch für die Hypothese, dass die Zellen ihre intrinsische ROS-Menge über die beschriebene Regulation von STAT3 und NF- $x$ B glutaminabhängig und mit Hilfe von Antioxidantien wie dem GSH unter der für sie toxischen Grenze halten können. Der Zusammenhang zwischen einer koaktiven GOT2Transkriptionsregulation von STAT3 und NF- $x$ B/RelA mit der Proliferationssicherung der P493$6^{\text {MYClow }}$-Zellen über eine gesteigerte Glutaminolyse und eine vermehrte ROS-Reduktion muss jedoch unter den dargestellten experimentellen Bedingungen insofern differenziert betrachtet werden, als in dieser Arbeit beschriebene, veränderte Glutathion-Konzentrationen zwar nach STAT3- und RELA-, nicht aber nach GOT2-Knockdown gezeigt werden konnten (Abbildung 11). Es muss jedoch angemerkt werden, dass aufgrund der großen interindividuellen Varianz der Ergebnisse nach der Nukleofektion und somit einer nicht möglichen statistischen Auswertung dieses Ergebnis zum jetzigen Zeitpunkt nicht verallgemeinert werden kann. Überraschenderweise war mit Ausnahme einer erniedrigten Basalmenge kein Einfluss eines GOT2-, STAT3- und RELAKnockdowns auf die IL10- und CpG-vermittelte ROS-Reduktion nachweisbar (Abbildung 10). Eine mögliche Erklärung hierfür ist, dass nukleofizierte Zellen aufgrund des insgesamt erhöhten Stresslevels nicht reproduzierbar für anschließende ROS-Konzentrationsmessungen geeignet sein könnten. Weiterhin müssen sicherlich noch Verfeinerungen in der Technik der Probenernte getestet werden, um die Glutathion-Analysen nachhaltiger auswerten zu können. Hierzu müssen zukünftig eine noch präzisere Probenernte und -behandlung, beispielsweise unter Sauerstoffentzug, sowie Zellkultur unter verschiedenen normoxischen/hypoxischen Bedingungen verglichen werden. Zudem wäre als Ergänzung und zur besseren Trennung der Glutathionsynthese und -reduktion eine Untersuchung der Enzyme Glutamatcysteinligasen und Glutathion-Synthetase 
sinnvoll, für die bereits eine Regulation durch NF- $x$ B beschrieben wurde (Lu 2014). RNASequenzierungen der Arbeitsgruppe zeigten sowohl eine Aktivierung der Glutathion-Synthetase und einer Untereinheit der Glutamatcysteinligase, als auch eine Aktivierung der GlutathionPeroxidase durch IL10 und CpG (Feist 2016). Die Glutathion-Reduktase hingegen wird nicht durch IL10 und CPG reguliert, sodass die Daten insgesamt mehr für eine vermehrte GlutathionSynthese als für eine vermehrte Reduktion sprechen (Feist 2016). In zukünftigen Analysen sollte des Weiteren das Thioredoxinsystem berücksichtigt werden, das ein weiteres wichtiges antioxidatives System in der Zelle darstellt (Kiebala et al. 2015). Deutlich wird zudem, dass das vorgeschlagene Modell eine sehr vereinfachte Idee in dem komplexen metabolischen Netzwerk der Zelle darstellt. Auch die mitochondriale GOT2 katalysiert eine Reaktion, die eine Schnittstelle der Glutaminolyse zwischen mitochondrialer Atmung und der Verwertung im Zytosol bildet. Während sich in der Literatur in Myc-abhängigen Tumoren Kohlenstoffatome des Glutamins in Metaboliten des Citratzyklus detektieren ließen, zeigten Ergebnisse der Arbeitsgruppe in diesem Zusammenhang, dass markierte Glutaminmoleküle nach IL10- und CpG-Stimulation auch durch vermehrte Nukleotid-Neusynthese und Aspartat-Synthese proliferationsfördernd sind (Yang et al. 2009; Anso et al. 2013; Feist 2016). Weitergehende Untersuchungen wie NADPH-Messungen, Differenzierungen zwischen mitochondrialem und zytosolischem ROS und Glutathion, IsotopenMarkierung des Glutamins zur Verfolgung des Abbauweges nach IL10- und CpG-Stimulationen sowie Messungen des Sauerstoffverbrauchs und pH-Wertes der Zelle mit Hilfe eines ExtracellularFlux(XF)-Analysegerätes könnten zum Gesamtverständnis beitragen. Letztendlich wäre ein nötiger weiterer Schritt die Übertragung der gewonnenen Erkenntnisse auf andere Zelllinien mit aberranter NF- $x$ B- und STAT3-Aktivierung sowie auf aggressive NHL-Zellen.

In dieser Arbeit wurde erstmalig gezeigt, dass die durch IL10- und CpG-vermittelte Proliferation der P493-6 ${ }^{\text {MYClow }-Z e l l e n ~ S T A T 3-~ u n d ~ N F-~} x$ B/RelA-abhängig ist. Weiterhin wurde erstmalig deutlich, dass die GOT2 durch STAT3 und RelA reguliert wird und wichtig für die Zellverdopplung der IL10- und CpG- stimulierten P493-6 MYClow $_{-Z}$ Zellen ist. Zudem wurde gezeigt, dass ein Glutaminmangel die Fähigkeit der Zellen einschränkt, mit ROS umzugehen, und dass Glutathion hierbei eine wichtige Rolle spielen kann.

\section{Zusammenfassung}

Die bedeutenden Therapiefortschritte durch kombinierte Immunochemotherapie für Patienten mit DLBCL als häufigstem Vertreter der aggressiven Non-Hodgkin Lymphome dürfen nicht darüber hinwegtäuschen, dass einige Patientin nicht von diesen Behandlungsmöglichkeiten profitieren 
und die Chemotherapie nach wie vor starke Nebenwirkungen aufweist. Somit ist ein besseres Verständnis onkogener Signalwege auch für eine verbesserte dosisreduzierte sowie individualisierte und gezielte Tumortherapie wichtig (Buske et al. 2017). Das tiefere Verständnis des tumorbedingt veränderten Zellmetabolismus kann hierbei zur Identifizierung spezifischer Angriffspunkte in Lymphomzellen beitragen (Hanahan und Weinberg 2011; Dang 2012). Als Modell für aggressive B-Zell-Lymphome mit komplexer Tumormikroumgebung und/oder onkogenem Signalnetzwerk diente die Modellzelllinie P493-6, um die Relevanz der Transkriptionsfaktoren STAT3 und NF- $x$ B bezüglich der Proliferation und Genexpression sowie der Modulation des Glutaminmetabolismus und der Redoxbalance zu untersuchen.

STAT3 und NF- $x$ B/RelA wurden als wichtige, durch IL10 und CpG aktivierte Transkriptionsfaktoren identifiziert, welche die Proliferation in der Modellzellreihe P493-6 im Myc ${ }^{\text {low }}$-Zustand regulieren. Zudem zeigte sich eine STAT3- und NF- $x$ B/RelA-vermittelte Transkriptionsregulation des in die Glutaminolyse und Zellproliferation involvierten Gens GOT2. Des Weiteren wurde die Relevanz der Glutaminolyse in einer IL10- und CpG-vermittelten Glutaminabhängigkeit der Proliferation offensichtlich. Somit konnte ein Modell vorgeschlagen werden, in dem IL10- und CPGvermittelt eine Koaktivität von STAT3 und NF- $x$ B/RelA durch die transkriptionelle Regulation von GOT2 zu einer gesteigerten Glutaminolyse und Zellproliferation beiträgt. Dieses Modell muss jedoch in der Zukunft auch darauf hin geprüft werden, ob es genau so oder ähnlich auch im Kontext aberranter STAT3- und NF- $x$ B-Koaktivität in verschiedenen Lymphomentitäten anwendbar ist. Bezüglich der ROS-Menge und Glutathion-Konzentration in P493-6 ${ }^{\text {MYClow }}$-Zellen kann zusammenfassend festgestellt werden, dass die Proliferation nach IL10- und CpG-Stimulation und die ROS-Mengen in Abhängigkeit von Glutamin und der Glutathionsynthese stehen. Überraschenderweise hatten weder der GOT2- noch der STAT3- und RELA-Knockdown unter den gewählten experimentellen Bedingungen Einfluss auf die IL10- und CpG- vermittelte ROSReduktion. Insgesamt geben die gewonnenen Ergebnisse einen Einblick in den Metabolismus der P493-6-Zellen mit einer besonderen Relevanz von STAT3 und NF- $x$ B im Hinblick auf die B-ZellProliferation und -Transformation. Dieses Wissen und mögliche Parallelen zum Lymphommetabolismus können in Zukunft gegebenenfalls zur Entwicklung neuer selektiver Tumortherapien beitragen. 


\section{Literaturverzeichnis}

Aggarwal BB (2004): Nuclear factor-kappaB: The enemy within. Cancer Cell $\underline{6}$, 203-208

Al-Hamadani M, Habermann TM, Cerhan JR, Macon WR, Maurer MJ, Go RS (2015): Non-

Hodgkin lymphoma subtype distribution, geodemographic patterns, and survival in the US: A longitudinal analysis of the National Cancer Data Base from 1998 to 2011. Am J Hematol 90, $790-795$

Alberghina L, Gaglio D (2014): Redox control of glutamine utilization in cancer. Cell Death Dis $\underline{5}, \mathrm{e} 1561$

Aldinucci D, Gloghini A, Pinto A, De Filippi R, Carbone A (2010): The classical Hodgkin's lymphoma microenvironment and its role in promoting tumour growth and immune escape. J Pathol 221, 248-263

Alizadeh AA, Eisen MB, Davis RE, Ma C, Lossos IS, Rosenwald A, Boldrick JC, Sabet H, Tran T, Yu X, et al. (2000): Distinct types of diffuse large B-cell lymphoma identified by gene expression profiling. Nature $\underline{403}, 503-511$

Ames BN, Gold LS, Willett WC (1995): The causes and prevention of cancer. Proc Natl Acad Sci U S A $\underline{92}, 5258-5265$

Anso E, Mullen AR, Felsher DW, Matés JM, DeBerardinis RJ, Chandel NS (2013): Metabolic changes in cancer cells upon suppression of MYC. Cancer Metab $\underline{1}, 7$

Balendiran GK, Dabur R, Fraser D (2004): The role of glutathione in cancer. Cell Biochem Funct 22, 343-352

Barrans S, Crouch S, Smith A, Turner K, Owen R, Patmore R, Roman E, Jack A (2010): Rearrangement of MYC Is Associated With Poor Prognosis In Patients With Diffuse Large B-Cell Lymphoma Treated in the Era of Rituximab. J Clin Oncol 28, 3360-3365

Baud V, Karin M (2009): Is NF-kappaB a good target for cancer therapy? Hopes and pitfalls. Nat Rev Drug Discov $\underline{8}, 33-40$

Béguelin W, Sawh S, Chambwe N, Chan FC, Jiang Y, Choo J-W, Scott DW, Chalmers A, Geng $\mathrm{H}$, Tsikitas L, et al. (2015): IL10 receptor is a novel therapeutic target in DLBCLs. Leukemia 29, 1684-1694

Ben-Neriah Y, Karin M (2011): Inflammation meets cancer, with NF- $x$ B as the matchmaker. Nat Immunol $\underline{12}, 715-723$

Blasius AL, Beutler B (2010): Intracellular Toll-like Receptors. Immunity $\underline{32}$, 305-315

Blinder V, Fisher SG (2008): The Role of Environmental Factors in the Etiology of Lymphoma. Cancer Invest 26, 306-316

Bollrath J, Greten FR (2009): IKK/NF-xB and STAT3 pathways: central signalling hubs in inflammation-mediated tumour promotion and metastasis. EMBO Rep 10, 1314-1319

Bours V, Villalobos J, Burd PR, Kelly K, Siebenlist U (1990): Cloning of a mitogen-inducible gene encoding a $x \mathrm{~B}$ DNA-binding protein with homology to the rel oncogene and to cellcycle motifs. Nature $\underline{348}, 76-80$

Brand K (1985): Glutamine and glucose metabolism during thymocyte proliferation. Pathways of glutamine and glutamate metabolism. Biochem J 228, 353-361 
Bromberg J (2002): Stat proteins and oncogenesis. J Clin Invest 109, 1139-1142

Buske C, Hutchings M, Ladetto M, Goede V, Mey U, Soubeyran P, Spina M, Stauder R, Trnený M, Wedding U, et al. (2017): ESMO Consensus Conference on malignant lymphoma: general perspectives and recommendations for the clinical management of the elderly patient with malignant lymphoma. Ann Oncol $\underline{0}, 1-19$

Cairns RA, Harris IS, Mak TW (2011): Regulation of cancer cell metabolism. Nat Rev Cancer 11 , 85-95

Caro P, Kishan AU, Norberg E, Stanley IA, Chapuy B, Ficarro SB, Polak K, Tondera D, Gounarides J, Yin H, et al. (2012): Metabolic Signatures Uncover Distinct Targets in Molecular Subsets of Diffuse Large B-Cell Lymphoma. Cancer Cell 22, 547-560

Choi J-W, Kim Y, Lee J-H, Kim Y-S (2013): MYD88 expression and L265P mutation in diffuse large B-cell lymphoma. Hum Pathol 44, 1375-1381

Compagno M, Lim WK, Grunn A, Nandula S V, Brahmachary M, Shen Q, Bertoni F, Ponzoni M, Scandurra M, Califano A, et al. (2009): Mutations of multiple genes cause deregulation of NF- $x \mathrm{~B}$ in diffuse large B-cell lymphoma. Nature $\underline{459}, 717-721$

Dang C V (2012): Links between metabolism and cancer. Genes Dev 26, 877-890

Dang C V, Hamaker M, Sun P, Le A, Gao P (2011): Therapeutic Targeting of Myc-Reprogrammed Cancer Cell Metabolism. J Mol Med 무, 205-212

Darnell JE, Kerr IM, Stark GR (1994): Jak-STAT Pathways and Transcriptional Activation in Response to IFNs and Other Extracellular Signaling Proteins. Science 264, 1415-1421

Davis RE, Brown KD, Siebenlist U, Staudt LM (2001): Constitutive Nuclear Factor $x$ B Activity Is Required for Survival of Activated B Cell-like Diffuse Large B Cell Lymphoma Cells. J Exp Med 194, 1861-1874

DeBerardinis RJ, Cheng T (2010): Q's next: The diverse functions of glutamine in metabolism, cell biology and cancer. Oncogene 29, 313-324

DeBerardinis RJ, Mancuso A, Daikhin E, Nissim I, Yudkoff M, Wehrli S, Thompson CB (2007): Beyond aerobic glycolysis: transformed cells can engage in glutamine metabolism that exceeds the requirement for protein and nucleotide synthesis. Proc Natl Acad Sci U S A $\underline{104}, 19345-19350$

DeBerardinis RJ, Lum JJ, Hatzivassiliou G, Thompson CB (2008): The Biology of Cancer: Metabolic Reprogramming Fuels Cell Growth and Proliferation. Cell Metab 7, 11-20

Didonato JA, Mercurio F, Karin M (2012): NF- $x$ B and the link between inflammation and cancer. Immunol Rev 246, 379-400

Ding BB, Yu JJ, Yu RY, Mendez LM, Shaknovich R, Zhang Y, Cattoretti G, Ye BH (2008): Constitutively activated STAT3 promotes cell proliferation and survival in the activated Bcell subtype of diffuse large B-cell lymphomas. Blood 111, 1515-1524

Dong R, Wang Q, He XL, Chu YK, Lu JG, Ma QJ (2007): Role of nuclear factor kappa B and reactive oxygen species in the tumor necrosis factor-alpha-induced epithelial-mesenchymal transition of MCF-7 cells. Braz J Med Biol Res 40, 1071-1078

Duckett CS (2002): Apoptosis and NF- xB: the FADD connection. J Clin Invest 109, 579-580

Duckwall CS, Murphy TA, Young JD (2013): Mapping cancer cell metabolism with ${ }^{13} \mathrm{C}$ flux analysis: Recent progress and future challenges. J Carcinog 12, 13

Dutta P, Le A, Vander Jagt DL, Tsukamoto T, Martinez G V, Dang C V, Gillies RJ (2013): 
Evaluation of $\mathrm{LDH}-\mathrm{A}$ and glutaminase inhibition in vivo by hyperpolarized ${ }^{13} \mathrm{C}$-pyruvate magnetic resonance spectroscopy of tumors. Cancer Res $\underline{73}$, 4190-4195

Feist M: Synergism of IL10R and TLR9 signaling affects gene expression, proliferation and metabolism in B cells: A comparative study of STAT3/NF- $x$ B and c-Myc mediated effects. Naturwissenschaftliche Diss. Göttingen 2016

Feist M, Kemper J, Taruttis F, Rehberg T, Engelmann JC, Gronwald W, Hummel M, Spang R, Kube D (2017): Synergy of interleukin 10 and toll-like receptor 9 signalling in B cell proliferation: Implications for lymphoma pathogenesis. Int J Cancer 140, 1147-1158

Ferlay J, Steliarova-Foucher E, Lortet-Tieulent J, Rosso S, Coebergh JWW, Comber H, Forman D, Bray F (2013): Cancer incidence and mortality patterns in Europe: estimates for 40 countries in 2012. Eur J Cancer 49, 1374-1403

Ghielmini M, Vitolo U, Kimby E, Montoto S, Walewski J, Pfreundschuh M, Federico M, Hoskin P, McNamara C, Caligaris-Cappio F, et al. (2013): ESMO Guidelines consensus conference on malignant lymphoma 2011 part 1: diffuse large B-cell lymphoma (DLBCL), follicular Lymphoma (FL) and chronic lymphocytic leukemia (CLL). Ann Oncol 24, 561-576

Ghosh S, Baltimore D (1990): Activation in vitro of NF- $x$ B by phosphorylation of its inhibitor IxB. Nature $\underline{344}, 678-682$

Ghosh S, Gifford AM, Riviere LR, Tempst P, Nolan GP, Baltimore D (1990): Cloning of the p50 DNA Binding Subunit of NF-xB: Homology to rel and dorsal. Cell $\underline{62}$, 1019-1029

Glass B, Ziepert M, Reiser M, Freund M, Trümper L, Metzner B, Feller A, Loeffler M, Pfreundschuh M, Schmitz N (2010): High-dose therapy followed by autologous stem-cell transplantation with and without rituximab for primary treatment of high-risk diffuse large B-cell lymphoma. Ann Oncol 21, 2255-2261

Grivennikov S, Karin M (2010): Dangerous liaisons: STAT3 and NF- $x$ B collaboration and crosstalk in cancer. Cytokine $\underline{21}, 11-19$

Gupta M, Han JJ, Stenson M, Maurer M, Wellik L, Hu G, Ziesmer S, Dogan A, Witzig TE (2012): Elevated serum IL-10 levels in diffuse large B-cell lymphoma: a mechanism of aberrant JAK2 activation. Blood 119, 2844-2853

Guttridge DC, Albanese C, Reuther JY, Pestell RG, Baldwin AS (1999): NF- $x$ B Controls Cell Growth and Differentiation through Transcriptional Regulation of Cyclin D1. Mol Cell Biol $\underline{19}, 5785-5799$

Hanahan D, Weinberg RA (2000): The Hallmarks of Cancer. Cell 100, 57-70

Hanahan D, Weinberg RA (2011): Hallmarks of Cancer: The Next Generation. Cell 144, 646-674

He G, Karin M (2011): NF- $x$ B and STAT3 - key players in liver inflammation and cancer. Cell Res $\underline{21}, 159-168$

Hemmi H, Takeuchi O, Kawai T, Kaisho T, Sato S, Sanjo H, Matsumoto M, Hoshino K, Wagner H, Takeda K, Akira S (2000): A Toll-like receptor recognizes bacterial DNA. Nature $\underline{408}$, $740-745$

Hodgkin T (1832): On some Morbid Appearances of the Absorbent Glands and Spleen. Med Chir Trans 17, 68-114

Horn H, Ziepert M, Becher C, Barth TFE, Bernd H, Feller AC, Klapper W, Hummel M, Stein H, Hansmann M, et al. (2013): MYC status in concert with BCL2 and BCL6 expression predicts outcome in diffuse large B-cell lymphoma. Blood 121, 2253-2263

Huang X, Meng B, Iqbal J, Ding BB, Perry AM, Cao W, Smith LM, Bi C, Jiang C, Greiner TC, et 
al. (2013): Activation of the STAT3 Signaling Pathway Is Associated With Poor Survival in Diffuse Large B-Cell Lymphoma Treated With R-CHOP. J Clin Oncol 31, 4520-4528

Hung M-H, Tai W-T, Shiau C-W, Chen K-F (2014): Downregulation of signal transducer and activator of transcription 3 by sorafenib: a novel mechanism for hepatocellular carcinoma therapy. World J Gastroenterol 20, 15269-15274

Inoue J, Gohda J, Akiyama T, Semba K (2007): NF-xB activation in development and progression of cancer. Cancer Sci $\underline{98}, 268-274$

Ishii KJ, Akira S (2006): Innate immune recognition of, and regulation by, DNA. Trends Immunol 27, 525-532

Jezierska-Drutel A, Rosenzweig SA, Neumann CA (2013): Role of Oxidative Stress and the Microenvironment in Breast Cancer Development and Progression. Adv Cancer Res $\underline{119}, 107-$ 125

Jin L, Alesi G, Kang S (2016): Glutaminolysis as a target for cancer therapy. Oncogene 35, 3619_ 3625

Kalinina E V, Chernov NN, Novichkova MD (2014): Role of Glutathione, Glutathione Transferase, and Glutaredoxin in Regulation of Redox-Dependent Processes. Biochem $\underline{79}$, 1562-1583

Kawai T, Akira S (2010): The role of pattern-recognition receptors in innate immunity: update on Toll-like receptors. Nat Immunol 11, 373-384

Kiebala M, Skalska J, Casulo C, Brookes PS, Peterson DR, Hilchey SP, Dai Y, Grant S, Maggirwar SB, Bernstein SH (2015): Dual Targeting of the Thioredoxin and Glutathione Anti-Oxidant Systems in Malignant B-Cells; A Novel Synergistic Therapeutic Approach. Exp Hematol 43, 89-99

Krieg AM, Yi A-K, Matson S, Waldschmidt TJ, Bishop GA, Teasdale R, Koretzky GA, Klinman DM (1995): CpG motifs in bacterial DNA trigger direct B-cell activation. Nature $\underline{374}$, 546549

Kube D, Holtick U, Vockerodt M, Ahmadi T, Haier B, Behrmann I, Heinrich PC (2001): STAT3 is constitutively activated in Hodgkin cell lines. Blood $\underline{98}, 762-770$

Lam LT, Wright G, Davis RE, Lenz G, Farinha P, Dang L, Chan JW, Rosenwald A, Gascoyne RD, Staudt LM (2008): Cooperative signaling through the signal transducer and activator of transcription 3 and nuclear factor- $x \mathrm{~B}$ pathways in subtypes of diffuse large B-cell lymphoma. Blood 111, 3701-3713

Le A, Lane AN, Hamaker M, Bose S, Gouw A, Barbi J, Tsukamoto T, Rojas CJ, Slusher BS, Zhang H, et al. (2012): Glucose-Independent Glutamine Metabolism via TCA Cycling for Proliferation and Survival in B Cells. Cell Metab $\underline{15}, 110-121$

Lech-Maranda E, Bienvenu J, Michallet A-S, Houot R, Robak T, Coiffier B, Salles G (2006): Elevated IL-10 plasma levels correlate with poor prognosis in diffuse large B-cell lymphoma. Eur Cytokine Netw 17, 60-66

Lee H, Herrmann A, Deng J, Kujawski M, Niu G, Li Z, Forman S, Jove R, Pardoll DM, Yu H (2009): Persistently activated Stat 3 maintains constitutive NF- $x$ B activity in tumors. Cancer Cell $\underline{15}, 283-293$

Lenardo MJ, Baltimore D (1989): NF-xB: A Pleiotropic Mediator of Inducible and Tissue-Specific Gene Control. Cell $\underline{58}, 227-229$

Lenz G, Wright G, Dave SS, Xiao W, Powell J, Zhao H, Xu W, Tan B, Goldschmidt N, Iqbal J, 
et al. (2008): Stromal Gene Signatures in Large-B-Cell Lymphomas. N Engl J Med $\underline{359}$, $2313-2323$

Lim K, Staudt LM (2013): Toll-Like Receptor Signaling. Cold Spring Harb Perspect Biol $\underline{5}$, a011247

Liu W, Le a., Hancock C, Lane a. N, Dang C V., Fan TW-M, Phang JM (2012): Reprogramming of proline and glutamine metabolism contributes to the proliferative and metabolic responses regulated by oncogenic transcription factor c-MYC. Proc Natl Acad Sci USA $\underline{109}$, 8983-8988

Lohr JG, Stojanov P, Lawrence MS, Auclair D, Chapuy B, Sougnez C, Cruz-Gordillo P, Knoechel B, Asmann YW, Slager SL, et al. (2012): Discovery and prioritization of somatic mutations in diffuse large B-cell lymphoma (DLBCL) by whole-exome sequencing. Proc Natl Acad Sci U S A $\underline{109}$, 3879-3884

Lu SC (2014): Glutathione Synthesis. Biochim Biophys Acta 1830, 3143-3153

Marnett LJ (2000): Oxyradicals and DNA damage. Carcinogenesis 21, 361-370

Martelli M, Ferreri AJM, Agostinelli C, Di Rocco A, Pfreundschuh M, Pileri SA (2013): Diffuse large B-cell lymphoma. Crit Rev Oncol Hematol 구, 146-171

Meister A (1991): Glutathione deficiency produced by inhibition of its synthesis, and its reversal; applications in research and therapy. Pharmacol Ther $\underline{51}, 155-194$

Mercurio F, Zhu H, Murray BW, Shevchenko A, Bennett BL, Li J, Young DB, Barbosa M, Mann M, Manning A, Rao A (1997): IKK-1 and IKK-2: Cytokine-Activated I $\varkappa$ B Kinases Essential for NF- $x$ B Activation. Science $278,860-866$

Meyer N, Penn LZ (2008): Reflecting on 25 years with MYC. Nat Rev Cancer $\underline{8}$, 976-990

Mondello P, Younes A (2015): Emerging drugs for diffuse large B-cell lymphoma. Expert Rev Anticancer Ther 15, 439-451

Monti S, Savage KJ, Kutok JL, Feuerhake F, Kurtin P, Mihm M, Wu B, Pasqualucci L, Neuberg D, Aguiar RCT, et al. (2005): Molecular profiling of diffuse large B-cell lymphoma identifies robust subtypes including one characterized by host inflammatory response. Blood $\underline{105}$, 1851-1561

Naresh KN, Srinivas V, Soman CS (2000): Distribution of various subtypes of non-Hodgkin's lymphoma in India: a study of 2773 lymphomas using R.E.A.L. and WHO Classifications. Ann Oncol 11, 63-67

Newsholme EA, Crabtree B, Ardawi MS (1985): Glutamine metabolism in lymphocytes: its biochemical, physiological and clinical importance. QJ Exp Physiol 70, 473-489

Ngo VN, Young RM, Schmitz R, Jhavar S, Xiao W, Lim K-H, Kohlhammer H, Xu W, Yang Y, Zhao H, et al. (2011): Oncogenically active MYD88 mutations in human lymphoma. Nature $\underline{470}, 115-119$

Nogai H, Wenzel S-S, Hailfinger S, Grau M, Kaergel E, Seitz V, Wollert-Wulf B, Pfeifer M, Wolf A, Frick M, et al. (2013): I $x \mathrm{~B}-\zeta$ controls the constitutive NF- $\varkappa \mathrm{B}$ target gene network and survival of ABC DLBCL. Blood 122, 2242-50

Odqvist L, Montes-Moreno S, Sánchez-Pacheco RE, Young KH, Martín-Sánchez E, Cereceda L, Sánchez-Verde L, Pajares R, Mollejo M, Fresno MF, et al. (2014): NFxB expression is a feature of both activated B-cell-like and germinal center B-cell-like subtypes of diffuse large B-cell lymphoma. Mod Pathol 27, 1331-1337

Ok CY, Chen J, Xu-Monette ZY, Tzankov a., Manyam GC, Li L, Visco C, Montes-Moreno S, 
Dybkaer K, Chiu a., et al. (2014): Clinical Implications of Phosphorylated STAT3

Expression in De Novo Diffuse Large B-cell Lymphoma. Clin Cancer Res 20, 5113-5123

Pajic A, Spitkovsky D, Christoph B, Kempkes B, Schuhmacher M, Staege MS, Brielmeier M, Ellwart J, Kohlhuber F, Bornkamm GW, et al. (2000): Cell cycle activation by c-myc in a Burkitt lymphoma model cell line. Int J Cancer $\underline{87}, 787-793$

Peng X, Gandhi V (2012): ROS-activated anticancer prodrugs: a new strategy for tumor-specific damage. Ther Deliv $\underline{3}, 823-833$

Pfreundschuh M, Kuhnt E, Trümper L, Österborg A, Trneny M, Shepherd L, Gill DS, Walewski J, Pettengell R, Jaeger U, et al. (2011): CHOP-like chemotherapy with or without rituximab in young patients with good-prognosis diffuse large-B-cell lymphoma: 6-year results of an open-label randomised study of the MabThera International Trial (MInT) Group. Lancet Oncol 12, 1013-1022

Pham-Huy LA, He H, Pham-Huy C (2008): Free Radicals, Antioxidants in Disease and Health. Int J Biomed Sci 4 , 89-96

Poli V, Camporeale A (2015): STAT3-Mediated Metabolic Reprograming in Cellular Transformation and Implications for Drug Resistance. Front Oncol $\underline{5}, 1-9$

Rawlings JS, Rosler KM, Harrison D a (2004): The JAK/STAT signaling pathway. J Cell Sci 117, $1281-1283$

Régnier CH, Song HY, Gao X, Goeddel D V, Cao Z, Rothe M (1997): Identification and Characterization of an IxB kinase. Cell $\underline{90}, 373-383$

Reitzer LJ, Wice BM, Kennell D (1979): Evidence That Glutamine, Not Sugar, Is The Major Energy Source for Cultured HeLa Cells. J Biol Chem 254, 2669-2676

Sato Y, Goto Y, Narita N, Hoon DSB (2009): Cancer Cells Expressing Toll-like Receptors and the Tumor Microenvironment. Cancer Microenviron 2, 205-214

Schrader A, Bentink S, Spang R, Lenze D, Hummel M, Kuo M, Arrand JR, Murray PG, Trümper L, Kube D, Vockerodt M (2012): High Myc activity is an independent negative prognostic factor for diffuse large B cell lymphomas. Int J Cancer 131, 348-361

Schuhmacher M, Staege MS, Pajic a, Polack a, Weidle UH, Bornkamm GW, Eick D, Kohlhuber F (1999): Control of cell growth by c-Myc in the absence of cell division. Curr Biol $\underline{9}, 1255$ 1258

Scuto A, Kujawski M, Kowolik C, Krymskaya L, Wang L, Weiss LM, Digiusto D, Yu H, Forman S, Jove R (2011): STAT3 Inhibition Is a Therapeutic Strategy for ABC-like Diffuse Large Bcell Lymphoma. Cancer Res $\underline{71}, 3182-3188$

Sen R, Baltimore D (1986): Multiple Nuclear Factors Interact with the Immunoglobulin Enhancer Sequences. Cell $\underline{46}, 705-716$

Siddiquee K, Zhang S, Guida WC, Blaskovich M a, Greedy B, Lawrence HR, Yip MLR, Jove R, McLaughlin MM, Lawrence NJ, et al. (2007): Selective chemical probe inhibitor of Stat3, identified through structure-based virtual screening, induces antitumor activity. Proc Natl Acad Sci U S A $104,7391-7396$

Siebenlist U, Franzoso G, Brown K (1994): Structure, regulation and function of NF-xB. Annu Rev Cell Biol 10, 405-455

Sinkovics JG (2015): The cnidarian origin of the proto-oncogenes NF- $x$ B/STAT and WNT-like oncogenic pathway drives the ctenophores (Review). Int J Oncol 47, 1211-1229

Smale ST (2011): Hierarchies of NF-xB target-gene regulation. Nat Immunol $\underline{12}$, 689-694 
Smith B, Schafer XL, Ambeskovic A, Spencer CM, Land H, Munger J (2016): Addiction to Coupling of the Warburg Effect with Glutamine Catabolism in Cancer Cells. Cell Rep 17, 821-836

Snapper CM, Zelazowski P, Rosas FR, Kehry MR, Tian M, Baltimore D, Sha WC (1996): B Cells from p50/NF- $x$ B Knockout Mice Have Selective Defects in Proliferation, Differentiation, Germ-Line $\mathrm{C}_{\mathrm{H}}$ Transcription, and Ig Class Switching. J Immunol 156, 183-191

Son J, Lyssiotis C a, Ying H, Wang X, Hua S, Ligorio M, Perera RM, Ferrone CR, Mullarky E, Shyh- N, et al. (2013): Glutamine supports pancreatic cancer growth through a KRAS-regulated metabolic pathway. Nature $\underline{496}, 101-105$

Song H, Wang R, Wang S, Lin J (2005): A low-molecular-weight compound discovered through virtual database screening inhibits Stat 3 function in breast cancer cells. Proc Natl Acad Sci U S A $\underline{102}, 4700-4705$

Szatrowski T, Nathan C (1991): Production of Large Amounts of Hydrogen Peroxide by Human Tumor Cells. Cancer Res $\underline{51}, 794-798$

Thornburg JM, Nelson KK, Clem BF, Lane AN, Arumugam S, Simmons A, Eaton JW, Telang S, Chesney J (2008): Targeting aspartate aminotransferase in breast cancer. Breast Cancer Res $\underline{10}, \mathrm{R} 84$

Tornatore L, Thotakura AK, Bennett J, Moretti M, Franzoso G (2012): The nuclear factor kappa B signaling pathway: Integrating metabolism with inflammation. Trends Cell Biol $\underline{22}, 557-$ 566

Toyokuni S, Okamoto K, Yodoi J, Hiai H (1995): Persistent oxidative stress in cancer. FEBS Lett $\underline{358}, 1-3$

Valera A, López-Guillermo A, Cardesa-Salzmann T, Climent F, González-Barca E, Mercadal S, Espinosa I, Novelli S, Briones J, Mate JL, et al. (2013): MYC protein expression and genetic alterations have prognostic impact in patients with diffuse large B-cell lymphoma treated with immunochemotherapy. Haematologica $\underline{98}, 1554-1562$

Vander Heiden MG, Cantley LC, Thompson CB (2009): Understanding the Warburg Effect: The Metabolic Requirements of Cell Proliferation. Science 324, 1029-1033

Verma IM, Stevenson JK, Schwarz EM, Van Antwerp D, Miyamoto S (1995): Rel/NF- xB/I xB family: intimate tales of association and dissociation. Genes Dev $\underline{9}, 2723-2735$

Wang J, Erickson JW, Fuji R, Ramachandran S, Gao P, Dinavahi R, Wilson KF, Ambrosio ALB, Dias SMG, Dang C V, Cerione R a (2010): Targeting mitochondrial glutaminase activity inhibits oncogenic transformation. Cancer Cell $\underline{18}, 207-219$

Warburg O, Wind F, Negelein E (1927): The metabolism of tumors in the body. J Gen Physiol $\underline{8}$, $519-530$

Ward PS, Thompson CB (2012): Metabolic Reprogramming: A Cancer Hallmark Even Warburg Did Not Anticipate. Cancer Cell 21, 297-308

Wilson WH, Young RM, Schmitz R, Yang Y, Pittaluga S, Wright G, Lih C-J, Williams PM, Shaffer AL, Gerecitano J, et al. (2015): Targeting B cell receptor signaling with ibrutinib in diffuse large B cell lymphoma. Nat Med 21, 922-926

Wise DR, Thompson CB (2010): Glutamine Addiction: A New Therapeutic Target in Cancer. Trends Biochem Sci $\underline{35}, 427-33$

Xiang Y, Stine ZE, Xia J, Lu Y, O'Connor RS, Altman BJ, Hsieh AL, Gouw AM, Thomas AG, Gao P, et al. (2015): Targeted inhibition of tumor-specific glutaminase diminishes cell- 
autonomous tumorigenesis. J Clin Invest 125, 2293-2306

Yang C, Sudderth J, Dang T, Bachoo RM, Bachoo RG, McDonald JG, DeBerardinis RJ (2009): Glioblastoma cells require glutamate dehydrogenase to survive impairments of glucose metabolism or Akt signaling. Cancer Res $\underline{69}, 7986-7993$

Yang JH, Li JH, Jiang S, Zhou H, Qu LH (2013): ChIPBase: A database for decoding the transcriptional regulation of long non-coding RNA and microRNA genes from ChIP-Seq data. Nucleic Acids Res $\underline{41}, 177-187$

Yoshida Y, Kumar A, Koyama Y, Peng H, Arman A, Boch J a., Auron PE (2004): Interleukin 1 Activates STAT3/Nuclear Factor- $x$ B Cross-talk via a Unique TRAF6- and p65-dependent Mechanism. J Biol Chem 279, 1768-1776

Yu H, Jove R (2004): The STATs of cancer--new molecular targets come of age. Nat Rev Cancer 4, 97-105

Zhao S, Wu D, Wu P, Wang Z, Huang J (2015): Serum IL-10 Predicts Worse Outcome in Cancer Patients: A Meta-Analysis. PLoS One 10, e0139598

Internetquellen:

www.servier.de/medical-art 


\section{Danksagung}

Mein herzlicher Dank geht an diejenigen, ohne die weder der experimentelle Abschnitt noch die Verfassung dieser Dissertation möglich gewesen wäre.

An erster Stelle ist mein Doktorvater Prof. Dr. Dieter Kube zu erwähnen, dem ich nicht nur für die Möglichkeit danken möchte, in seiner Forschungsgruppe zu arbeiten, sondern auch für die vielen hilfreichen Gespräche sowie die geduldige Beantwortung etlicher Fragen mit wertvollen Ratschlägen.

Zudem bedanke ich mich bei Herrn Prof. Dr. Lorenz Trümper für die Möglichkeit, die Promotion in seiner Abteilung zu absolvieren.

Ein ganz besonderes Dankeschön gebührt meiner Betreuerin Dr. Maren Feist für die bemühte und sorgsame Einarbeitung, die zahlreichen Ideen, die Hilfestellung bei der Verfolgung des roten Fadens durch die Arbeit, ihr Vertrauen mir gegenüber sowie den täglichen Spaß an der Arbeit. In ihr hatte ich stets eine Ansprechpartnerin in allen Belangen und ich habe die gemeinsame Laborzeit sehr genossen.

Weiterhin bedanke ich mich bei Isabel Rausch und Annekatrin Arlt, die mir bis zum Schluss mit Rat und Tat zur Seite standen und sich viel Zeit für meine Fragen genommen haben, bei Moritz Harenberg für die freundschaftliche und fachliche Hilfestellung sowie bei allen weitereren Mitarbeitern der AG Kube für die schöne Laborzeit. 